UC46

U5t

no. 98/89

乙n...... vurs

of Engineers

Construction Engineering

USACERL Technical Report 98/89

Research Laboratories

July 1998

\title{
Structural Evaluation Procedures for Heavy Wood Truss Structures
}

by

Mohsen A. Issa

Ghassan Al-Chaar

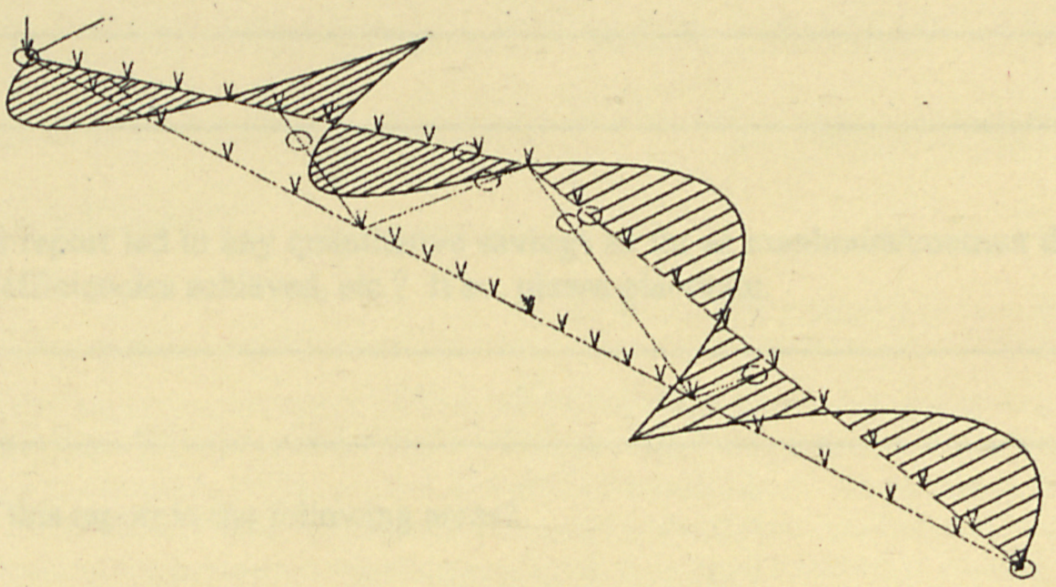

Army Regulation 420-70, Buildings and Structures, requires the inspection of trusses, roof framing, and other structural items every 2 to 5 years. In some cases, detailed evaluations of heavy wood structures are needed as subsequent steps of inspection to check structural integrity under design loads specified by current building codes. An evaluation procedure for wood structures differs from conventional methods used in steel, concrete, and masonry structures because, in wood construction, the allowable stresses used in design may not represent the actual strength of members in existing structures.
This study documented comprehensive procedures for the structural evaluation of heavy wood truss structures and identified commercially available nondestructive tests that can be used to determine the mechanical properties of existing members. Also investigated were issues related to modeling of wood structures necessary to create models that can reproduce the behavior of the prototypes.

\author{
Research Library \\ US Army Engineer Waterways \\ Experiment Station \\ Vicksburg. Milssissippi
}


The contents of this report are not to be used for advertising, publication, or promotional purposes. Citation of trade names does not constitute an official endorsement or approval of the use of such commercial products. The findings of this report are not to be construed as an official Department of the Army position, unless so designated by other authorized documents. 


\section{USER EVALUATION OF REPORT}

REFERENCE: USACERL Technical Report 98/89, Structural Evaluation Procedures for Heavy Wood Truss Structures

Please take a few minutes to answer the questions below, tear out this sheet, and return it to USACERL. As user of this report, your customer comments will provide USACERL with information essential for improving future reports.

1. Does this report satisfy a need? (Comment on purpose, related project, or other area of interest for which report will be used.)

2. How, specifically, is the report being used? (Information source, design data or procedure, management procedure, source of ideas, etc.)

3. Has the information in this report led to any quantitative savings as far as manhours/contract dollars saved, operating costs avoided, efficiencies achieved, etc.? If so, please elaborate.

4. What is your evaluation of this report in the following areas?

a. Presentation:

b. Completeness:

c. Easy to Understand:

d. Easy to Implement:

e. Adequate Reference Material:

f. Relates to Area of Interest:

g. Did the report meet your expectations?

h. Does the report raise unanswered questions? 
i. General Comments. (Indicate what you think should be changed to make this report and future reports of this type more responsive to your needs, more usable, improve readability, etc.)

5. If you would like to be contacted by the personnel who prepared this report to raise specific questions or discuss the topic, please fill in the following information.

$$
\text { Name: }
$$

Telephone Number:

Organization Address:

6. Please mail the completed form to:

Department of the Army

CONSTRUCTION ENGINEERING RESEARCH LABORATORIES

ATTN: CECER-TR-I

P.O. Box 9005

Champaign, IL 61826-9005 


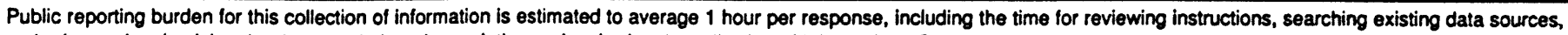

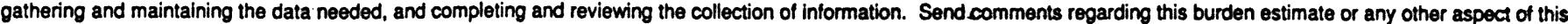

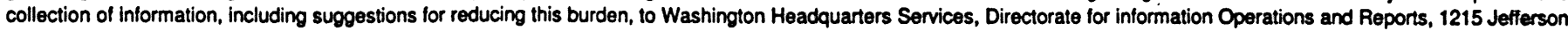
Davis Highway, Suite 1204, Arlington, VA 22202-4302, and to the Otfice of Management and Budget, Paperwork Reduction Project (0704-0188), Washington, DC 20503.

\begin{tabular}{|l|l|l}
\hline 1. AGENCY USE ONLY (Leave Blank) & 2. REPORT DATE & 3. REPORT TYPE AND DATES COVERED
\end{tabular}

\begin{tabular}{|l|c|c|} 
& July 1998 & \multicolumn{2}{|c}{ Final } \\
\hline 4. TITLE AND SUBTITLE & 5. FUNDING & .
\end{tabular}

Structural Evaluation Procedures for Heavy Wood Truss Structures NUMBERS

MIPR

W26HBF62741104

WU R56

6. AUTHOR(S)

Mohsen A. Issa and Ghassan Al-Chaar

7. PERForiming ORGANIZATION NAME(S) AND ADDRESS(ES)

U.S. Army Construction Engineering Research Laboratories (USACERL)

P.O. Box 9005

Champaign, IL 61826-9005

8. PERFORMING ORGANIZATION

REPORT NUMBER

TR $98 / 89$

9. SPONSORING / MONITORING AGENCY NAME(S) AND ADDRESS(ES)

U.S. Army Center for Public Works (USACPW) .

ATTN: USACPW-ES

7701 Telegraph Road

Alexandria, VA 22315-3862

11. SUPPLEMENTARY NOTES

Copies are available from the National Technical Information Service, 5285 Port Royal Road, Springfield, VA 22161.

12a. DISTRIBUTION / AVAILABILITY STATEMENT

12b. DISTRIBUTION CODE

Approved for public release; distribution is unlimited.

13. ABSTRACT (Maximum 200 words)

Army Regulation 420-70, Buildings and Structures, requires the inspection of trusses, roof framing, and other structural items every 2 to 5 years. In some cases, detailed evaluations of heavy wood structures are needed as subsequent steps of inspection to check structural integrity under design loads specified by current building codes. An evaluation procedure for wood structures differs from conventional methods used in steel, concrete, and masonry structures because, in wood construction, the allowable stresses used in design may not represent the actual strength of members in existing structures.

This study documented comprehensive procedures for the structural evaluation of heavy wood truss structures and identified commercially available nondestructive tests that can be used to determine the mechanical properties of existing members. Also investigated were issues related to modeling of wood structures necessary to create models that can reproduce the behavior of the prototypes.

\begin{tabular}{|l|l|l|}
\hline $\begin{array}{l}\text { 14. SUBJECT TERMS } \\
\text { wOod structures } \\
\text { structural reliability } \\
\text { evaluation techniques }\end{array}$ & nondestructive testing \\
\hline $\begin{array}{c}\text { 17. SECURITY CLASSIFICATION } \\
\text { OF REPORT } \\
\text { Unclassified }\end{array}$ & $\begin{array}{c}\text { 18. SECURITY CLASSIFICATION } \\
\text { OF THIS PAGE } \\
\text { Unclassified }\end{array}$ & $\begin{array}{c}\text { 19. SECURITY CLASSIFICATION } \\
\text { OF ABSTRACT } \\
\text { Unclassified }\end{array}$ \\
\hline
\end{tabular}




\section{Foreword}

This study was conducted for the U.S. Army Center for Public Works (USACPW), under Military Interdepartmental Purchase Request (MIPR) No. W26HBF62741104, Work Unit R56, "Structural Evaluation Procedures for Heavy Wood Truss Structures." The technical monitors were Fidel Rodriguez and Dave Bhol, CECPW-ES.

The work was performed by the Engineering Division (FL-E) of the Facilities Technology Laboratory (FL), U.S. Army Construction Engineering Research Laboratories (USACERL). The USACERL principal investigator was Ghassan Al-Chaar. Special appreciation is given to John R. Hayes, Jr., for his review and to Sean M. Marzano and Robert Stadler for their assistance in literature search. Larry M. Windingland is Chief, CECER-FL-E; L. Michael Golish is Acting Operations Chief, CECER-FL; and Alan W. Moore is the responsible Technical Director, CECER-FL. The USACERL technical editor was William J. Wolfe, Technical Resources.

COL James A. Walter is Commander and Dr. Michael J. O'Connor is Director of: USACERL. 


\section{Contents}

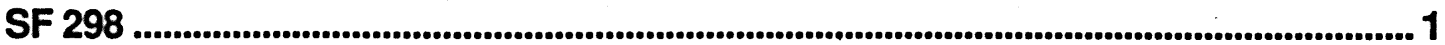

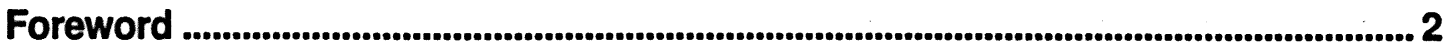

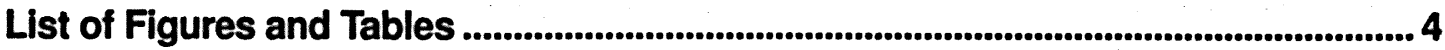

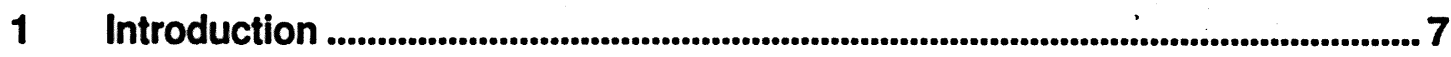

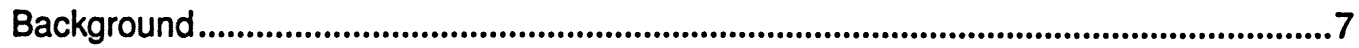

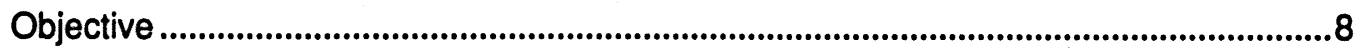

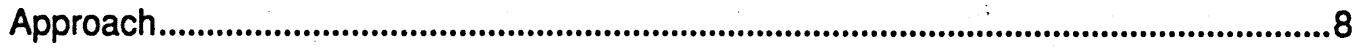

2 Evaluation and Specifications for Wood Structures ....................................... 9

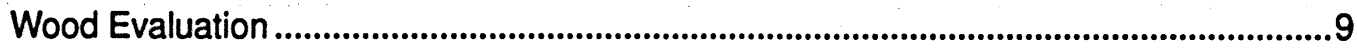

Changes to the National Design Specification for Wood Construction 1944-1991 .........14

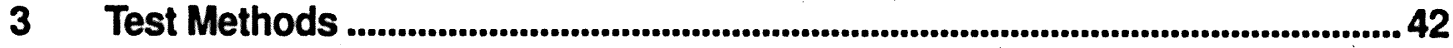

Nondestructive Testing Methods for Wood .................................................................42

Description of Nondestructive Methods ........................................................................43

Typical NDT Methods..................................................................................................44

Evaluation of Nondestructive Methods .......................................................................51

4. Discussion and Analysis....................................................................................... 56

Modeling and Evaluation of Wood Structures .........................................................56

Analytical Procedures for Modeling Wood Truss Joints .................................................58

Influence of Fasteners and Bolts ...............................................................................58

Modeling Wood Trusses.................................................................................................55

Basic Assumptions and Model Description of Fink Truss .........................................60

Basic Assumptions and Model Description of Large Timber Truss ..................................61

Results of Analyzed Fink Truss Models .......................................................................63

Results of Analyzed Large Timber Truss Models .......................................................74

Recommended Structural Evaluation Procedure for Wood Trusses..................................78

Recommended Evaluation Procedure for Bolted Wood Connections................................80

5 Summary and Conclusions ........................................................................ 83

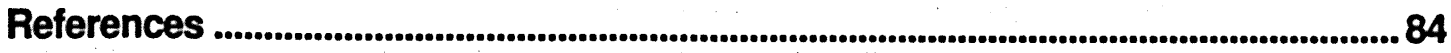

Appendix: Nondestructive Measuring Equipment and Methods ...................................88

Distribution 


\section{List of Figures and Tables}

\section{Figures}

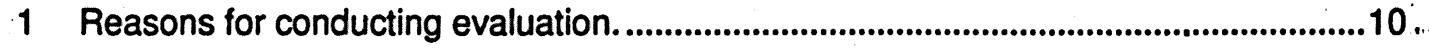

2 Evaluation procedures for heavy wood trusses. .....................................................57

3 Modeled Fink truss with applied loads. .................................................................60

4 Large timber truss model with element numbers. ....................................................62

5 Large timber truss model with node numbers...........................................................6.

6. Moment diagram for semi-rigid truss model..........................................................67

7 Shear diagram for semi-rigid truss model............................................................6.

8 Moment diagram for top chord of semi-rigid truss model............................................68

9 Moment diagram for bottom chords of semi-rigid truss model. ....................................68

10 Moment diagram for web chords of semi-rigid truss model. ......................................69

11 Moments for member 5-7 at node $i$ for the six different models...................................69

12 Moments for member 5-7 at node $\mathrm{j}$ for the six different models..................................70

13 Displacements for tension splice joint for the six different models..............................71

\section{Tables}

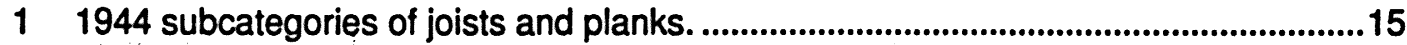

21977 lumber designations and modifications. ..................................................................16

31991 Normal Conditions of Use descriptions. ................................................................17

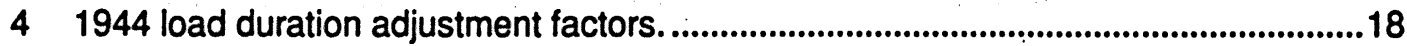

51948 revisions of load duration adjustment factors....................................................19

. 61968 modifications to adjustment factors for abnormal moisture conditions..................19

- 71977 temperature adjustment factors. .........................................................................19

81986 modifications to temperature adjustment factors for range of moisture

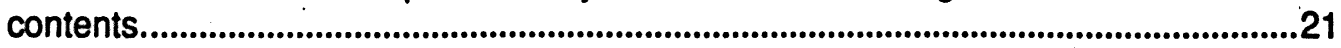

91986 adjustment factors for lumber pressure impregnated with fire retardant chemicals. .................................................................................................................................21

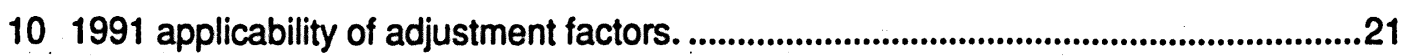

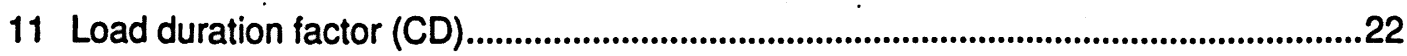

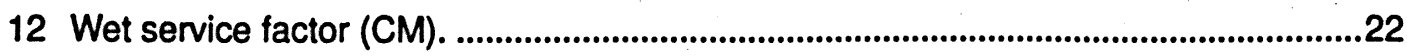




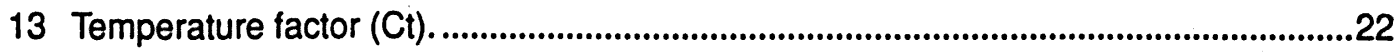

141968 adjustment factors for lumber loaded on the wide face.....................................227

151977 determination of effective length for loading condition. .......................................28

161986 determination of le for loading condition.........................................................31

171991 shear stress factors for horizontal shear. .........................................................34

181991 adjustment factors for geometry and size of sawn lumber. .................................37

191991 flat-use factors for members loaded on the wide face. .....................................37

20 Examples of 1968 revisions for standard dressed (S4S) dimensions..........................38.

21 Summary of code changes for allowable stresses.....................................................40

22 Research summary of correlation between nondestructive testing (NDT) parameters and properties of degraded wood.

23 Research summary of nondestructive testing (NDT) concepts for in-place evaluation of wood structures.

24 Section properties for $1 / 2$-in. edge elements of semi-rigid models. ..............................62

25 Nominal dimensions for elements in large timber truss. ............................................62

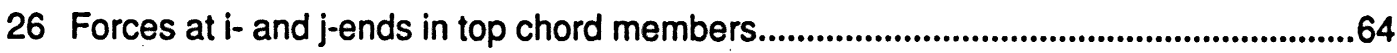

27 Forces at $i$ - and $j$-ends in bottom chord members......................................................65

28 Forces at $i$ - and $j$-ends in web chord members. ........................................................66

29 Comparison of predicted joint displacements from each of the three models................71

30 Forces at $i$ - and $j$-ends in top chord members for semi-rigid models. ...........................72

31 Forces at $i$ - and $j$-ends in top chord members for semi-rigid models. .............................72

32 Forces at $\mathrm{i}$ - and $\mathrm{j}$-ends in bottom chord members for semi-rigid models.......................72

33 Forces at $\mathrm{i}$ - and j-ends in bottom chord members for semi-rigid models. .....................73

34 Forces at $i$ - and $j$-ends in web chord members for semi-rigid models. ..........................73

35 Forces at $\mathrm{i}$ - and $\mathrm{j}$-ends in web chord members for semi-rigid models. ..........................73

36 Comparison of predicted joint displacements for semi-rigid models. .............................74

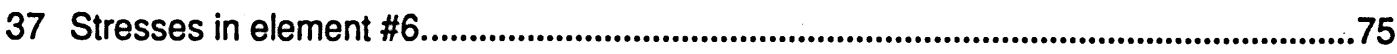

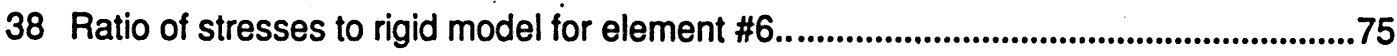

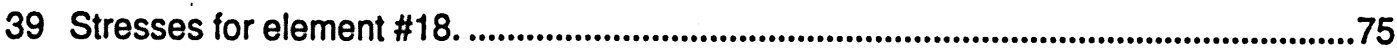

40 Ratio of stresses to rigid model for element \#18 ..........................................................76

41 Stresses for element \#30..........................................................................................76

42 Ratio of stresses to rigid model for element \#30 .......................................................76

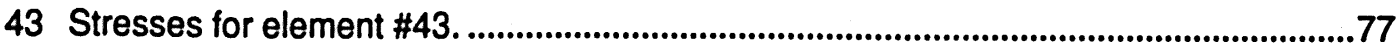

44 Ratio of stresses to rigid model for element \#43..........................................................77

A1 Nondestructive equipment and organization locations..................................................88

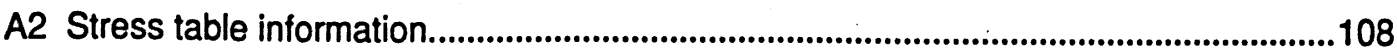




$$
\text { Page } 6
$$

Blank 


\section{Introduction}

\section{Background}

Army Regulation 420-70, Buildings and Structures (HQDA 29 May 1992), requires the inspection of trusses, roof framing, and other structural items every 2 to 5 years. In some cases, detailed evaluations of heavy wood structures are needed as subsequent steps of inspection to check structural integrity under design loads specified by current building codes.

The original allowable stresses of typical species of wood materials may be reduced significantly due to changes in code requirements and material conditions. Many wooden structures were built per old National Design Specifications (NDS), which have changed several times since 1956 with respect to allowable stresses in wood. For example, the 1982 NDS code reduced allowable values for bending, tension, shear, and compression stresses in wood members by a minimum of $7,46,29$, and 13 percent; respectively. Moreover, physical damage as manifested in splits and decay will reduce the structural capacity of a member. Allowable stresses for such members are not easily quantified.

Developing an accurate evaluation procedure depends on the computation of member stress demand with respect to its stress capacity. A comprehensive evaluation procedure must consider all of the parameters that describe the existing conditions of the structure's materials that may increase or decrease the actual and allowable stresses.

Any procedure used to evaluate the condition of wood structures must be based on methods that appropriately define the structural behavior of wood and wood based materials. The most productive methods to obtain the real properties of wood material use nondestructive techniques. Several nondestructive methods to determine the mechanical properties of existing wood and wood-based members are now commercially available, and should be evaluated for overall effectiveness and feasibility in application to structural wood.

One critical issue in the performance of wood structures is the connectivity of wood members. Joints and connections in wood structures are susceptible to 
failure and are often seen as the cause of a structure's overall failure. It is also necessary to model wood structures to reproduce the behavior of prototypes and their components. Although truss joints are designed as pin connections, joints possess some level of rotational capacity that can influence the response of structures to loads and change the response from that of a true truss to that of a frame. As a result, the rotational capacities of common joint details must be investigated to ascertain their rotational stiffness.

\section{Objective}

The objective of this work was to develop a complete, detailed structural evaluation procedure for wood trusses and other support members, to ensure their structural adequacy.

\section{Approach}

1. National Design Specifications, first issued in 1944, were compared with current codes.

2. Allowable stresses of typical species of wood materials were determined.

3. Methods for employing nondestructive tests to determine basic materials properties of existing wood structures were investigated.

4. Issues related to modeling of wood structures to reproduce the behavior of prototypes were investigated. The two most important issues were:

a. Determining the mechanical properties of existing members

b. Determining the rotational properties of existing members.

5. The rotational capacity of joints was investigated. 


\section{Evaluation and Specifications for Wood Structures}

\section{Wood Evaluation}

Several different factors can prompt the need for an evaluation of the load-carrying capability of a timber structure, including:

- partial or complete collapse of the structure

- development of a state of unserviceability of the structure due to excessive deflection, vibration, or cracking

- changes in the use of the structure

- changes in the applicable building code, particularly with respect to prescribed loads

- fire damage

- and reduction in the strength of wood structural members due to damage, ..... modifications, partial failure, deformation, decay, insect attack or settlement of the structure.

Figure 1 flowcharts the reasons reported for conducting evaluation.

The selection of approaches and methods for use in structural evaluation is somewhat influenced by the specific reason for carrying. out the evaluation. However, there are four distinct phases:

1. Inspection of the condition of members and connections, and of the structural environment

2. Determination of the loads on the structure

3. Structural analysis, e.g., finite element analysis, to determine the effects of loads on individual members and connections

4. Assessment of the ability of members and connections to resist the applied loads. 


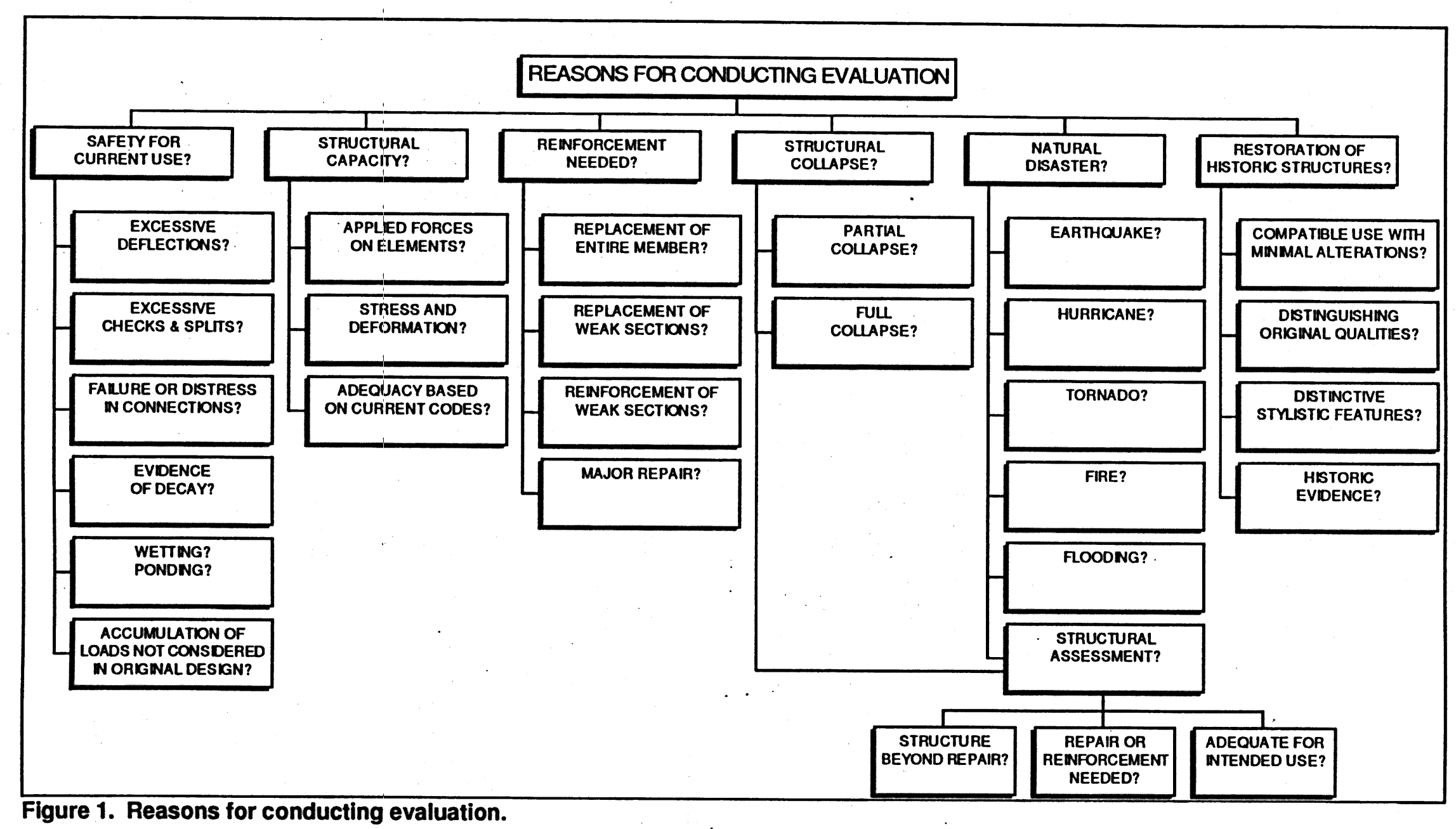

Figure 1. Reasons for conducting evaluation. 
These evaluation steps may be followed by design of reinforcement or by specification of use or occupancy restrictions if the structure proves to be unsafe or unserviceable.

\section{Inspection}

Although the inspection of timber structures is not within the scope of this report, a few points are worth emphasizing here. Regardless of whether the structure is a building (residential, commercial, agricultural or public), a bridge, a retaining wall, a cooling tower, or any other type, several specific items must form the basis of the inspection:

1. The condition of the wood and connections must be ascertained to judge whether they are as sound or as good as when new. The quality of the wood and other elements must be determined in a manner that permits assignment of safe or reasonable allowable stresses. For timber, this usually means that the species must be determined and the individual members must be graded according to one of the current visual stress grading rules.

2. The dimensions of the individual elements and of the structure in general are required to permit a structural analysis. Where structural drawings are available, the existing layout and dimensions may be checked against these drawings. Where drawings are not available, the inspection must include a survey of all relevant dimensions.

3. The service environment of the structure must be noted so that allowable stresses may be properly assigned. Where environments are unusual or severe in terms of temperature, moisture, acidity or proximity to soil, the conditions should be carefully noted along with the type and degree of protection that has been or can be provided for the wood.

4. Any information related to the magnitude and distribution of loads on the structure should be obtained at the time of inspection. This information must include a listing of the building materials to calculate dead loads, and any features that might affect the magnitude or distribution of superimposed loads.

\section{Determination of Loads}

In preparation for the structural analysis phase of an evaluation, it is necessary to have a complete description of the loads that act or might reasonably be expected to act on a structure during its service life. The load types and their sources are: 
1. Dead loads include the weights of all permanent materials in or on the structure, including such items as framing members, connections, deck, flooring, roofing, walls, mechanical equipment, and electrical systems. Many structures support permanent fixtures that do not fall into any of the above classifications. These too must be taken into account.

2. Loads due to occupancy and use are determined in relation to the intended purpose of the structure. Floor loads may vary greatly depending on the intended structural use.

3. Snow loads govern the design of many roof structures in areas other than the southern States. Recommended snow loads for various localities are provided by building officials or by the model codes. These recommended loads are based on observations of snow depth on the ground. Consideration must also be given to local snow loads due to drift of snow that is influenced by the orientation of the structure relative to the direction of snow blow.

4. Wind loads govern the design of many structures. Much of the annual damage to structures is caused by wind.

5. Earthquake loads sometimes govern the design of timber structures if all other potential loads have been properly taken into account. Nonetheless, all structures should be designed to resist moderate earthquakes without significant damage and to resist major earthquakes without collapse.

6. Rain loads occur on roofs where insufficient allowance has been made for drainage.

7. Other loads that may act on structural elements include those due to thermal or hygroscopic expansion (humidity), differential settlement of foundations, and pre- or post-tensioning systems.

\section{Structural Analysis}

In evaluating a structure, the structural analysis is used to determine what types and magnitudes of forces are applied to the individual elements by the loads on the structures, and the stresses and deformations produced in the elements by the applied forces.

To perform the structural analysis, it is necessary to model the structure in a way that realistically reflects the response of the entire assembly to the applied loads. The model must include an accurate geometric analog and must be able to deflect in proportion to the stiffnesses of the actual components. 
The following design parameters are usually calculated in the analysis of timber structures. This list is not exhaustive, but should form a reasonable starting point for any particular structure:

1. Lumber decking: deflection and bending stress using appropriate assumptions of continuity based on deck-laying patterns, bearing stress, shear stress (necessary only if the decking is laid on edge rather than flat), stress reversal due to wind uplift, localized high wind suctions at edges of a structure, and ability of fasteners to resist uplift forces on decking due to wind suction.

2. Joists and purlins: bending stress, shear stress, bearing stress, deflection, and lateral stability. On a sloping or curved roof, oblique joists or purlins should be analyzed for biaxial bending except where there exists some other means of resisting the component of load in the plane of the roof, as by diaphragm action, by blocking to the eaves, or by attaching tie rods to the ridge beam.

3. Diaphragms and shear walls: nail forces due to shear and flexure, axial stress in eave and ridge members, racking loads in "web" materials.

4. Beams and girders: bending stress, shear stress, bearing stress at supports and at points of concentrated applied loads, deflection, additional normal stress due to axial forces applied to beams, lateral stability, stress reversals.

5. Compression members: slenderness in two planes, axial compression stress, bending due to end moments, eccentric compression forces or transverse bending, possibility of axial stress reversal due to uplift, and capacity of lateral supports to provide a minimum of 4 to 5 percent of the axial capacity of the member.

6. Connections: check various possible directions of load application. Note that friction should never be considered as a contributor to the capacity of a joint because its contribution cannot be counted on at all times, if drying shrinkage occurs, friction can be greatly diminished. However, in analyzing a collapse, the possible role of friction should be taken into account.

7. Axial stresses in bracing members.

8. Foundations: horizontal and vertical reaction forces including possible uplift forces.

\section{Estimating Load-Carrying Capacity of Structural Elements}

The final step in the evaluation of a structural member is to check its ability to resist the applied loads while maintaining a reasonable factor of safety against failure and to check that deflections are within recommended values. The suc- 
cessful completion of this step for any member assumes that the forces and stresses have been accurately calculated and that the allowable stresses and modulus of elasticity for the member are known. When the loading history on a given structural member is not known with any accuracy and if the member is used under a new loading condition for which it was not originally intended, 90 percent of the normal design stress values otherwise permitted is recommended. It is also important to know the date the structure was designed and built when trying to assess the allowable design stresses and principles used in the design as both have changed materially over the past 25 years.

Also note that lumber sizes are generally smaller than they were 30 years ago. Prior to 1968, the Standard Dressed (S4S) Sizes of lumber were obtained by simply subtracting $3 / 8$ in. ( 1 in. $=25.4 \mathrm{~mm}$ ) from both the nominal width and the depth dimensions for those dimensions 4 in. or less or by subtracting $1 / 2$ in. for any larger dimension. After 1968, actual sizes were obtained by subtracting $1 / 2$ in. from all nominal dimensions.

For example, for a $2 \times 8$ in. in 1991, the approximate changes in cross-sectional properties from those of a $2 \times 8$ prior to 1968 are:

Cross-sectional area: 11 percent less

Section modulus: 14 percent less

Moment of inertia: 17 percent less

Surface appearance of wood can be deceptive. Decay may have begun through the end grain and may not be readily apparent. It may be necessary to take small wood cores with an increment borer for visual examination. It is highly recommended that all test holes in members exposed to adverse conditions be plugged with treated wood plugs or dowels so as not to introduce decay at these locations.

\section{Changes to the National Design Specification for Wood Construction 1944-1991}

The National Design Specification for Wood Construction (NDS) was first published in 1944 by the National Lumber Manufacturers Association (now the American Forest and Paper Association) under the title National Design Specification for Stress-Grade Lumber and Its Fastenings. Since then, 17 editions have been published $(1944,1947,1948,1950,1951,1952,1953,1957,1960,1962$, $1968,1971,1973,1977,1982,1986$, and 1991). The NDS has gone through some 
rather significant changes in its 47 years that can be organized into several categories. These categories, as they relate to sawn lumber trusses, include General Design Requirements and Scope, Modifications to the Design Values, Design Provisions and Equations, and Mechanical Fasteners, Lumber Sizes, and Design Values.

\section{General Design Requirements and Scope}

The 1944 NDS was strictly based on an allowable stress design procedure using an elastic stress-strain theory for calculating induced stresses. This design procedure remained unchanged from the original edition of the code through the present 1991 edition, although at the time of this report, work towards a specification based on the Load and Resistance Factor Design method was well under way. The scope of the NDS, though, changed over the years along with some of the general design requirements. These design requirements include lumber designations, design loads, and normal service conditions.

In 1944, the code provided design guidelines for visually graded sawn lumber (stress-grade lumber), glued laminated structural members, and mechanical fasteners. In 1968, machine stress-rated lumber was added to the specification, and by 1971, this scope broadened to include, in addition to the above, machine stress-rated sawn lumber and round timber piles. The 1991 edition additionally includes machine-evaluated lumber.

The NDS subdivides the Sawn Lumber category into three subcategories: (1) joists and planks, (2) beams and stringers, and (3) posts and timbers. In 1944, these designations were defined as listed in Table 1.

In 1971, the designation "Joists and Planks" was renamed "Dimension Lumber" and was redefined as lumber of the same thickness, but with a width $\geq 2$ in. In 1977, the lumber designation of decking was added and the definitions were modified (Table 2).

Table 1. 1944 subcategories of joists and planks.

\begin{tabular}{|l|l|}
\hline Lumber Designation & Requirements \\
\hline Joists and Planks & Rectangular cross-section from $2^{\prime \prime}$ to $5^{\prime \prime}$ thick, and $\geq 4^{\prime \prime}$ wide \\
\hline Beams and Stringers & $\begin{array}{l}\text { Rectangular cross-section } \geq 5^{n} \text { thick, } \geq 8^{\prime \prime} \text { wide, and graded with } \\
\text { respect to bending when loaded on the narrow face }\end{array}$ \\
\hline Posts and Timbers & $\begin{array}{l}\text { Approximately square cross-section } \geq 5^{\prime \prime} \times 5^{\prime \prime} \text { and graded with respect } \\
\text { to longitudinal loading where bending strength not critical }\end{array}$ \\
\hline
\end{tabular}


Table 2. 1977 lumber designations and modifications.

\begin{tabular}{|l|l|}
\hline Lumber Designation & Requirements \\
\hline Dimension & Rectangular cross-section from 2 to 4 in. thick, and $\geq 2$ in. wide \\
\hline Beams and stringers & $\begin{array}{l}\text { Rectangular cross-section } \geq 5 \text { in. thick, width more than } 2 \text { in. greater } \\
\text { than thickness, and graded with respect to bending when loaded on the } \\
\text { narrow face }\end{array}$ \\
\hline Posts and timbers & $\begin{array}{l}\text { Approximately square cross-section } \geq 5 \times 5 \text { in., with width not more than } \\
2 \text { in. greater than the thickness, and graded with respect to longitudinal } \\
\text { loading where bending strength not critical }\end{array}$ \\
\hline Decking & $\begin{array}{l}\text { From } 2 \text { to } 4 \text { in. thick, and } \geq 6 \text { in. wide, tongued and grooved or grooved } \\
\text { for a spline on the narrow face }\end{array}$ \\
\hline
\end{tabular}

These designations and definitions remained unchanged through the 1991 edition, with the exception that, starting with the 1991 code, there was no longer a width restriction on the decking.

Throughout its history, the NDS prescribed no load combinations. Instead, it stated that the design loads were to be "the most severe distribution, concentration, and combination of dead, live, snow, wind, earthquake, erection, and other static and dynamic forces." The only guidance that the code gave is that the probabilities of the full wind and full snow loads or the full wind and full earthquake loads acting simultaneously are remote. The code also stated that the magnitudes of the loads shall be in accordance with the governing building code. These provisions in the NDS have remained unchanged since the original 1944 edition.

The material properties of wood are very sensitive to specific temperature, moisture condition, load duration, and type of pressure treatment in which the structural member is used. For this reason, the design values must be assigned with respect to "Normal Conditions of Use" using modifications for service conditions other than normal. These "Normal Conditions of Use" are defined in the 1944 code for lumber continuously dry (as in most covered structures), pressureimpregnated by an approved process and preservative, and subjected to longterm (permanent) loading. The 1948 edition of the code modified the assumptions of normal loading duration. Normal loading duration was defined as a load that stresses the member to its full design value and has a duration of approximately 10 years (continuously or cumulatively). In 1962 , the code included an adjustment to the design values for lumber pressure-impregnated with fireretardant chemicals. Normal moisture condition was quantitatively defined for the first time in the 1968 NDS for each specific wood species and grade, although the vast majority assume a member surfaced dry or green and used at a 19 percent moisture content. In 1977, the effect of temperature was taken into account and the NDS stated that the design values were valid for normal tem- 
perature fluctuations and occasional short-term heating up to $150{ }^{\circ} \mathrm{F}\left({ }^{\circ} \mathrm{F}=.\left[{ }^{\circ} \mathrm{C}\right.\right.$ $x$ 1.8] + 32) The normal moisture condition was also more specifically defined:

1. An in-use moisture content $\leq 19$ percent regardless of the type of sawn lumber and the moisture content at the time of manufacture, OR

2. An in-use moisture content $\leq 15$ percent applicable to 2 to 4 in. thick sawn lumber manufactured at a moisture content $\leq 15$ percent.

These Normal Conditions of Use remain mostly unchanged through the 1991 edition. The only exception is that the normal moisture condition for sawn lumber is now uniformly defined as an in-use moisture content $\leq 19$ percent regardless of the type of sawn lumber and the moisture content at the time of manufacture. Table 3 summarizes the Normal Conditions of Use for the 1991 NDS.

\section{Adjustments to the Design Values}

The most significant changes to the National Design Specification for Wood Construction apply to the various adjustment factors for the tabulated design val- . ues. These adjustment factors can be grouped into two distinct categories: general adjustment factors relating to the conditions of use and specific adjustment factors relating to individual design values and the geometric properties of the particular member. In this section, only those adjustment factors that relate to the conditions of use will be discussed. Those adjustment factors that are associated with specific design values and the geometric properties of a particular member will be discussed in: “Design Provisions and Equations" (p 22).

The 1944 NDS cites only what are, in effect, load duration adjustments. These adjustments are correlated to specific load cases (Table 4).

Table 3. 1991 Normal Conditions of Use descriptions.

\begin{tabular}{|l|l|}
\hline Condition & Normal Conditions of Use \\
\hline Temperature & $\begin{array}{l}\text { Normal temperature fluctuations and occasional, short- } \\
\text { term heating up to 150 } \mathrm{F}\end{array}$ \\
\hline Moisture condition & $\begin{array}{l}\text { An in use moisture content } \leq 19 \% \text { regardless of the type } \\
\text { of sawn lumber and the moisture content at the time of } \\
\text { manufacture }\end{array}$ \\
\hline Load duration & $\begin{array}{l}\text { A load that stresses the member to its full design value } \\
\text { and has a duration of approximately } 10 \text { years } \\
\text { (continuously or cumulatively) }\end{array}$ \\
\hline Wood preservative treatment & $\begin{array}{l}\text { A member pressure-impregnated by an approved process } \\
\text { and preservative }\end{array}$ \\
\hline Fire retardent treatment & Amember not treated with fire retardent chemicals \\
\hline
\end{tabular}


Table 4. 1944 load duration adjustment factors.

\begin{tabular}{|l|c|}
\hline Load Case & Adjustment Factor \\
\hline Dead Load + Temporary Snow Load & 1.15 \\
\hline Dead Load + Permanent Snow Load & 1.00 \\
\hline Dead Load + Wind or Earthquake Load & 1.50 \\
\hline Dead Load + Short-term Load (<5 minutes) & 1.50 \\
\hline Dead Load + Live Load + Wind Load & 1.50 \\
\hline Impact & $\begin{array}{l}\text { If the stresses induced by impact loads are less } \\
\text { than the design values for permanent loads AND } \\
\text { Impact + Dead + Long-term Live and/or Short-term } \\
\text { Live are less than twice the design values for } \\
\text { permanent loads }\end{array}$ \\
\hline
\end{tabular}

The above adjustments are not cumulative and apply to all design values except modulus of elasticity. The code also provides for an adjustment factor of 1.50 for horizontal shear in joint details. In 1948, the load duration adjustment factors were revised and remained unchanged until the 1991 edition (Table 5).

The load duration adjustment factors above are not cumulative with respect to. each other, but do apply in combination with the other factors (this holds true through the 1991 NDS). Additionally, adjustment factors, for the design value of compression perpendicular to grain, of 1.10 for seasoned lumber used under continuously dry conditions and 0.90 for lumber used under continuously wet conditions were added. The 1951 code revised these adjustment factors to 0.67 for lumber used under continuously wet conditions and eliminated the provision for seasoned lumber used under continuously dry conditions. An adjustment factor of 0.90 for compression parallel to grain in members under continuously wet service conditions was added in 1953. In 1957, the design value of end grain in bearing parallel to grain was added with an adjustment factor, for service conditions other than normal, of 0.77 for members less than 4 in. thick and 0.91 for members more than 4 in. thick. The code also included an adjustment factor of 0.90 for the modulus of elasticity of members under continuously wet service conditions. The 1962 revision added an adjustment factor for all design values of 0.90 for members pressure-impregnated with fire-retardant chemicals. The stresses resulting from this adjustment are subject to the duration of load adjustments. In 1968, there was a major change with respect to the adjustment factors for moisture conditions other than normal. Table 6 summarizes these adjustment factors.

The 1973 revision made only a few minor additions to the adjustment factors. These included additional adjustment factors, applicable only to Redwoods, of 1.15 for the design value of compression parallel to grain, and 1.04 for the design value of modulus of elasticity. There was also a clarification that provided an 
adjustment factor of 1.50 to the design value for shear as applied to joint details with mechanical fasteners at a distance greater than 5 times the depth from the end of the member. The total shear, though, was not to exceed the design value on the basis of the full cross section without this adjustment factor. The 1977 edition of the code introduced adjustment factors for different temperature conditions along with minor changes and additions to the adjustment factors from the previous edition. Table 7 summarizes the temperature adjustment factors. In addition, the NDS revised the adjustment factor due to impact loads to state that any impact loads require an adjustment factor of 2.00 (the NDS no longer differentiates between impact induced stresses greater than and less than those induced by normal loading).

Table 5. 1948 revisions of load duration adjustment factors.

\begin{tabular}{|l|c|}
\hline Load Duration & $\begin{array}{l}\text { Adjustment } \\
\text { Factor }\end{array}$ \\
\hline Any load with a duration not exceeding 2 months, as for snow (not applicable to E) & 1.15 \\
\hline Any load with a duration not exceeding 7 days (not applicable to E) & 1.25 \\
\hline Any wind or earthquake loads (not applicable to E) & $1.331 / 3$ \\
\hline $\begin{array}{l}\text { Impact loads where induced stress due to impact > induced stress due to normal } \\
\text { loading (not applicable to E) }\end{array}$ & 2.00 \\
\hline $\begin{array}{l}\text { Impact loads where induced stress due to impact < induced stress due to normal } \\
\text { loading (not applicable to E) }\end{array}$ & 1.00 \\
\hline $\begin{array}{l}\text { Members fully stressed to their maximum design value for many years (not } \\
\text { applicable to E) }\end{array}$ & 0.90 \\
\hline
\end{tabular}

Table 6. 1968 modifications to adjustment factors for abnormal moisture conditions.

\begin{tabular}{|l|l|l|l|l|l|l|}
\hline $\begin{array}{l}\text { Lumber Size } \\
\text { and Service } \\
\text { Condition }\end{array}$ & $\begin{array}{l}\text { Extreme } \\
\text { Fiber In } \\
\text { Bending }\end{array}$ & $\begin{array}{l}\text { Tension } \\
\text { Parallel to } \\
\text { Grain }\end{array}$ & $\begin{array}{l}\text { Horizontal } \\
\text { Shear }\end{array}$ & $\begin{array}{l}\text { Compression } \\
\text { Perpendicular } \\
\text { to Grain }\end{array}$ & $\begin{array}{l}\text { Compression } \\
\text { Parallel to } \\
\text { Grain }\end{array}$ & $\begin{array}{l}\text { Modulus of } \\
\text { Elasticity }\end{array}$ \\
\hline $\begin{array}{l}\text { 2-4-in. Thick } \\
\text { Moisture Content } \\
<15 \%\end{array}$ & 1.08 & 1.08 & 1.05 & 1.00 & 1.17 & 1.05 \\
\hline $\begin{array}{l}2-4 \text {-in. Thick } \\
\text { Moisture Content } \\
>19 \%\end{array}$ & 0.86 & 0.84 & 0.97 & 0.67 & 0.70 & 0.97 \\
\hline $\begin{array}{l}>\text {-in. Thick } \\
\text { Moisture Content }\end{array}$ & 1.00 & 1.00 & 1.00 & 0.67 & 0.91 & 1.00 \\
\hline$>19 \%$
\end{tabular}

Table 7. 1977 temperature adjustment factors.

\begin{tabular}{|l|l|}
\hline Service Condition & Adjustment Factor \\
\hline $0 \%$ moisture content, cooling below $68{ }^{\circ} \mathrm{F}$ & For $\mathrm{E}:+0.04 \% /{ }^{\circ} \mathrm{F}$ for other design values: $+0.17 \%{ }^{\circ} \mathrm{F}$ \\
\hline $0 \%$ moisture content, heating above $68{ }^{\circ} \mathrm{F}$ & For $\mathrm{E}:-0.04 \% /{ }^{\circ} \mathrm{F}$ for other design values: $-0.17 \%{ }^{\circ} \mathrm{F}$ \\
\hline $12 \%$ moisture content, cooling below $68{ }^{\circ} \mathrm{F}$ & For $\mathrm{E}:+0.14 \% /{ }^{\circ} \mathrm{F}$ for other design values: $+0.32 \%{ }^{\circ} \mathrm{F}$ \\
\hline $12 \%$ moisture content, heating above $68{ }^{\circ} \mathrm{F}$ & For $\mathrm{E}:-0.19 \% /{ }^{\circ} \mathrm{F}$ for other design values: $-0.49 \%{ }^{\circ} \mathrm{F}$ \\
\hline
\end{tabular}


They additionally state that, for impact loads on members pressure impregnated with preservative salts to the heavy retentions required for marine exposures, the adjustment factor shall be 1.00. The final change in 1977 was that the adjustment factor for members pressure impregnated with fire retardant chemicals also applies to fastener details. In 1982, there were once again a few minor revisions to the adjustment factors. The temperature adjustment factor for the modulus of elasticity for 12 percent moisture content, cooling below $68^{\circ} \mathrm{F}$ was changed to +0.15 percent $/{ }^{\circ} \mathrm{F}$, and for the modulus of elasticity for 12 percent moisture content, heating above $68^{\circ} \mathrm{F}$ was changed to -0.21 percent $/{ }^{\circ} \mathrm{F}$. The only other change was that an adjustment factor for impact loads on members pressure impregnated with fire retardant chemicals was added with a value of 1.00 . In the 1986 edition, the adjustment factors for temperature became more comprehensive, with a provision for 24 percent moisture content (Table 8). In addition to the above, the code also more specifically defines the adjustment factor for lumber pressure impregnated with fire retardant chemicals (Table 9):

In 1991, several major changes were made to the adjustment factors in addition to a more understandable system for the applicability of these adjustment factors. Table 10 summarizes the applicability of the adjustment factors to the design values, where $F_{b}$ is the bending design value, $F_{t}$ the tension design value parallel to grain, $F_{v}$ the shear design value parallel to grain, $F_{c \perp}$ the compression design value perpendicular to grain, $F_{c}$ the compression design value parallel to grain, $E$ the modulus of elasticity, and $F_{g}$ the bearing design value. The allowable design values are then obtained by multiplying the tabulated design values by all applicable adjustment factors.

The load duration adjustment factors remained unchanged except for wind and earthquake loading, which changed to 1.6. The adjustment factor for moisture service condition was simplified to provide for two distinct situations, dry or wet. Similarly, the adjustment factor for temperature service conditions was simplified to reflect specific temperature ranges. Finally, the adjustment factor for members pressure impregnated with fire retardant chemicals was no longer quantified, but rather, the designer was referred to the chemical manufacturer for the effect on the design values. Tables 11 to 13 give a full summary of the adjustment factors due to the various service conditions. 
Table 8. 1986 modifications to temperature adjustment factors for range of moisture contents.

\begin{tabular}{|l|c|c|c|}
\hline Design Value & Moisture Content & Cooling below $688^{\circ} \mathrm{F}$ & Heating above $68{ }^{\circ} \mathrm{F}$ \\
\hline Modulus of & $0 \%$ & $+0.09 \% /{ }^{\circ} \mathrm{F}$ & $-0.11 \% /{ }^{\circ} \mathrm{F}$ \\
Elasticity, & $12 \%$ & $+0.13 \% /^{\circ} \mathrm{F}$ & $-0.13 \% /{ }^{\circ} \mathrm{F}$ \\
Tension parallel & $24 \%$ & $+0.38 \% /^{\circ} \mathrm{F}$ & $-0.15 \% /{ }^{\circ} \mathrm{F}$ \\
to grain & & & \\
\hline Other design & $0 \%$ & $+0.14 \% /{ }^{\circ} \mathrm{F}$ & $-0.19 \% /{ }^{\circ} \mathrm{F}$ \\
values and & $12 \%$ & $+0.24 \% /^{\circ} \mathrm{F}$ & $-0.38 \% /{ }^{\circ} \mathrm{F}$ \\
fasteners & $24 \%$ & $+0.84 \% /{ }^{\circ} \mathrm{F}$ & $-0.57 \% /{ }^{\circ} \mathrm{F}$ \\
\hline
\end{tabular}

Table 9. 1986 adjustment factors for lumber pressure impregnated with fire retardant chemicals.

\begin{tabular}{|l|c|}
\hline Design Value & Adjustment Factor \\
\hline Extreme fiber in bending & 0.85 \\
\hline Tension parallel to grain & 0.80 \\
\hline Horizontal shear & 0.90 \\
\hline Compression perpendicular to grain & 0.90 \\
\hline Compression parallel to grain & 0.90 \\
\hline Modulus of elasticity & 0.90 \\
\hline Fastener design loads & 0.90 \\
\hline
\end{tabular}

Table 10. 1991 applicability of adjustment factors.

\begin{tabular}{|c|c|c|c|c|c|c|c|c|c|c|c|c|c|}
\hline & 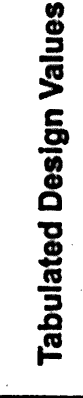 & 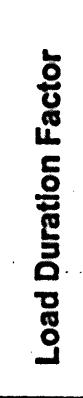 & 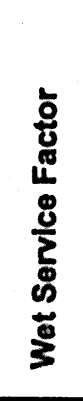 & 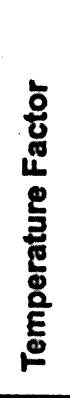 & 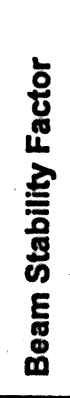 & 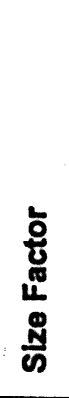 & 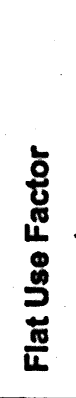 & 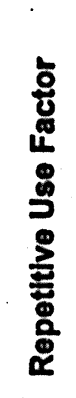 & 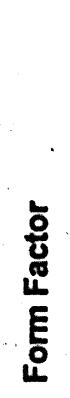 & 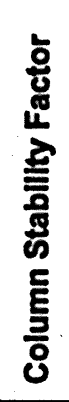 & 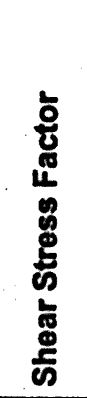 & 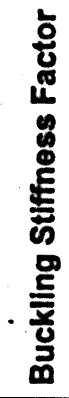 & 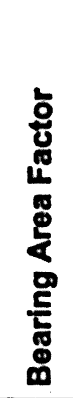 \\
\hline$F_{b}^{\prime}=$ & $\left(F_{0}\right)$ & $\left(C_{D}\right)$ & $\left(C_{m}\right)$ & $\left(C_{1}\right)$ & $\left(C_{L}\right)$ & $\left(C_{f}\right)$ & $\left(C_{n}\right)$ & (C,) & $\left(C_{1}\right)$ & $\bullet$ & - & - & - \\
\hline$F_{1}^{\prime}=$ & (F) & $\left(C_{0}\right)$ & $\left(C_{n}\right)$ & (C) & $\bullet$ & $\left\langle\mathrm{C}_{\mathrm{f}}\right)$ & $\bullet$ & $\bullet$ & $\bullet$ & $\bullet$ & $\bullet$ & $\cdot$ & $\bullet$ \\
\hline$F_{V}^{\prime}=$ & $\left(F_{v}\right)$ & $\left(C_{0}\right)$ & $\left(C_{w}\right)$ & (C) & 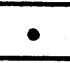 & • & 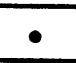 & - & $\bullet$ & $\bullet$ & $\left(C_{k}\right)$ & $\cdot$ & $\cdot$ \\
\hline$F_{c \perp}^{\prime}=$ & $\left(F_{c 1}\right)$ & - & $\left(C_{m}\right)$ & $\left(C_{1}\right)$ & $\bullet$ & - & - & - & $\bullet$ & $\bullet$ & - & • & $\left(C_{b}\right)$ \\
\hline$F_{c}^{\prime}=$ & $\left(F_{c}\right)$ & $\left(C_{0}\right)$ & $\left(C_{m}\right)$ & $\left(C_{1}\right)$ & $\bullet$ & $\left(C_{F}\right)$ & • & - & • & $\left(C_{p}\right)$ & • & $\bullet$ & - \\
\hline$E^{\prime}=$ & (E) & $\bullet$ & $\left(C_{n}\right)$ & (C) & $\bullet$ & $\bullet$ & $\bullet$ & - & $\bullet$ & $\bullet$ & $\bullet$ & $\left(C_{f}\right)$ & $\cdot$ \\
\hline$F_{g}^{\prime}=$ & $\left(F_{0}\right)$ & $\left(C_{D}\right)$ & - & (C) & • & - & - & - & - & - & - & - & - \\
\hline
\end{tabular}


Table 11. Load duration factor (CD)

\begin{tabular}{|l|c|l|}
\hline Load Duration & $\mathbf{C}_{0}$ & Typical Design Loads \\
\hline Permanent & 0.9 & Dead load \\
\hline 10 years & 1.0 & Occupancy live load \\
\hline 2 months & 1.15 & Snow load \\
\hline 7 days & 1.25 & Construction load \\
\hline 10 minutes & 1.6 & Wind/earthquake load \\
\hline Impact & 2.0 & Impact load \\
\hline
\end{tabular}

Table 12. Wet service factor (CM).

\begin{tabular}{|c|c|c|c|c|c|}
\hline$F_{0}$ & $F_{1}$ & $F_{y}$ & $\mathbf{F}_{c L}$ & $F_{c}$ & $\mathbf{E}$ \\
\hline $\begin{array}{l}0.85 \text { when }\left(F_{b}\right)\left(C_{F}\right) \leq 1150 p s i, \\
C_{u}=1.0\end{array}$ & 1.0 & 0.97 & 0.67 & $\begin{array}{l}0.80 \text { when }\left(F_{b}\right)\left(C_{f}\right) \leq 750 p s i, \\
C_{u}=1.0\end{array}$ & 0.90 \\
\hline
\end{tabular}

Table 13. Temperature factor (Ct).

\begin{tabular}{|l|c|c|c|c|}
\hline \multirow{3}{*}{$\begin{array}{l}\text { Design } \\
\text { Values }\end{array}$} & \multirow{2}{*}{$\begin{array}{c}\text { In Service } \\
\text { Moisture Conditions }\end{array}$} & $\mathrm{T} \leq 100^{\circ} \mathrm{F}$ & $100{ }^{\circ} \mathrm{F} \leq \mathrm{T} \leq 125{ }^{\circ} \mathrm{F}$ & $125{ }^{\circ} \mathrm{F} \leq \mathrm{T} \leq 150^{\circ} \mathrm{F}$ \\
\cline { 3 - 5 } & Wet or Dry & 1.0 & 0.9 & 0.9 \\
\hline$F_{1}, E$ & Dry & 1.0 & 0.8 & 0.7 \\
\hline$F_{b}, F_{v}, F_{c}$ & Wet & 1.0 & 0.7 & 0.5 \\
\hline and $F_{c 1}$ & &
\end{tabular}

\section{Design Provisions and Equations}

The 1944 edition of the National Design Specification for Wood Construction relied on the Allowable Stress Design method in conjunction with elastic stressstrain theory. The code demanded that the induced stresses not exceed the allowable design values multiplied by the appropriate adjustment factors. Note: for simplicity, the notation adopted by the 1991 edition of the code will be used for describing the equations from the other editions). This remained unchanged through the 1991 edition. The design equations and provisions can be divided into the categories of bending members, columns, beam-columns, tension members, bearing requirements, and bracing requirements. These basic divisions are consistent from the original code through the 1991 edition. In 1944, the general flexural design equation for calculating the induced extreme fiber stress was:

$$
f_{b}=\frac{M c}{I}=\frac{M}{S}
$$

where:

$$
\begin{aligned}
& M=\text { the applied moment } \\
& S=\text { the section modulus. }
\end{aligned}
$$


A provision for bending members of circular cross section states that their strength is equal to an equivalent bending member of square cross section. The general design equation for calculating the induced horizontal shear stress at the neutral axis was given as:

$$
f_{V}=\frac{V Q}{I b}
$$

[Eq 2]

where:

$$
\begin{aligned}
& \mathrm{V}=\text { the applied vertical shear force } \\
& \mathbf{Q}=\text { the first moment of the area above or below the neutral axis } \\
& \text { about the neutral axis } \\
& \mathrm{I}=\text { the moment of inertia } \\
& \mathrm{b}=\text { the width of bending member at the neutral axis. }
\end{aligned}
$$

When determining the applied shear force for checked beams, the code provided the following equations for concentrated and distributed loads that take into account the stress redistribution effects associated with such beams:

$$
\begin{gathered}
V=\frac{10 P(l-x)(x / d)^{2}}{9 l\left[2+(x / d)^{2}\right]} \text { for concentrated loads } \\
V=\frac{W}{2}\left(1-\frac{2 d}{l}\right) \text { for uniformly distributed loads }
\end{gathered}
$$

where:

$$
\begin{aligned}
& P=\text { value of the concentrated load } \\
& \mathbf{l}=\text { span } \\
& \mathbf{x}=\text { distance from the reaction to the concentrated load } \\
& \mathrm{d}=\text { depth of the beam } \\
& W=\text { total value of the uniform load. }
\end{aligned}
$$

The design value of compression perpendicular to grain applied to bearings of any length at the ends of the member and to all bearings greater than 6 in. in length at any other location. For bearings less than 6 in. in length and more than 3 in. from the end of the member, the code provides the adjustment factor:

$$
\frac{l_{b}+0.375}{l_{b}}
$$

where $l_{b}=$ the length of the bearing. 
Column design in the 1944 code was divided into two separate column types, simple columns and spaced columns each with slightly different design provisions. The equations for the allowable design values for simple columns were based on the column slenderness ratio, $1 / d$, and a constant $K$, which is dependent on the design values $E$ and $F_{c^{*}} K$ is the slenderness ratio at which a column transitions from an intermediate length column to a long column. These design equations were defined as:

Short Columns (1/d $\leq 11)$ :

$$
F_{c}^{\prime}=F_{c}
$$

[Eq 6]

Intermediate Columns $(11<\mathrm{l} / \mathrm{d}<\mathrm{K})$ :

$$
\begin{gathered}
K=\frac{\pi}{2} \sqrt{\frac{E}{5 F_{c}}}=0.702 \sqrt{\frac{E}{F_{c}}} \\
F_{c}^{\prime}=F_{c}\left[1-\frac{1}{3}\left(\frac{l}{K d}\right)^{4}\right]
\end{gathered}
$$

where:

$$
\begin{aligned}
& P=\text { total load } \\
& A=\text { cross sectional area } \\
& \mathbf{l}=\text { unbraced length of column } \\
& d=\text { smallest side dimension of column. }
\end{aligned}
$$

Long Columns ( $\mathrm{K} \leq \mathrm{l} / \mathrm{d})$ :

$$
F_{c}^{\prime}=\frac{0.329 E}{(1 / d)^{2}}
$$

[Eq 9]

The design equations for spaced columns were very similar, with the exception that an extra factor was included to account for two "column fixity" conditions:

a. The center of resistance of the end connectors are within $1 / 20$ from the end of the column

b. The center of resistance of the end connectors are between $1 / 20$ and $1 / 10$ from the end of the column. 
This factor multiplied with $E$, and had a value of 2.5 for condition " $a$ " and 3.0 for condition "b." In addition, the code also placed limitations on the slenderness ratio of the columns:

- simple columns: $1 / d \leq 50$

- individual members of spaced columns: $1 / d \leq 80$ and $12 / d \leq 40$ where $l_{2}=$ the distance from the center of resistance of the connectors in the end blocks to center of the spacer block.

The code also included provisions for combined loadings of tension or compression with flexure. The design equations were:

$$
\text { Combined tension and flexure: } \frac{P / A}{F_{t}}+\frac{M / S}{F_{b}} \leq 1
$$

Combined compression and flexure: $\frac{P / A}{F_{c}^{\prime}}+\frac{M / S}{F_{b}} \leq 1$

where:

$$
\begin{aligned}
& M=\text { total moment } \\
& \mathbf{S}=\text { section modulus } .
\end{aligned}
$$

In an effort to eliminate the need to calculate the effects of lateral buckling, the code includes lateral bracing requirements based on the nominal depth to thickness ratio:

1. Ratio $=2$; no support necessary

2. Ratio $=3$; ends shall be held in position

3. Ratio = 4; the piece shall be held in line, as in a well-bolted chord member in a truss

4. Ratio = 5; one edge shall be held in line

5. Ratio $=6$; bridging at intervals $\leq 8 \mathrm{ft}$

6. Ratio = 7; both edges shall be held in line

7. If a beam is subject to both flexure and compression parallel to grain, the ratio may be as much as 5 if one edge is held firmly in line; if dead load is sufficient to induce tension on the underside of the member, the ratio may be as much as 6. 
The final design equation presented in the 1944 edition of the NDS, known as the Hankinson formula, calculates the allowable unit stress in the direction of the load for compression at an angle to the grain of the member:

$$
F_{\theta}=\frac{F_{c} F_{c \perp}}{F_{c} \sin ^{2} \theta+F_{c \perp} \cos ^{2} \theta}
$$

[Eq 12]

In 1953, the code prescribed a major change to the column design formulas. In an effort to simplify the design process, the column design formulas no longer differentiated between column lengths (i.e., short, intermediate, and long columns). There was only one equation for simple columns and two equations for spaced columns, as follows (all of the other slenderness ratio limits carry over without change):

$$
\begin{aligned}
& F_{c}^{\prime}=\frac{0.30 E}{(1 / d)^{2}} \text { for simple square or rectangular columns } \\
& F_{c}^{\prime}=\frac{0.75 E}{(1 / d)^{2}} \text { for spaced columns with fixity condition " } \mathrm{a} \text { " } \\
& F_{c}^{\prime}=\frac{0.90 E}{(1 / d)^{2}} \text { for spaced columns with fixity condition " } \mathrm{b} \text { " }
\end{aligned}
$$

where:

$$
\begin{aligned}
& \mathrm{d}=\text { dimension of least side of individual members } \\
& 1=\text { unsupported length. }
\end{aligned}
$$

The fixity condition definitions remain unchanged from the previous edition.

In 1957, the only change to the design provisions was the requirement that to obtain spaced column action, end spacer blocks must be used when the individual members have an:

$$
\mathrm{V} d>\sqrt{\frac{0.30 E}{F_{c}}}
$$

The only significant change in the 1968 edition of the NDS was the addition of an adjustment factor for lumber loaded on the wide face. For 2 to 4 in. thick lumber used flatwise, the bending design value, $F_{b}$, shall be multiplied by the following adjustment factors (Table 14). 
Table 14. 1968 adjustment factors for lumber loaded on the wide face.

\begin{tabular}{|l|l|l|l|}
\hline Width & \multicolumn{3}{|c|}{ Thickness } \\
\hline & 2 in. & 3 in. & 4 in. \\
\hline 2 to 4 in. & 1.10 & 1.04 & 1.00 \\
\hline 6 in. and wider & 1.22 & 1.16 & 1.11 \\
\hline
\end{tabular}

In 1971, only a few minor changes were made to the design. The equations for combined flexural and axial loading remain unchanged with the exception that if:

$$
l / d>\sqrt{\frac{0.30 E}{F_{c}}}
$$

for a member under combined flexure and axial compression, then:

$$
\frac{P / A}{F_{c}^{\prime}}+\frac{M / S}{F_{b}-P / A} \leq 1
$$

must be satisfied. The lateral bracing requirements also included a change that eliminated the allowance for the depth-to-thickness ratio to be as great as 6 for members under combined flexure and axial compression where the dead load is sufficient to induce tension in the underside of the member. All other design equations and provisions remained unchanged.

The 1973 edition of the National Design Specification for Wood Construction included very few changes to the design formulas and provisions from the 1971 edition. The only addition was a modification factor for bending members called the Size Factor:

$$
C_{F}=\left(\frac{12}{d}\right)^{1 / 9}
$$

where $d=$ the depth of the bending member.

This Size Factor modified only the tabulated design value for bending stress, $F_{b}$. All other design equations and provisions remained unchanged.

In 1977, the NDS included a number of revisions and additions from the previous edition including two additional sections relating to the specific require- 
ments of sawn lumber and glued laminated structural members. For bending members, a "Slenderness Factor," defined as:

$$
C_{s}=\sqrt{\frac{l_{e} d}{b^{2}}} \leq 50
$$

[Eq 20]

was introduced into the code. The value of the variable, le, was determined based on the unbraced length of the bending member, lu, as follows (Table 15):

Table 15. 1977 determination of effective length for loading condition.

\begin{tabular}{|l|c|}
\hline Loading Condition & $I_{U}$ \\
\hline Single span with concentrated load at center & $1.61 I_{u}$ \\
\hline Single span with uniformly distributed load & $1.92 I_{u}$ \\
\hline Single span with equal end moments & $1.84 I_{u}$ \\
\hline Cantilever beam with concentrated load at unsupported end & $1.69 I_{u}$ \\
\hline Cantilever beam with uniformly distributed load & $1.06 I_{u}$ \\
\hline Single span or cantilever with an arbitrary load, a conservative value & $1.92 I_{u}$ \\
\hline
\end{tabular}

The slenderness factor was used to modify the extreme fiber in bending design value as follows:

$$
\begin{gathered}
\text { Short Beams }\left(\mathrm{C}_{\mathrm{s}} \leq 10\right): F_{b}^{\prime}=F_{b} \\
\text { Intermediate Beams }\left(10<\mathrm{C}_{\mathrm{s}} \leq \mathrm{C}_{\mathrm{K}}\right): F_{b}^{\prime}=F_{b}\left[1-1 / 3\left(\frac{C_{S}}{C_{K}}\right)^{4}\right]
\end{gathered}
$$

Where $C_{K}=\sqrt{\frac{3 E}{5 F_{b}}}$

$$
\text { Long Beams }\left(\mathrm{C}_{\mathrm{k}}<\mathrm{C}_{\mathrm{s}}<50\right): \quad F_{b}^{\prime}=\frac{0.40 E}{\left(C_{s}\right)^{2}}
$$

The size factor introduced in the 1973 code still existed, but its modifications were not cumulative with the slenderness factor (i.e., when applying the two modification factors independently, the smaller value obtained shall be used). The 1977 edition also introduced a "Form Factor," $C_{f}$ with the value of 1.8 for round beams and 1.414 for rectangular beams loaded through their diagonal. This factor is technically not new since all it does is simply quantify a statement from the previous edition, which said that round beams and rectangular beams loaded through their diagonal shall have the same strength as a square beam of equal cross-sectional area. One of the largest and most important changes in- 
troduced in the 1977 NDS was the manner in which the design values for compression members were calculated. The equations revert back to what was originally suggested published in the 1944 edition with some minor alterations, for simple solid columns:

$$
\text { Short Columns (1/d <11): } F_{C}^{\prime}=F_{C}
$$

$$
\begin{gathered}
\text { Intermediate Columns }(11<\mathrm{l} / \mathrm{d}<\mathrm{K}): F_{C}^{\prime}=F_{C}\left[1-\frac{1}{3}\left(\frac{l / d}{K}\right)^{4}\right] \\
\text { Long Columns }(1 / \mathrm{d}>\mathrm{K}): F_{C}^{\prime}=\frac{0.30 E}{(l / d)^{2}}
\end{gathered}
$$

where:

$$
\begin{aligned}
& K=0.671 \sqrt{\frac{E}{F_{C}}} \\
& 1 / d=\begin{array}{l}
\text { the lesser of the two ratios with respect to the two sides of the } \\
\text { column. }
\end{array}
\end{aligned}
$$

Spaced columns, as in 1944, used the same formulas as above with the addition of a factor multiplying $\mathrm{E}$ equal to $\mathbf{2 . 5}$ for fixity condition "a" and 3.0 for fixity condition "b." The 1977 edition also amended the formula for combined flexure and axial compression to reflect the changes in the column formulas, as follows:

$$
\frac{f_{c}}{F_{c}^{\prime}}+\frac{f_{b}}{F_{b}-J f_{c}} \leq 1
$$

where:

$$
\begin{aligned}
& J=\frac{l_{e} / d-11}{K-11} \quad \text { (unitless convenience factor) } \\
& 0 \leq J \leq 1 \\
& J=0 \text { for short columns }(1 / \mathrm{d}<1) \\
& J=1 \text { for long columns }(1 / \mathrm{d}>\mathrm{K}) .
\end{aligned}
$$

Additionally, the code provided a buckling stiffness factor, $C_{\mathrm{T}}$, for cases where $2 \mathrm{x}$ $4 \cdot$ in. or smaller truss compression chords have plywood sheathing attached to 
the narrow face. The value of this buckling stiffness factor is summarized as follows:

if $1<96$ in. and the thickness of the plywood is greater than $3 / 8$ in., then:

$C_{T}=1+0.0021_{e}$ for wood seasoned to a moisture content of 19 percent

$\mathrm{C}_{\mathrm{T}}=1+0.0011_{\mathrm{e}}$ for unseasoned or partially seasoned wood

if $l_{e}>96$ in., the value of the buckling stiffness factor shall be taken as the value for a chord with $l_{\bullet}=96 \mathrm{in}$.

The buckling stiffness modifies the design value for compression parallel to grain in the same way as the modification factor for fixity conditions of spaced columns.

The 1982 edition of the code included only minor changes to the design formulas and provisions, the first of which introduced a more comprehensive formula related to calculating the effective lengths, $l_{e}$, of bending members. The 1977 code assumed an $l_{u} / d$ ratio of 17 , but in 1982 , the code added the factor:

$$
0.85+\frac{2.55}{\left(l_{u} / d\right)}
$$

[Eq 28]

to be multiplied with $1_{0}$, for other ratios. This factor did not apply to single span beam with equal end moments or single span or cantilever beams with an arbitrary load. The numerical constant in the $C_{K}$ equation for beams changed from 0.6 to 0.811 in addition to the constant in the $F_{b}^{\prime}$ equation for long beams changing from 0.40 to 0.438 . Another minor change was the introduction of an effective length factor for columns based on the end conditions. The previous codes mentioned that the formulas were intended for pinned-pinned end conditions and adjustments should be made accordingly, but in 1982 these adjustments were quantified in the appendix. Additionally, the formulas for combined flexural and axial loading were revised:

Flexure and axial tension: $\frac{f_{t}}{F_{t}}+\frac{f_{b}}{F_{b}} \leq 1 \quad \frac{\dot{f_{b}}-f_{t}}{F_{b}^{\prime}} \leq 1$

Flexure and axial compression: $\frac{f_{c}}{F_{c}^{\prime}}+\frac{f_{b}}{F_{b}^{\prime}-J f_{c}} \leq 1$ 
where $\quad J=\frac{l_{e} / d-11}{K-11}$

The buckling stiffness factor, $\mathrm{C}_{\mathrm{T}}$, for use with $2 \times 4$ in: or smaller truss compression chords with $3 / 8$ in. or thicker plywood sheathing nailed to the narrow face changes was changed:

if $1 . \leq 96$ in. and seasoned to moisture content $\leq 19$ percent: $C_{T}=1+\frac{2300 l_{e}}{E_{0.05}}$

$$
1.596 \text { in. and unseasoned: } C_{T}=1+\frac{1200 l_{e}}{E_{0.05}}
$$

where:

$$
\begin{aligned}
\mathrm{E}_{0.05}=: & \text { Level of modules of elasticity exceeded by } 95 \text { percent probability } \\
& \text { (Appendix A, NDS 1994). } \\
\mathrm{E}_{0.05}= & 0.589 \mathrm{E} \text { for visually graded lumber } \\
\mathrm{E}_{0.05}= & 0.819 \mathrm{E} \text { for machine graded lumber. }
\end{aligned}
$$

When checking the design in the plane of bending, the slenderness ratio, $1_{\text {ddd }}$ in the plane of bending shall be used to calculate $F_{c}^{\prime}$ and $\mathrm{J}$, but when checking the design perpendicular to the plane of bending, the slenderness ratio, $l_{\text {ddd }}$ perpendicular to the plane of bending shall be used to calculate $F_{c}^{\prime}$ and $J$ shall be set equal to zero.

In 1986, the code again included only minor changes to the design formulas and provisions. The provisions for calculating the effective length of bending members with respect to specific loading conditions changed to the following (although the formula for the slenderness factor, Cs, did not) (Table 16):

Table 16. 1986 determination of $I$, for loading condition.

\begin{tabular}{|l|c|}
\hline Loading Condition & $I_{\bullet}$ \\
\hline Single span with concentrated load at center & $1.37 I_{u}+3 d$ \\
\hline Single span with uniformly distributed load & $1.63 I_{u}+3 d$ \\
\hline Single span with equal end moments & $1.84 I_{u}$ \\
\hline Cantilever beam with concentrated load at unsupported end & $1.44 I_{u}+3 d$ \\
\hline Cantilever beam with uniformly distributed load & $0.90 I_{u}+3 d$ \\
\hline For single span or cantilever with any load, conservative value & $\mathrm{I}_{u}$ for $I_{J} / d>14.31 .63 I_{u}+3 d$ for \\
& $\mathrm{V} / d<14.3$ \\
\hline
\end{tabular}

There was a minor clarification to the provision for checking the design of a member under combined flexure and axial compression perpendicular to the plane of bending. 
$\mathrm{J}$ shall be based on $1 / \mathrm{d}$ when $\mathrm{C}$ s $>10$

$\mathrm{J}=0$ when $\mathrm{C}_{\mathrm{s}} \leq 10$

The variable $\mathrm{F}_{\mathrm{c}}$ in the formula for calculating the design value at an angle to the grain of the member was replaced by $F_{z}$, the design value for end grain bearing parallel to grain. The last change to 1986 code was related to shear in bending members. According to the code, the design value for horizontal shear was permitted to be doubled for continuous or cantilevered bending members with a thickness of 2 to 4 in. Additionally, the formulas for determining the vertical shear force for use in the horizontal shear stress calculations changed:

uniformly distributed load:

$$
V=\frac{W}{2}\left(1-\frac{2 d}{l_{c}}\right) C_{v}
$$

where:

$$
\begin{aligned}
& C_{v}=0.95+\frac{\sqrt{l_{c} / d}}{250}-1.32\left(d / l_{c}\right)+11.5\left(d / l_{c}\right)^{3} \leq 1 \\
& l_{c}=\text { clear span }
\end{aligned}
$$

concentrated load:

$$
V=\frac{P\left(l_{c}-x\right)(x / d)^{2}}{l_{c}\left[2+(x / d)^{2}\right]}
$$

In 1991, the National Design Specification for Wood Construction went through some fairly major revisions. The most visible change was, of course, a much more user friendly organization, although many more changes were also made to the content of the design equations and provisions. The formulas for calculating the design value at the extreme fiber in bending were based on a beam stability factor:

$$
C_{L}=\frac{1+\left(F_{b E} / F_{b}^{*}\right)}{1.9}-\sqrt{\left[\frac{1+\left(F_{b E} / F_{b}^{*}\right)}{1.9}\right]^{2}-\frac{F_{b E} / F_{b}^{*}}{0.95}}
$$


where:

$F_{b}^{*}=$ tabulated bending design value multiplied by all applicable adjustment factors except $\mathrm{C}_{\mathrm{fu}}, \mathrm{C}_{\mathrm{v}}$, and $\mathrm{C}_{\mathrm{L}}$

$F_{b E}=\frac{K_{b E} E^{\prime}}{R_{B}^{2}}$

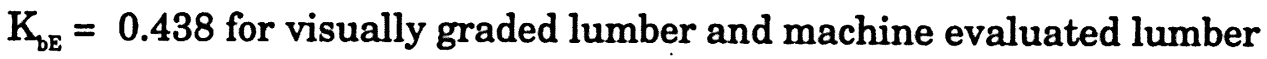

$\mathrm{K}_{\mathrm{bE}}=0.609$ for products with COVE $\leq 0.11$ (COVE is defined in Appen$\operatorname{dix}$ A, NDS 1991)

$R_{B}=$ the slenderness ratio directly proportional to the effective length, le, of the bending member as

$R_{B}=\sqrt{\frac{l_{e} d}{b^{2}}} \leq 50$

, where the effective length is calculated as follows:

\begin{tabular}{|c|c|c|}
\hline Cantilever Beams• & when $I_{w 0}<7$ & when $I_{w d} \geq 7$ \\
\hline uniformly distributed load & $L_{0}=1.33 I_{v}$ & $L_{0}=0.90 I_{u}+3 d$ \\
\hline concentrated load @ unsupported end & $L_{0}=1.87 I_{u}$ & $L_{0}=1.44 I_{u}+3 d$ \\
\hline Single Span Beams & When $I_{w d}<7$ & when $I_{w d} \geq 7$ \\
\hline uniformly distributed load & $L_{0}=2.06 \mathrm{I}_{u}$ & $L_{0}=1.63 I_{u}+3 d$ \\
\hline $\begin{array}{l}\text { concentrated load @ center with no intermediate lateral } \\
\text { support }\end{array}$ & $L_{0}=1.80 I_{v}$ & $L_{0}=1.37 I_{u}+3 d$ \\
\hline concentrated load @ center with lateral support @ center & $L_{0}=1.11 I_{u}$ & \\
\hline 2 equal concentrated loads and lateral support @ 1/3 pts. & $L_{0}=1.68 I_{u}$ & \\
\hline 3 equal concentrated loads and lateral support @ 1/4 pts. & $L_{0}=1.54 I_{u}$ & \\
\hline 4 equal concentrated loads and lateral support @ 1/5 pts. & $L_{0}=1.68 I_{u}$ & \\
\hline 5 equal concentrated loads and lateral support @ 1/6 pts. & $L_{0}=1.73 \mathrm{I}_{\mathrm{u}}$ & \\
\hline 6 equal concentrated loads and lateral support @ $1 / 7$ pts. & $L_{0}=1.78 \mathrm{I}_{\mathrm{u}}$ & \\
\hline $\begin{array}{l}7 \text { or more equal concentrated loads, evenly spaced, w/ } \\
\text { lateral support @ pts. of load }\end{array}$ & $L_{0}=1.84 I_{v}$ & \\
\hline equal end moments & $L_{0}=1.84 I_{u}$ & . \\
\hline $\begin{array}{l}\text { For single span or cantilever members with any other load, } \\
\text { then: }\end{array}$ & $\begin{array}{l}L_{0}=2.06 \mathrm{I}_{u} \\
L_{0}=1.63 \mathrm{I}_{\mathrm{u}} \\
L_{0}=1.84 \mathrm{I}_{\mathrm{u}}\end{array}$ & $\begin{array}{l}\text { when } I_{w d}<7 \\
\text { when } 7 \leq I_{w d} \leq 14.3 \\
\text { when } I_{w d}>714.3\end{array}$ \\
\hline
\end{tabular}


This factor is based primarily on the lateral support conditions of the particular bending member and as such, is equal to one if:

- the depth of the member does not exceed its breadth OR

- the member conforms to the lateral support requirements (which remain unchanged from the 1986 edition of the code) OR

- the compression edge of the member is fully supported throughout its length to prevent lateral displacement and the points of bearing are secured to prevent lateral rotation

The 1991 code also greatly changed the way the design values for horizontal shear were calculated to include adjustment factors for splits and shakes (Table 17).

Table 17. 1991 shear stress factors for horizontal shear.

\begin{tabular}{|c|c|c|}
\hline $\begin{array}{l}\text { Length of split on wideface of } \\
\text { 2-in. (nominal) C.lumber }\end{array}$ & $\begin{array}{l}\text { Length of split on wideface of } \\
\text { 3-in. (nominal) } C_{H} \text { and thicker } \\
\text { lumber }\end{array}$ & $\begin{array}{l}\text { Size of shake in 2-in. } \\
\text { (nominal) and } C_{\mu} \text { lumber }\end{array}$ \\
\hline $\begin{array}{ll}\text { no split } & 2.00 \\
1 / 2 \times \text { wide face } & 1.67 \\
3 / 4 \times \text { wide face } & 1.501 \\
1 \times \text { wide face } & 1.331 \\
11 / 2 \times \text { wide face or more } & 1.00\end{array}$ & $\begin{array}{lr}\text { no split } & 2.00 \\
1 / 2 \times \text { wide face } & 1.67 \\
3 / 4 \times \text { wide face } & 1.50 \\
1 \times \text { wide face } & 1.33 \\
1 \mathrm{1} / 2 \times \text { wide face or more } 1.00\end{array}$ & $\begin{array}{lr}\text { no shake } & 2.00 \\
1 / 2 \times \text { wide face } & 1.67 \\
3 / 4 \times \text { wide face } & 1.50 \\
.1 \times \text { wide face } & 1.33 \\
11 / 2 \times \text { wide face or more } 1.00\end{array}$ \\
\hline
\end{tabular}

The code also provided a "Column Stability Factor," $\mathrm{C}_{\mathrm{p}}$, for the calculation of the allowable design value for compression parallel to grain, which, for solid columns, is:

$$
C_{P}=\frac{1+\left(F_{c E} / F_{c}^{*}\right)}{2 c}-\sqrt{\left[\frac{1+\left(F_{c E} / F_{c}^{*}\right)}{2 c}\right]^{2}-\frac{F_{c E} / F_{c}^{*}}{c}}
$$

where: $F_{c}^{*}=$ tabulated design value multiplied by all applicable adjustment factors except CP

$$
F_{c E}=\frac{K_{c E} E^{\prime}}{\left(l_{e} / d\right)^{2}}
$$




$$
\begin{aligned}
K_{\mathrm{cE}}= & 0.3 \text { for visually graded lumber and machine evaluated lumber } \\
(\mathrm{MEL}) & \\
\mathrm{K}_{\mathrm{cE}}= & 0.418 \text { for products with } \mathrm{COVE} \leq 0.11 \\
\mathrm{c}= & 0.8 \text { for sawn lumber. }
\end{aligned}
$$

The determination of $\mathrm{C}_{\mathrm{p}}$ is identical for spaced columns, except that:

$$
F_{c E}=\frac{K_{X} K_{c E} E^{\prime}}{\left(l_{e} / d\right)^{2}}
$$

where: $K_{x}=2.5$ for fixity condition " $a$ "

$$
\mathrm{K}_{\mathrm{x}}=3.0 \text { for fixity condition " } \mathrm{b} \text {." }
$$

The equations for combined loading also changed to reflect the changes in column and beam design in addition to providing for loading on both faces of the member. These equations are summarized as:

Flexure and Axial Tension:

$$
\begin{gathered}
\frac{f_{t}}{F_{t}^{\prime}}+\frac{f_{b}}{F_{b}^{*}} \leq 1 \text { AND } \\
\frac{f_{b}-f_{t}}{F_{b}^{* *}} \leq 1
\end{gathered}
$$

[Eq 39]

where: $F_{b}^{*}=$ bending design value multiplied by all applicable adjustment factors except $C_{L}$

$F_{b}^{* *}=$ bending design value multiplied by all applicable adjustment factors except $C_{v}$. 
Flexure and Axial Compression:

$$
\left[\frac{f_{c}}{F_{c}^{\prime}}\right]^{2}+\frac{f_{b 1}}{F_{b 1}^{\prime}\left[1-\left(f_{c} / F_{c E 1}\right)\right]}+\frac{f_{b 2}}{F_{b 2}^{\prime}\left[1-\left(f_{c} / F_{c E 2}\right)-\left(f_{b 1} / F_{b E}\right)^{2}\right]} \leq 1
$$

where: $\quad F_{c E x}=\frac{K_{c E} E^{\prime}}{\left(l_{e x} / d_{x}\right)^{2}}$

$x=1$ or 2 for loads applied to the narrow face or wide face, respectively

$x=1$ or 2 for loads applied to the narrow face or wide face, respectively.

The 1991 code also included a number of adjustment factors based solely on the geometry and size of the member, the first of which was the size factor. For rectangular sawn lumber bending members greater than 5 in. thick, with a depth greater than 12 in., the bending design value, $F_{b}$, was to be multiplied by the size factor:

$$
C_{F}=(12 / d)^{1 / 9} \leq 1.0
$$

Table 18 lists the size factors corresponding to the applicable design values for dimension lumber 2 to 4 in. thick.

-The final change to the 1991 National Design Specification for Wood Construction was the addition of a flat-use factor, $C_{f o}$, for members 2 to 4 in. thick loaded on the wide face, Table 19 lists the values. 
Table 18. 1991 adjustment factors for geometry and size of sawn lumber.

\begin{tabular}{|c|c|c|c|c|c|}
\hline \multirow[b]{2}{*}{ Grades } & \multirow[b]{2}{*}{ Width } & \multicolumn{2}{|c|}{$\begin{array}{c}\mathrm{F}_{\mathrm{b}} \\
\text { Thickness }\end{array}$} & \multirow[b]{2}{*}{$F_{1}$} & \multirow[b]{2}{*}{ F } \\
\hline & & $2 \& 3$ in. & $4 \mathrm{in}$. & & \\
\hline $\begin{array}{l}\text { Select structural, } \\
\text { No. } 1 \text { \& Btr. No. } 1 \text {, } \\
\text { No. } 2 \text {, No. } 3\end{array}$ & $\begin{array}{c}2,3, \& 4 \text { in. } \\
5 \text { in. } \\
6 \text { in. } \\
8 \text { in. } \\
10 \text { in. } \\
12 \text { in. } \\
14 \text { in. \& Wider }\end{array}$ & $\begin{array}{l}1.5 \\
1.4 \\
1.3 \\
1.2 \\
1.1 \\
1.0 \\
0.9\end{array}$ & $\begin{array}{l}1.5 \\
1.4 \\
1.3 \\
1.3 \\
1.2 \\
1.1 \\
1.0\end{array}$ & $\begin{array}{l}1.5 \\
1.4 \\
1.3 \\
1.2 \\
1.1 \\
1.0 \\
0.9\end{array}$ & \begin{tabular}{c|}
1.15 \\
1.1 \\
1.1 \\
1.05 \\
1.0 \\
1.0 \\
0.9
\end{tabular} \\
\hline Stud & $\begin{array}{c}2,3, \& 4 \text { in. } \\
5 \& 6 \text { in. } \\
\end{array}$ & $\begin{array}{l}1.1 \\
1.0 \\
\end{array}$ & $\begin{array}{l}1.1 \\
1.0 \\
\end{array}$ & $\begin{array}{l}1.1 \\
1.0 \\
\end{array}$ & $\begin{array}{l}1.05 \\
1.0 \\
\end{array}$ \\
\hline $\begin{array}{l}\text { Construction \& } \\
\text { standard }\end{array}$ & $2,3, \& 4$ in. & 1.0 & 1.0 & 1.0 & 1.0 \\
\hline Utility & $\begin{array}{c}4 \text { in. } \\
2 \& 3 \text { in. }\end{array}$ & $\begin{array}{l}1.0 \\
0.4 \\
\end{array}$ & $\begin{array}{l}1.0 \\
\text { N/A }\end{array}$ & $\begin{array}{l}1.0 \\
0.4\end{array}$ & $\begin{array}{l}1.0 \\
0.6\end{array}$ \\
\hline
\end{tabular}

Table 19. 1991 flat-use factors for members loaded on the wide face.

\begin{tabular}{|c|c|c|}
\hline Width & \multicolumn{2}{|c|}{ Thickness } \\
\hline & 2 \& 3 in. & 4 in. \\
\hline 2 \& 3 in. & 1.0 & N/A \\
$4^{\prime \prime}$ & 1.1 & 1.0 \\
$5^{\prime \prime}$ & 0.1 & 1.05 \\
$6^{\prime \prime}$ & 1.15 & 1.05 \\
$8^{\prime \prime}$ & 1.15 & 1.05 \\
$10^{\prime \prime} \&$ Wider & 1.2 & 1.1 \\
\hline
\end{tabular}

\section{Mechanical Fasteners, Lumber Sizes, and Design Values}

Of all the sections in the National Design Specification for Wood Construction, the tables of the design values have changed the most. With every new edition, there is at least a slight modification to the tabulated design values. In 1960 , tabulated section properties and dress sizes of the most common standard dimensions of lumber were included. The code also provides guidelines for the design of wood connections.

Table A1 in the Appendix shows the scanned images of the design value tables from the 1944 edition of the code. Changes to the design values typically take the form of relatively small adjustments (less than 10 percent) from one edition to another. The cumulative effect of these changes over a number of years, however, is rather significant. Another difficulty with tracking these changes is the fact that the names and grading designations of some of the wood species tended to be altered through the years in addition to including new species and deleting old ones. For example, in 1948, the species formerly know as Southern Shortleaf 
Pine was changed to Southern Pine and in 1950 the species formerly known as Tidewater Red Cypress was changed to Southern Coast Cypress. There are many other examples (too many to enumerate here) of this sort of change, coupled with the aforementioned small changes in the design values themselves from edition to edition, that makes charting the specific changes an overwhelming task. One can draw some general conclusions, though, of the how the modifications have manifested themselves and what impact they have had on the design of wood structures. In 1968, a separate design value for tension parallel to grain was introduced. In general, each design value changed independently to reflect new grading and testing procedures and normal changes in the actual wood strength. When comparing the 1968 edition with the 1991 edition, it can be seen that the design values, in general, change as follows:

- $F_{b}$ - decrease of 15 to 30 percent, for Southern Pine increase of 35 percent

- $F_{t}$ - decrease of 10 to 30 percent, for Southern Pine increase of 30 percent

- $F_{\mathrm{v}}$ - no change, for Southern Pine increase of 10 percent

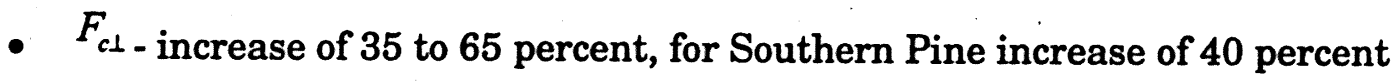

- $\mathrm{F}_{\mathrm{c}}$ - decrease of 10 to 20 percent for Southern Pine and-Douglas Fir-Larch, increase of 6 to 30 percent

- E - decrease of 15 percent to an increase of 5 percent with many species not having any change.

It is important to reiterate that the above percentages hold true for the majority of soft wood species, but are by no means comprehensive due to the difficulties mentioned above.

In 1968, the Standard Dressed (S4S) Sizes of structural lumber were revised for selected sizes. The Standard Dressed Sizes are the actual dimensions of the lumber and are used in calculating the working stresses of a particular member. The nominal dimensions of the lumber are those referenced in the code and used by the industry. If either the nominal width or thickness dimension of the mem- . ber was 4 in. or less, that dimension was decreased 1/8 in. This constitutes a substantial change in the way structural wood design (particularly for light wood frames and trusses) was carried out. Table 20 gives examples.

Table 20. Examples of 1968 revisions for standard dressed (S4S) dimensions.

\begin{tabular}{|c|c|c|}
\hline Nominal Size & Standard Dressed Size before1968 & Standard Dressed Size 1968-present \\
\hline $2 \times 4$ & $1 \frac{5}{8} \times 3 \frac{5}{8}$ & $1 \frac{1}{2} \times 3 \frac{1}{2}$ \\
\hline $3 \times 12$ & $2 \% / 8 \times 11 \frac{1 / 2}{21 / 2 \times 11 \frac{1}{2}}$ \\
\hline
\end{tabular}


Lastly, a large part of the NDS concerns itself with the design of the various connections associated with wood construction and practices. Although the topic of connection design lies outside the scope of this report, it is nonetheless instructive to provide at least a list of the various types of connections that the code deals with and how that list has changed since 1944. The 1944 NDS included connection design provisions for split ring, toothed ring, claw plate, and shear plate connectors, bolts, lag screws, nails and spikes, drift pins, and wood screws. Each of these connector types had associated tables of design values that were based on connector groupings of the wood species. Unfortunately, neither the number of groupings nor the composition of the individual groups were the same for the different connectors. This system of assigning design values to connections remained unchanged until 1991 when most of the connector groupings (with the exception of split ring and shear plate connectors) were consolidated into one set of groupings based on the specific gravities of the wood species. In 1948, provisions for claw plates were removed from the code. The types of connectors remained unchanged until 1973 when the provisions for toothed ring connectors were removed. In 1977 provisions for metal plate connectors and spike grids were added. This list of connector types is still valid for the 1991 edition.

\section{Summary of Code Changes for Allowable Stresses}

The 1944, NDS was based on allowable stress design using elastic stress-strain theory for calculating the stresses. This design procedure has remained unchanged from the original edition of the code through the present 1991 edition. Throughout the history of the NDS code, no load combinations have been prescribed. Rather it states that the design loads are to be the most severe distribution, concentration, and combination of dead, live, snow, wind, earthquake, erection, and other static and dynamic forces. The only guidance that the code gives is that the probabilities are remote that full wind and full snow loads or the full wind and full earthquake loads will act simuitaneously. The code also states that the magnitudes of the loads shall be in accordance with the governing building code. These provisions have remained unchanged since the original 1944 edition of the code. Table 21 summarizes the code changes with respect to allowable stresses for each year. 
Table 21. Summary of code changes for allowable stresses.

\begin{tabular}{|c|c|}
\hline NDS Code & Summary of Changes for Allowable Stresses \\
\hline 1944 & $\begin{array}{l}\text { Included provisions for allowable unit stresses which may be increased by } 15 \% \text { for } \\
\text { snow loading combined with dead load, and } 50 \% \text { for wind or earthquake loading. } \\
\text { Where maximum snow load remains permanently on the structure, the allowable } \\
\text { stresses shall not be increased. For other loading not exceeding a duration of } 5 \\
\text { minutes, the allowable stresses may also be increased by } 50 \% \text {. The above increases } \\
\text { are not cumulative. For wind in combination with permanent loading, the allowable } \\
\text { unit stresses may be increased by } 50 \% \text {, provided that the resulting structural } \\
\text { members are not smaller than those required for permanent loading alone. These } \\
\text { provisions do not apply to the modulus of elasticity. These increases apply to } \\
\text { mechanical fastenings except as otherwise noted. } \\
\text { The allowable unit stresses for permanent loading may be used without regard to } \\
\text { impact if the stress induced by impact does not exceed the allowable unit stress for . } \\
\text { permanent loading; however, the sum of stresses induced by any combination of } \\
\text { loading, e.g., impact with dead, long-time live, and/or short-time live loading, shall not } \\
\text { exceed twice the allowable unit stress for permanent loading. }\end{array}$ \\
\hline
\end{tabular}

The allowable unit stresses in flexure for joist and plank grades apply to material with the load applied to either the narrow or wide face. Allowable unit stresses in flexure for beam and stringer grades apply only to material with the load applied to the narrow face. Beam grades ordinarily are graded for use on simple spans. When used as a continuous beam, the grading provisions customarily applied to the middle $1 / 3$ of the length of simple spans shall be applied to the middle $2 / 3$ of the length of pieces to be used over the entire length of pieces to be used over three or more spans.

The allowable unit stresses for compression parallel to grain in post and timber grades apply to columns with an $\mathrm{l} / \mathrm{d}$ ratio of 11 or less. The allowable unit stresses for compression parallel to grain given for joist and plank and beam and stringer grades apply to columns with an $\mathrm{e} / \mathrm{d}$ ratio of 11 or less, when the sum of the sizes of all knots in any 6 inches of the length of the piece shall not exceed twice the maximum permissible size of knot, while two knots of maximum permissible size shall not be within the same 6 inches of length on any face. For other $\mathrm{e} / \mathrm{d}$ ratios, allowable unit stresses shall be determined by the formulas given for wood columns.

The allowable unit stresses for shear in joint details may be $50 \%$ greater than the horizontal shear values otherwise permitted. In joists supported on a ribbon or ledger board and spiked to the studs, the allowable unit stresses for compression perpendicular to grain may be increased by $50 \%$. If a wood compression member that bears on a metal plate or strap, e.g., as at the heel joint of a truss, contains no knot at the bearing greater in diameter than $1 \frac{1}{2}$ inches or $1 / 4$ the minimum crosssectional dimension of the member, whichever is lesser, the allowable unit stress for. bearing is given for various species, or if the loading is at an angle to grain, shall be determined by the Hankinson formula.

1971 When the duration of the full maximum load does not exceed the period indicated, increase the allowable unit stresses; $15 \%$ for 2 months duration, as for snow; $25 \%$ for 7 days duration; $33 \%$ for wind or earthquake; and $100 \%$ for impact.

When a member is fully stressed to the maximum allowable stress for many years, either continuously or cumulatively under the condition of maximum design load, use working stresses $90 \%$ of those given. The values given for service conditions apply under conditions continuously $d r y$, as in most covered structures. When used under other conditions, the values for unseasoned lumber shall be reduced $9 \%$ and for seasoned lumber shall be reduced $33 \%$. 


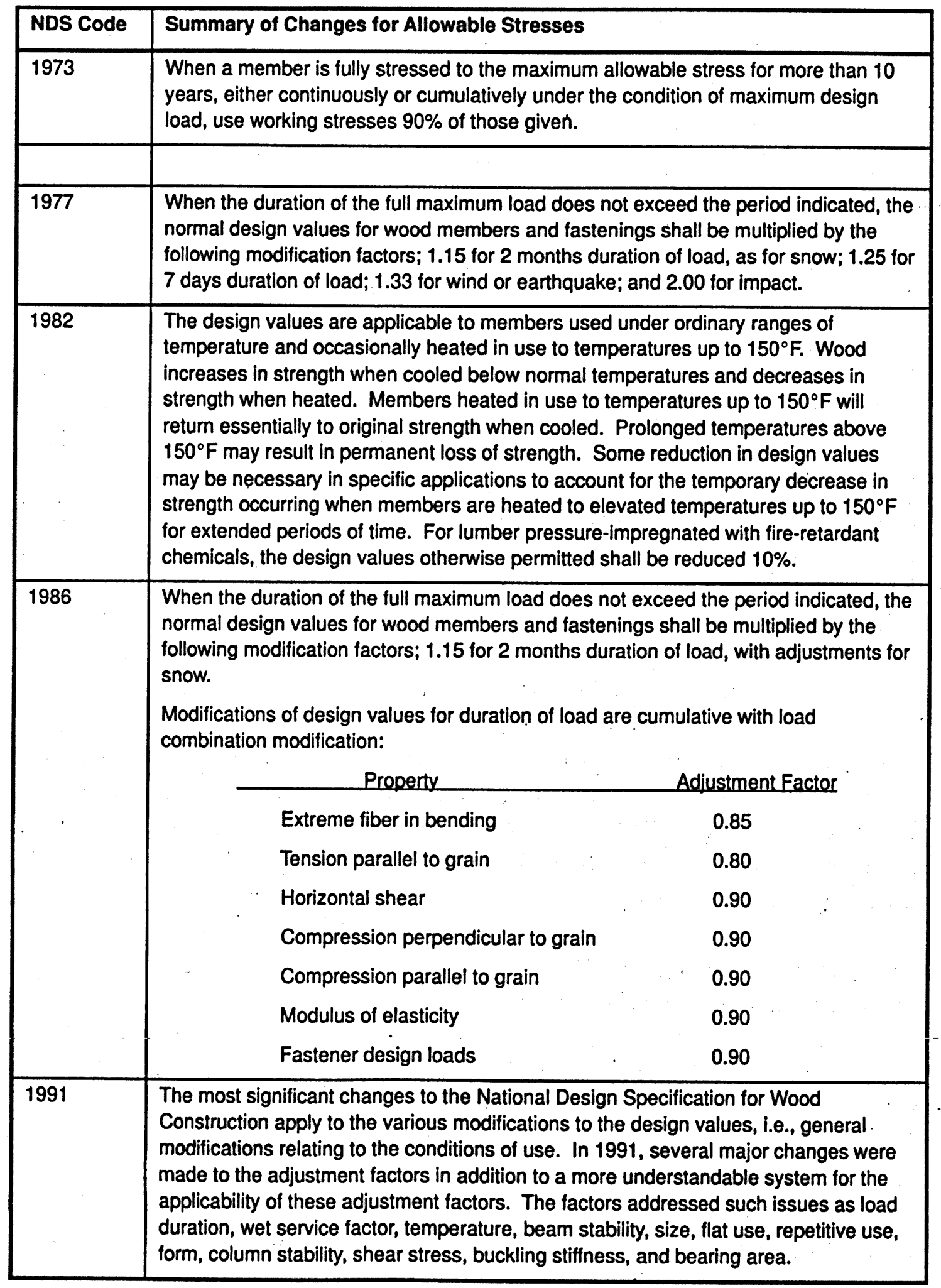




\section{Test Methods}

\section{Nondestructive Testing Methods for Wood}

Techniques of Nondestructive Evaluation (NDE) are increasingly being used in industrial applications to assess various properties of wood and wood products and in-place wooden structures. One NDE technique commonly used to evaluate mechanical properties of wood products is based on the measurement of vibrational characteristics. Longitudinal stress wave NDE techniques use lowlevel stress waves to measure two fundamental energy properties: storage and dissipation. Energy storage is the speed at which a wave travels in a material. Energy dissipation is the rate at which a wave attenuates. These properties are related to the same mechanisms that control the mechanical behavior of a material. Consequently, useful relationships can be obtained between stress wave speed and attenuation and the elasticity and strength of a material.

Ross and Pellerin found that stress wave speed and attenuation are excellent indices of the mechanical properties of wood-based composites. Under controlled laboratory conditions, Pellerin et al. showed that stress wave velocity is a good indicator of wood decomposition when caused by brown rot fungi, but a poor indicator when caused by termites.

The first step in using an NDE technique for monitoring biological degradation of wood members is developing an inexpensive, readily available measurement system. The measurement system for monitoring stress wave behavior in degraded wood consists of an impact and signal acquisition system coupled to a relatively inexpensive data storage device. Signal analysis is also performed using inexpensive personal computers. Results are easily analyzed and compared to give the researcher near real-time information.

Some of the more common nondestructive testing methods are based on a variety of physical and mechanical properties of structural wood. The Appendix to this report elaborates on the following detailed listing of these factors and the corresponding nondestructive techniques are: 
1. Size (rulers, calipers, verniers, and various electronic devices)

2. Density (penetrating gamma radiation)

3. Moisture content

a. Resistance measuring moisture meters

b. Capacity type meters

c. Radio frequency (RF) power loss meters

d. Microwave absorption meter

e. Neutron scatter equipment

f. Surface hygrometers .

g. Boring techniques

4. Visual stress grading

5. Mechanical grading

a. Continuous Lumber Tester (CLT 1)

b. Stress-o-matic machine

c. Micro-stress grading machine

d. Computermatic machine

6. Vibrational grading

a. Sub-sonic vibrational methods

b. Sonic vibrational methods

7. Stress wave propagation

\section{Description of Nondestructive Methods}

It is well known that wood has defects that diminish its mechanical properties. These defects can be due to the structure of the wood itself or to external agents. Examples of such structural defects are the knots caused by dead branches covered by successive annual rings. External agents can cause warping and swelling due to hygroscopic effects, circumferential shrinkage, or splits produced by frost, internal annular shake produced by the separation of contiguous growth rings, the rotting of wood and dry rots.

Another phenomenon that cannot be considered a defect, but rather a negative quality of wood as a material, is the percentage of moisture. The moisture content, besides causing deformations over time due to non-uniform drying, diminishes the properties of the material. These properties differ greatly according to 
the direction of the wood. This is due to the remarkable anisotropy of wood, whose tissue is a system of fibers along the tree axis. The anisotropy is maximum along the axial direction and less along the radial one.

\section{Typical NDT Methods}

To understand the wide spectrum that makes up nondestructive testing, it is helpful to list and review those technical approaches most widely used worldwide.

\section{Radiography (RT)}

Radiography involves the use of penetrating gamma or X-radiation to examine parts and products for imperfections. An X-ray machine or radioactive isotope is used as a source of radiation. Radiation is directed through a part and onto film or other media. The resulting shadowgraph shows the internal soundness of the part. Possible imperfections are indicated as density changes in the film in the same manner as an X-ray shows broken bones.

\section{Magnetic Particle Testing (MT)}

This method is accomplished by inducing a magnetic field in a ferromagnetic material and then dusting the surface with iron particles (either dry or suspended in liquid). Surface imperfections distort the field and concentrate iron particles near imperfections.

\section{Ultrasonic Testing (UT)}

Ultrasonics uses transmission of high-frequency sound waves into a material to detect imperfections within or to locate changes in material properties. The most commonly used ultrasonic testing technique is pulse echo. In this method, sound is introduced into a test object and reflections (echoes) are returned to a receiver from internal imperfections or from the part's geometrical surfaces.

\section{Liquid Penetrant Testing (PT)}

Test objects or material is coated with visible or fluorescent dye solution. Excess dye is then removed from the surface, and a dry developer is applied. The developer acts as blotter, drawing penetrant out of imperfections open to the surface. With visible dyes, vivid color contrasts between the penetrant and developer make "bleedout" easy to see. With fluorescent dyes, ultraviolet light is used 
to make the bleedout fluoresce brightly, so that imperfections can readily be seen.

\section{Electromagnetic Testing (ET)}

Electrical currents are generated in a conductive material by an induced alter-: nating magnetic field. Interruptions in the flow of electric currents (eddy currents) caused by imperfections or changes in the material's conductive properties, will cause changes in the induced magnetic field. These changes, when detected, indicate the presence of change in the test object.

\section{Leak Testing (LT)}

Several techniques are used to detect and locate leaks in pressure containment parts, pressure vessels, and structures. Leaks can be detected by using electronic listening devices, pressure gauge measurements, liquid and gas penetrant techniques, and/or a simple soap-bubble test.

\section{Acoustic Emission Testing (AE)}

When a solid material is stressed, imperfections within the material emit short bursts of acoustic energy called "emissions." As in ultrasonic testing, acoustic emissions can be detected by special receivers. Emission sources can be evaluated through the study of their intensity, rate, and location.

\section{Visual and Optical Testing (VT)}

Visual examiners follow procedures that range from simple to very complex. Some procedures involve comparison of workmanship samples with production parts.

\section{Special NDT Methods}

NDT engineers and technicians also use magnetic resonance imaging, vibration monitoring, laser ultrasonics, holography, and many other specialized methods. The following techniques are used to nondestructively evaluate wood and woodbased materials.

\section{Static Bending Techniques}

Measuring the Modulus of Elasticity (MOE) of a member by static bending techniques is the foundation of Machine Stress Rating (MSR) of lumber. This rela- 
tively simple measurement involves using the load-deflection relationship of a simply supported beam loaded at its midspan. The modulus of elasticity can be computed directly by using equations derived from fundamental mechanics of materials and used to infer strength.

Measuring flexural MOE by static bending techniques has been successfully .... used to grade lumber by using machines that approximate simply supported boundary conditions. Such machines consistently maintain these conditions. However, an in-place environment yields boundary conditions that may vary considerably in even the simplest structure. Consequently, application of this technique for in-place assessment of wood members has been limited.

\section{Transverse Vibration Techniques}

An analogy can be drawn between the behavior of a vibrating beam and the vibration of a mass that is attached to a weightless spring and internal damping force. A mass is supported from a rigid body by a weightless spring with a certain stiffness. This stiffness is used to obtain an expression for the dynamic MOE by assuming a simply supported beam.

Transverse vibration techniques are significantly influenced by boundary conditions. Most researchers conducting laboratory studies using this technique devote considerable time to ensure that simple end conditions are attained. However, such conditions frequently do not exist with wood members in structures. Consequently, use of this technique has been limited for in-place evaluations.

\section{Stress Wave Techniques}

Speed of sound transmission and attenuation of induced stress waves in a material are frequently used as Nondestructive Technique (NDT) parameters. To illustrate these techniques, consider the application of one-dimensional wave theory to the homogeneous viscoelastic bar. A wave is generated after an impact hits the end of the bar and travels along the bar at a constant speed, which is then reflected back down the bar. Energy is dissipated as the wave travels through the bar. Although the speed of the wave remains constant, movement of particles diminish with each successive passing of the wave. Eventually all particles of the bar come to rest. The modulus of elasticity can be calculated using the propagation speed as well as the mass density of the bar.

Wood is neither homogeneous nor isotropic, hence the usefulness of onedimensional wave theory for describing stress wave behavior in wood could be considered ambiguous. However, several researchers have explored application 
of the theory by examining actual wave forms resulting from propagating waves in wood and wood products and have found that one-dimensional wave theory is adequate for describing wave behavior.

One commonly used technique that employs stress wave NDT technology uses simple time-of-flight-type measurement systems to determine speed of wave propagation. In these measurement systems, a mechanical or ultrasonic impact is used to impart a longitudinal wave into a member. Piezoelectric sensors are placed at two points on the member and used to sense passing of the wave. The time it takes for the wave to travel between sensors is measured and used to compute wave propagation speed.

The stress wave equipment induces a compressive impact stress wave in the end of a specimen when a solenoid activated hammer strikes a steel wedge clamped to the end of a specimen. Two accelerometers are fastened to the specimen some distance apart to sense passage of the stress wave. The accelerometer nearer to the hammer end (impact end) starts a microsecond counter and the accelerometer farther from the hammer end stops the microsecond counter as the stress wave advances past each accelerometer. Thus, the microsecond counter times the stress wave as it travels the distance between the two accelerometers.

An impact stress wave induced in the end of lumber with knots does not maintain a normal, perpendicular-to-the-axis profile in its transit by a knot and the cross grain associated with the knot. Contours of constant stress wave transit time tend to lead in zones of clear wood in the direction of the slope of annual rings and lag behind the knot. The sensitivity in detecting the presence of knots varies with timing procedures. Of three timing procedures evaluated, average timing appears more consistent in detecting short segments containing knots from adjacent clear wood segments than either fastest point of centerline timing.

The modulus of elasticity based on stress waves tends to be higher than the modulus of elasticity based on static bending, particularly in segments of lumber containing a knot. The correlation between the two moduli of elasticity depends greatly on specimen quality and stress timing procedure. The two were best correlated based on average timing or barkside centerline timing and least correlated with stress wave obtained modulus of elasticity based on fastest point timing.

From impact tests on each end of a specimen, the direction of the impact stress wave affects transit timing somewhat. The differences in transit time for a given length of specimen due to the impact's end tended to be higher for fastest 
point timing than for average or centerline timing. Stress wave timing is not very sensitive to relative knot as correlations between knot-area ratio and transit time were generally poor to insignificant within a specimen.

The static modulus of elasticity responded to the presence of knots or related grain distortion. This modulus was lower for 1-ft spans containing a knot than for adjacent clear wood 1-ft spans. As expected, this modulus increased systematically as knot area ratio was reduced through ripping off $3 / 4$-in. inch strips from the lumber.

As a general observation, some caution is suggested in applying stress wave techniques for machine stress rating lumber. Suitable devices could be developed for either average or fastest point timing. Otherwise, centerline timing could be used with accelerometers, but grading might be less efficient than for average timing.

Some additional factors need to be evaluated: (1) depending on the size and soundness of a knot, stress wave detection may be affected somewhat if the accelerometer fixed in a machine comes to rest on a knot; (2) to determine the effectiveness of grading that uses stress waves, the modulus of elasticity should be examined against lumber strength directly rather than by inference through the static modulus of elasticity strength relations. This approach is recommended due to the lack of perfect or near-perfect correlation between the two moduli of elasticity in typical lumber.

Longitudinal stress wave NDT techniques have been investigated by researchers for assessing wood members in structures. The influence that boundary conditions have on speed of sound transmission measurements has been shown to be significantly less than that for static bending or transverse vibration techniques. Thus, many researchers have examined longitudinal stress wave NDT techniques for in-place assessment of wood members. Acoustic emission techniques have also been extensively researched for application to wood-based materials. These techniques rely on the application of stress to a member to generate a stress wave.

Future in-place assessment NDT research should focus on furthering the application of stress wave techniques. Stress wave NDT techniques have been extensively investigated under laboratory conditions and used by inspection professionals on a limited basis. However, many questions remain unanswered regarding the effectiveness of stress wave NDT techniques to evaluate members in complicated structures. No published work documents how wave behavior is 
affected by the varied boundary conditions found in wood structures. In addition, little information has been published on the relationship between excitation system characteristics and wave behavior. Research efforts in these two areas would advance state-of-the-art inspection techniques considerably.

\section{Ultrasonic Methods}

Ultrasonic measurements are carried out by means of both the pulse velocity and the pulse attenuation techniques. The first technique, widely used in nondestructive evaluation, consists of measuring the time travel of a pulse or a train of waves through a known path length in the material. The ultrasonic unit uses a timing circuit that is triggered when the received echo reaches a prescribed magnitude. The second technique analyzes the amplitude of the received ultrasonic signal. The attenuation depends on the frequency of the transducers and on the size and number of flaws encountered between the transmitter and the receiver. Pulse level attenuation is obtained from two successive ultrasonic echoes by measuring the difference between their peak levels. The ultrasonic technique, which uses the pulse attenuation measurements, is more sensitive than that which uses the pulse velocity measurements for detecting and positioning flaws in wood. However, the method based on the pulse velocity measurements is very effective in determining the moisture content.

Ultrasonic inspection methods are suggested as extending the usefulness of existing stress grading methods to promote greater confidence in the structural use of timber. The ultrasonic pulse velocity method shows promise for a wide range of uses for in situ testing of structures as well as the routine inspection of a variety of manufactured components. Some of its special advantages are:

1. The shape and size of the material under test does not appear to present any serious restrictions.

2. The method of testing does not induce any additional stresses on a structure already under load.

3. It is possible to make repeated measurements throughout the service life of $a$ : structure, where necessary.

4. Measurements that appear to be in error can be checked and rechecked without altering the condition of the timber.

5. Measurements are made rapidly where suitable plane surfaces are accessible, so that a detailed survey of all parts of a complete structure is often feasible. 
6. Closer inspection of critical parts of a structure, such as heavily loaded joints or components of dubious quality, may then be made selectively.

7. It is entirely nondestructive both to the timber under test and the operator.

Pulse velocity measurements relate directly to the elastic properties of wood. They are therefore sensitive to any deviations in the grain direction, since wood is highly anisotropic. The grain disturbances may not necessarily be visible on the surface. It has also been found that measurements follow similar trends to strength changes caused by the fluctuations in density of wood and local defects. Under suitable circumstances, both the strength and stiffness of material such as timber and plywood in fully fabricated components may be assessed without resorting to structural loading.

The principle of relating stiffness to strength is similar to the basis on which most mechanical stress grading of timber has developed. The difference is that the ultrasonic method is not limited to raw material of simple geometrical cross section. With care, the ultrasonic pulse method may be used to locate hidden defects such as decay pockets and hidden knots, or manufacturing defects such as cracks in gluelines. Flaws in the path of the ultrasonic pulse cause alterations in the apparent velocity of the wave-front measured over a known path length. This is accompanied by attenuation of the waves, which is an additional indication that some internal defect may exist.

Some uncertainty still remains in interpreting the results of ultrasonic measurements in timber. The test does no more than measure the speed at which sound waves travel through the material in a particular mode or direction. All other information on the strength and state of the material or structure is inferred. The relationship between pulse velocity and the complex elasticity of wood is yet slightly obscure. Furthermore, the internal structure of wood imposes severe restrictions on the scope and precision of ultrasonic testing, e.g., when compared with testing most metals. Despite these difficulties, some progress has been made in the use of ultrasonics to test timber structures and components. It is more versatile than the vibration tests, which depend on measuring resonant frequency, though probably not so reliable for determining elastic constants. Its principal virtues are speed and adaptability to different structural sections, and the opportunity to repeat readings, either for checking, or to trace any progressive deterioration with time. Its special limitations are the necessity, (and occasional uncertainty) of good surface contact with the transducers, difficulties where cavities occur in a structure, and the lack of any digital output on the present equipment. It should be therefore considered more as a means of augmenting mechanical tests than replacing them. 


\section{Other Techniques}

Several other NDT techniques have been investigated for use with wood:

1. The attenuation of $x$-rays has been investigated for detecting internal voids in wood and for inspecting utility poles and trees.

2. Screw withdrawal and pick- or probing-type tests have been examined. These inexpensive techniques provide information about a member at a point and are consequently of limited value for inferring strength for large members. However, they are useful for detecting surface damage of members.

3. The Pilodyn test is used to detect surface damage. This instrument consists of a spring-loaded pin device that drives a hardened steel pin into the wood. Depth of the pin penetration is used as a measure of degree of degradation.

Simple mechanical tests are frequently used for in-service inspection of wood members in structures. For example, sounding-, pick-, or probing-type tests are used by inspectors of wood structures to indicate the condition of a structural member. The underlying premise for the use of such tests is that degraded wood is relatively soft and will have a low resistance to probe penetration.

\section{Evaluation of Nondestructive Methods}

Several researchers have studied the correlation between nondestructive testing parameters and the properties of degraded wood. Table 22 gives a detailed research summary with respect to this correlation. The parameters measured included natural frequency, dynamic modulus of elasticity, speed of sound, acoustic emission events, and root mean square voltage frequency. The properties reported included static modulus of elasticity, ultimate compressive stress, stress at various levels, maximum moment, and alkali solubility.

Table 23 summarizes research conducted using nondestructive testing concepts for in-place evaluation of wood structures. The parameters measured included speed of sound, dynamic modulus of elasticity, resonant frequencies, density, bending modulus of elasticity, logarithmic decrement, and phase shifts. 
Table 22. Research summary of correlation between nondestructive testing (NDT). parameters and propertles of degraded wood.

\begin{tabular}{|c|c|c|c|c|c|c|c|}
\hline Reference & NDT technique & Material & $\begin{array}{l}\text { Degradation } \\
\text { agent }\end{array}$ & $\begin{array}{l}\text { NDT parameters } \\
\text { measured }\end{array}$ & Static test & $\begin{array}{l}\text { Reported } \\
\text { properties }\end{array}$ & $\begin{array}{l}\text { Comparison of NDT parameters and } \\
\text { static properties (correlation } \\
\text { coefficient, unless noted) }\end{array}$ \\
\hline $\begin{array}{l}\text { Wang et al. } \\
\text { (1980) }\end{array}$ & $\begin{array}{l}\text { Free transverse } \\
\text { vibration } \\
\text { (cantilever } \\
\text { bending) }\end{array}$ & $\begin{array}{l}\text { Small, clear } \\
\text { eastern } \\
\text { white pine } \\
\text { sapwood } \\
\text { specimens } \\
\end{array}$ & $\begin{array}{l}\text { Brown rot } \\
\text { fungi }\end{array}$ & Natural frequency & None & & $\begin{array}{l}\text { Significant loss in frequency as early as } \\
7 \text { days after inoculation }\end{array}$ \\
\hline $\begin{array}{l}\text { Chudnoff et } \\
\text { al. (1984) }\end{array}$ & $\begin{array}{l}\text { Longitudinal } \\
\text { stress wave } \\
\text { (parallel to } \\
\text { grain) }\end{array}$ & $\begin{array}{l}\text { Decayed and } \\
\text { sound mine } \\
\text { props; } 26 \\
\text { species or } \\
\text { species } \\
\text { groupings }\end{array}$ & & $E_{0}$ & $\begin{array}{l}\text { Compression } \\
\text { parallel to } \\
\text { grain }\end{array}$ & $E_{c}$, UCS & $\begin{array}{l}E_{c} \text { and } E_{d}-0.84-0.97 \text { (all species } \\
\text { combined, hardwoods, maple, and } \\
\text { oaks) } E_{c} \text { and } E_{d}-0.73-0.81 \text { (all species } \\
\text { combined, southern pines, lodgepole } \\
\text { pine) } U C S \text { and } E_{d}-0.85-0.95 \text { (all } \\
\text { species combined, hardwoods, maple, } \\
\text { and oaks) }\end{array}$ \\
\hline $\begin{array}{l}\text { Pellerin et } \\
\text { al. (1985) }\end{array}$ & $\begin{array}{l}\text { Longitudinal } \\
\text { stress wave } \\
\text { (parallel to } \\
\text { grain) }\end{array}$ & $\begin{array}{l}\text { Small, clear } \\
\text { southern } \\
\text { yellow pine } \\
\text { specimens }\end{array}$ & $\begin{array}{l}\text { Brown rot } \\
\text { fungi } \\
\text { Termites }\end{array}$ & $C, E_{d} C, E_{d}$ & $\begin{array}{l}\text { Compression } \\
\text { parallel to } \\
\text { grain }\end{array}$ & UCS & $\begin{array}{l}\text { UCS and C: } 0.47 \text { (controls) } 0.73 \\
\text { (exposed) } 0.80 \text { (control and } \\
\text { exposed)UCS and } E_{\mathrm{d}}: 0.86 \text { (controls) } \\
0.86-0.89 \text { (exposed) } 0.94 \text { (control and } \\
\text { exposed)UCS and C: } 0.65 \text { (controls) } \\
0.21 \text { (exposed) } 0.28 \text { (control and } \\
\text { exposed)UCS and } E_{\mathrm{d}}: 0.90 \text { (controls) } \\
0.79 \text { (exposed) } 0.80 \text { (control and } \\
\text { exposed) }\end{array}$ \\
\hline Reference & NDT technique & Material & $\begin{array}{l}\text { Degradation } \\
\text { agent }\end{array}$ & $\begin{array}{l}\text { NDT parameters } \\
\text { measured }\end{array}$ & Static test & $\begin{array}{l}\text { Reported } \\
\text { properties }\end{array}$ & $\begin{array}{l}\text { Comparison of NDT parameters and } \\
\text { static properties (correlation coefficient, } \\
\text { unless noted) }\end{array}$ \\
\hline $\begin{array}{l}\text { Beall and } \\
\text { Wilcox } \\
\text { (1986) }\end{array}$ & Acoustic & $\begin{array}{l}\text { Small, clear } \\
\text { white fir } \\
\text { specimens }\end{array}$ & $\begin{array}{l}\text { Brown rot } \\
\text { fungi }\end{array}$ & $\overline{A E}$ & Compression & $\begin{array}{l}\text { Stress at } \\
\text { various } \\
\text { levels }\end{array}$ & $\begin{array}{l}\text { AE events were very sensitive to } \\
\text { degree of mass loss and stress level }\end{array}$ \\
\hline
\end{tabular}




\begin{tabular}{|c|c|c|c|c|c|c|c|}
\hline Reference & NDT technique & Material & $\begin{array}{l}\text { Degradation } \\
\text { agent }\end{array}$ & $\begin{array}{l}\text { NDT parameters } \\
\text { measured }\end{array}$ & Static test & $\begin{array}{l}\text { Reported } \\
\text { properties }\end{array}$ & $\begin{array}{l}\text { Comparison of NDT parameters and } \\
\text { static properties (correlation } \\
\text { coefficient, unless noted) }\end{array}$ \\
\hline $\begin{array}{l}\text { Rutherford } \\
\text { et al. (1987) }\end{array}$ & $\begin{array}{l}\text { Longitudinal } \\
\text { stress wave } \\
\text { (perpendicular } \\
\text { to grain) }\end{array}$ & $\begin{array}{l}\text { Small, clear } \\
\text { Douglas-fir } \\
\text { specimens }\end{array}$ & $\begin{array}{l}\text { Brown rot } \\
\text { fungi }\end{array}$ & $C, E_{d}$ & $\begin{array}{l}\text { Compression } \\
\text { perpendicular } \\
\text { to grain }\end{array}$ & $E_{c}$, UCS & $\begin{array}{l}E_{c} \text { and } C-0.91 E_{c} \text { and } E_{d}-0.94 U C S \\
\text { and } C-0.67-0.70 U C S \text { and } E_{d}- \\
0.79 U C S \text { and } M O E-0.80\end{array}$ \\
\hline $\begin{array}{l}\text { Patton- } \\
\text { Mallory and } \\
\text { De Groot } \\
\text { (1989) }\end{array}$ & $\begin{array}{l}\text { Longitudinal } \\
\text { stress wave }\end{array}$ & $\begin{array}{l}\text { Small, clear } \\
\text { southern } \\
\text { yellow pine } \\
\text { specimens }\end{array}$ & $\begin{array}{l}\text { Brown rot } \\
\text { fungi }\end{array}$ & $\begin{array}{l}\text { C, root mean } \\
\text { square voltage } \\
\text { frequency content } \\
\text { of received signal }\end{array}$ & Bending & $\begin{array}{l}\text { Maximum } \\
\text { moment, } \\
\text { alkali } \\
\text { solubility }\end{array}$ & $\begin{array}{l}\text { C decreased in a linear fashion with } \\
\text { increasing decay degradation; signal } \\
\text { strength decreased with increasing } \\
\text { decay degradation; high frequency } \\
\text { components of signal were attenuated } \\
\text { with very early stages of decay } \\
\text { degradation }\end{array}$ \\
\hline
\end{tabular}

AE = Acoustic emission events

$\mathrm{C}=$ Speed of sound

$E_{c}=$ Modulus of elasticity obtained from a static compression test

$E_{d}=$ Dynamic modulus of elasticity obtained from either transverse vibration or stress wave measurements

MOE = Modulus of elasticity

MOR $=$ Modulus of rupture

UCS $=$ Ultimate compressive stress 
Table 23. Research summary of nondestructive testing (NDT) concepts for in-place evaluation of wood structures.

\begin{tabular}{|c|c|c|c|c|c|c|}
\hline Reference & NDT technique & Type of structure & Location & Material & $\begin{array}{l}\text { NDT parameters } \\
\text { measured }\end{array}$ & Analysis performed-conclusions \\
\hline Le日 (1965) & $\begin{array}{l}\text { Longitudinal } \\
\text { stress wave }\end{array}$ & $\begin{array}{l}\text { 18th century, } \\
\text { mansion roof }\end{array}$ & $\begin{array}{l}\text { United } \\
\text { Kingdom }\end{array}$ & $\begin{array}{l}\text { Solid sawn } \\
\text { timber }\end{array}$ & C & $\begin{array}{l}\text { Developed empirical relationship } \\
\text { between speed of sound transmission } \\
\text { and residual strength }\end{array}$ \\
\hline $\begin{array}{l}\text { Hoyle and } \\
\text { Pellerin } \\
\text { (1978) }\end{array}$ & $\begin{array}{l}\text { Longitudinal } \\
\text { stress wave } \\
\text { (perpendicular to } \\
\text { grain) } \\
\end{array}$ & School building & Idaho & $\begin{array}{l}\text { Curved glulam } \\
\text { arches (span } \\
120 \mathrm{ft} \text {, rise } 33 \\
\mathrm{ft} \text { ) }\end{array}$ & C & $\begin{array}{l}\text { Detected decay in exposed ends of } \\
\text { arches; mapped out areas of decay }\end{array}$ \\
\hline $\begin{array}{l}\text { Lanius et al. } \\
\text { (1981) }\end{array}$ & $\begin{array}{l}\text { Longitudinal } \\
\text { stress wave }\end{array}$ & Barn & Washington & $\begin{array}{l}2 \times 12 \text { in. } \\
\text { joists }\end{array}$ & $C, E_{d}$ & $\begin{array}{l}\text { Estimated residual strength of } \\
\text { members }\end{array}$ \\
\hline $\begin{array}{l}\text { Dunlop } \\
\text { (1983) }\end{array}$ & $\begin{array}{l}\text { Acoustic } \\
\text { resonance }\end{array}$ & Wood poles & Australia & $\begin{array}{l}\text { Wood utility } \\
\text { poles }\end{array}$ & Resonant frequencies & $\begin{array}{l}\text { Test diagnosed large percentage of } \\
\text { poles in sample set correctly }\end{array}$ \\
\hline $\begin{array}{l}\text { Browne and } \\
\text { Kuchar } \\
\text { (1985) }\end{array}$ & $\begin{array}{l}\text { Longitudinal } \\
\text { stress wave }\end{array}$ & $\begin{array}{l}\text { Dielectric support } \\
\text { stand for testing } \\
\text { large aircraft in a } \\
\text { simulated flight } \\
\text { situation } \\
\end{array}$ & New Mexico & $\begin{array}{l}\text { Glulam, } \\
\text { structural } \\
\text { timber }\end{array}$ & $C, E_{d}$ & $\begin{array}{l}\text { MOE determined, strength properties } \\
\text { inferred }\end{array}$ \\
\hline Neal (1985) & $\begin{array}{l}\text { Longitudinal } \\
\text { stress wave } \\
\text { (parallel and } \\
\text { perpendicular to } \\
\text { grain) }\end{array}$ & $\begin{array}{l}\text { Large military test } \\
\text { stand } \\
\text { (TRESTLE)Small } \\
\text { military test } \\
\text { standLarge military } \\
\text { test stand } \\
\end{array}$ & $\begin{array}{l}\text { New } \\
\text { MexicoNew } \\
\text { MexicoArizon } \\
\text { a }\end{array}$ & $\begin{array}{l}\text { GlulamGlulam } \\
\text { Glulam, solid } \\
\text { sawn timber }\end{array}$ & $E_{d} E_{d} E_{d}$ & $\begin{array}{l}\text { Structural framework was not } \\
\text { degraded; exposed deck system was } \\
\text { degradedStructural framework and } \\
\text { decks were degradedAccessible } \\
\text { structural degradation had not occurred }\end{array}$ \\
\hline $\begin{array}{l}\text { Aggour et } \\
\text { al. (1986) }\end{array}$ & $\begin{array}{l}\text { Longitudinal } \\
\text { stress wave } \\
\text { (perpendicular to } \\
\text { grain) }\end{array}$ & Bridge piling & Maryland & Piling & C, density & $\begin{array}{l}\text { Correlation of density and C to } \\
\text { compressive strength of pile }(r=0.98)\end{array}$ \\
\hline
\end{tabular}




\begin{tabular}{|c|c|c|c|c|c|c|}
\hline Reference & NDT technique & Type of structure & Location & Material & $\begin{array}{l}\text { NDT parameters } \\
\text { measured }\end{array}$ & Analysis performed-conclusions \\
\hline $\begin{array}{l}\text { Abbott and } \\
\text { Elcock } \\
\text { (1987) }\end{array}$ & $\begin{array}{l}\text { Full size static } \\
\text { MOE test }\end{array}$ & Wood poles & $\begin{array}{l}\text { United } \\
\text { Kingdom }\end{array}$ & $\begin{array}{l}\text { Wood utility } \\
\text { poles }\end{array}$ & Bending MOE & $\begin{array}{l}\text { Correlative relationship between MOE } \\
\text { and residual strength of poles }(r=0.68)\end{array}$ \\
\hline $\begin{array}{l}\text { Hoyle and } \\
\text { Rutherford } \\
\text { (1987) }\end{array}$ & $\begin{array}{l}\text { Longitudinal } \\
\text { stress wave } \\
\text { (parallel and } \\
\text { perpendicular to } \\
\text { grain) }\end{array}$ & Timber bridges & $\begin{array}{l}\text { Northwestern } \\
\text { United States }\end{array}$ & $\begin{array}{l}\text { Solid sawn } \\
\text { timber }\end{array}$ & $C, E_{d}$ & $\begin{array}{l}\text { Revealed signs of decay in } 1 \text { of } 12 \\
\text { bridges; reevaluation every } 3 \text { years } \\
\text {. }\end{array}$ \\
\hline $\begin{array}{l}\text { Murphy et } \\
\text { al. (1987) }\end{array}$ & Vibration & Wood poles & $\begin{array}{l}\text { Western } \\
\text { Canada }\end{array}$ & $\begin{array}{l}\text { Wood utility } \\
\text { poles } \\
\text { (Douglas-fir } \\
\text { cedar) }\end{array}$ & Resonant frequencies & Comparison to pole stiffness $(r=0.82)$ \\
\hline $\begin{array}{l}\text { Anthony } \\
\text { and Bodig } \\
\text { (1989) }\end{array}$ & Stress wave & $\begin{array}{l}\text { Wood cooling } \\
\text { tower, poles }\end{array}$ & $\begin{array}{l}\text { Texas, } \\
\text { Western } \\
\text { United States }\end{array}$ & $\begin{array}{l}\text { Solid sawn } \\
\text { timber, poles }\end{array}$ & C, $\delta$, phase shifts & $\begin{array}{l}\text { Determined rate of strength } \\
\text { degradation }\end{array}$ \\
\hline $\begin{array}{l}\text { Pellerin } \\
\text { (1989) }\end{array}$ & $\begin{array}{l}\text { Longitudinal } \\
\text { stress wave }\end{array}$ & $\begin{array}{l}\text { University football } \\
\text { stadiumPiers }\end{array}$ & $\begin{array}{l}\text { WashingtonW } \\
\text { ashington }\end{array}$ & $\begin{array}{l}\text { Solid sawn } \\
\text { timberLarge } \\
\text { wood beam, } \\
\text { stringers } \\
\text { supported by } \\
\text { wood pilings }\end{array}$ & CC & $\begin{array}{l}\text { Found severe decay degradation; } \\
\text { structure was dismantled; substructure } \\
\text { collapsed under its own } \\
\text { weightReplaced structural members } \\
\text { containing decay }\end{array}$ \\
\hline
\end{tabular}

" $\mathrm{C}=$ Speed of sound

* = Logarithmic decrement

$E_{d}=$ Dynamic modulus of elasticity obtained from either transverse vibration or stress wave measurements

MOE $=$ Modulus of elasticity

$r=$ Correlation coefficient

$1 \mathrm{ft}=0.3 \mathrm{~m}, 1$ in. $=25.4 \mathrm{~mm}$ 


\section{Discussion and Analysis}

\section{Modeling and Evaluation of Wood Structures}

Figure 1 outlined the reasons for conducting structural evaluations. Figure 2 outlines a recommended evaluation procedure for heavy wood structures. The procedure starts with collecting data through available documents and drawings on the structure under consideration. Next, the site is inspected to verify the collected data and to determine the current condition of members and joints before further analysis. This evaluation checks the structural adequacy of members and joints. This chapter discusses modeling techniques that yield a greater level of accuracy.

Conventional procedures for the analysis of wood trusses are based on the assumption that the member-end connections are either pinned or completely rigid. Although these assumptions are not entirely consistent with actual conditions, they have been accepted due to the simplification of analysis and design. The actual connections of wood trusses are semi-rigid, allowing some relative movement between the joined members in the plane of the truss. The movement may be axial, translational, or rotational due to concentric or eccentric forces in the members. Axial or rotational deformation of the joints can be responsible for a substantial proportion of the overall deformation of a structure. Often, such deformation has a significant bearing on the internal force distribution.

Structural characteristics of joints are derived from full scale tests. Maraghechi and Itani (1984) reported that axial and rotational stiffnesses of joints have noticeable influence on member forces, while shear stiffness has little effect. In trusses with large chord sizes, the effect of eccentricities may be significant and should be taken into account. The three main mechanisms that identify failure are; (1) capacity use of individual members or connections, (2) excessive deformation caused by loss of stiffness of failed components, and (3) development of an unstable structure caused by member or connection failure. 


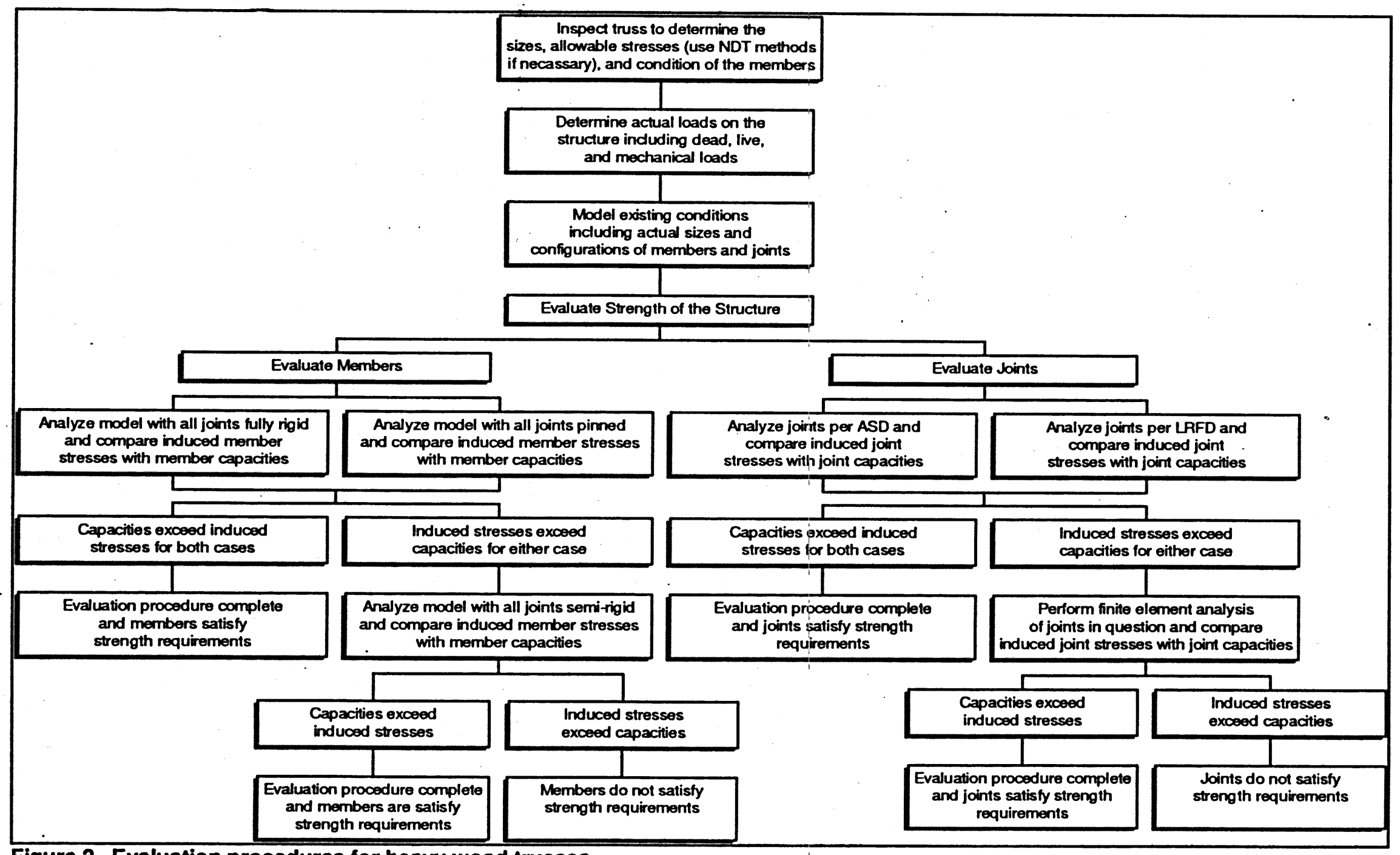

Figure 2. Evaluation procedures for heavy wood trusses. 


\section{Analytical Procedures for Modeling Wood Truss Joints}

Several researchers (Maraghechi and Itani 1984; Lau 1987; Masse and Salinas 1988) have simulated the behavior of semi-rigid connections by means of equivalent springs and fictitious members. This method either estimates or calibrates the dimensions of the fictitious members according to joint stiffness. Another method to include the behavior of semi-rigid connections in the analysis is to modify the stiffness properties of the individual members having a semirigid connection at one or both ends (Weaver and Gere 1986; Fu and Seckin 1988; Sasaki et al. 1988). This method entails modifying the fixed end forces and stiffness matrices of the members.

Gupta et al. (1992) reported that the predicted behavior of a truss depends on the joint assumption. They concluded that the predicted maximum deflection of a Fink truss with the semi-rigid joint assumption was 34 percent less than that for the same truss with a pinned joint assumption. The predicted maximum moment in the truss with semi-rigid joint assumption was 13 percent less than that for the same truss with rigid joint assumption.

\section{Influence of Fasteners and Bolts}

If the fastener is longer than the sum of the thicknesses of the members being connected, and the fastener is other than a dowel, then end conditions of the fastener may affect the load-deformation behavior of the joint. The head and nut, or the accompanying washers, will restrain the otherwise free rotation at the ends of the fastener. This is especially important if the fastener ends can embed into the joint members, as in the case of wood outer members. Although full rotational fixity of the fastener ends may be modeled, this would occur only in special joint configurations, or if steel outer members are used. The usual condition would be in between free head rotation and full fixity or clamped ends.

For timber trussed structures with mechanical fasteners, most of the deflection of the structure is due to slip in the joints. For statically indeterminate structures, such as chords, continuous over two or more spans, the stiffness of the joints has considerable influence on the bending moment distribution.

Mechanical fasteners have enjoyed widespread popularity in wood construction. Although small dowel type connectors, e.g., nails and spikes, have dominated 
light frame building, bolted joints in wood are commonly used in heavy timber construction. Ease of installation, inspection, and repair; high load-carrying capacity; amenability to field assembly; and low cost are only a few of the reasons for the popularity of bolted joints.

A great deal of work has been performed to predict bolted joint behavior based on double shear connections subjected to uniaxial, lateral loads. This is the rationale since bolted joints routinely experience loading of this type in many applications. However, there are some structural applications in which bolted joints are exposed to combined bending and tension. There are cases in which load is applied parallel to the bolt axis.

The problem of quantifying the mechanical behavior of bolted joints subjected to bending/tension is quite complex. Numerous issues contribute to this complexity including the many sources of material and geometric nonlinearities associated with these joints. Localized material crushing at the support reaction, under the washer, and at the loading point, contributes to the material nonlinearities in the system. Changing bearing area at the reaction as the applied load lifts the wood off the resisting boundary is the largest source of geometric nonlinearity in the system.

When modeling a 3-D structure with material and geometric homogeneity in one direction using the finite element method, it is common to simplify the problem to 2-D. However, for bolted joints subjected to bending/tension loading, the direction perpendicular to the plane of tip deflection does not exhibit homogeneity at the bolt location. The inclusion of a steel bolt penetrating two pieces of wood makes this degeneration problematic.

\section{Modeling Wood Trusses}

The actual connections of wood trusses are semi-rigid, i.e., some relative axial, translational, or rotational movement is allowed between the joined members in the plane of the truss. The deformation of the joints has a great effect on the overall deformation of a truss and often has a significant bearing on the internal force distribution. The main objective of this task is to address this issue by modeling two typical trusses, and to recommend a model for use in frame analysis.

Linear finite element analysis was done, which consisted of modeling the wood truss by using the finite element package "ALGOR." To analyze the truss as a 
structural frame with members that possess different end boundary conditions, three dimensional two-noded beam elements were used. A maximum of three translational degrees-of-freedom and three rotational degrees of freedom were defined at each node for the beam elements.

\section{Basic Assumptions and Model Description of Fink Truss}

The first truss considered in this study is a Fink truss. This truss has a $28 \mathrm{ft}$ $(8.53 \mathrm{~m})$ span, $5: 12$ slope, $5.833 \mathrm{ft}(1.778 \mathrm{~m})$ height, and is spaced $2 \mathrm{ft}(0.61 \mathrm{~m})$ on center. All truss members are $2 \times 4$ in. $(38 \times 89 \mathrm{~mm}$ ). Figure 3 presents the modeled truss, including joint numbering and load distribution.

The material used for the truss members was Southern Pine wood with a modulus of elasticity of $1600 \mathrm{ksi}$ and density of $0.0197 \mathrm{lb} / \mathrm{cu}$ in. Joints 1 and 8 are heel joints; 3 and 7 are web joints; 5 is a tension splice joint; and 4 is a ridge joint. One of the following four, different end conditions were used for each member in accordance with model assumptions:

- both ends pinned

- both ends rigid

- one end rigid and the other end semi-rigid

- one end pinned and the other end semi-rigid.

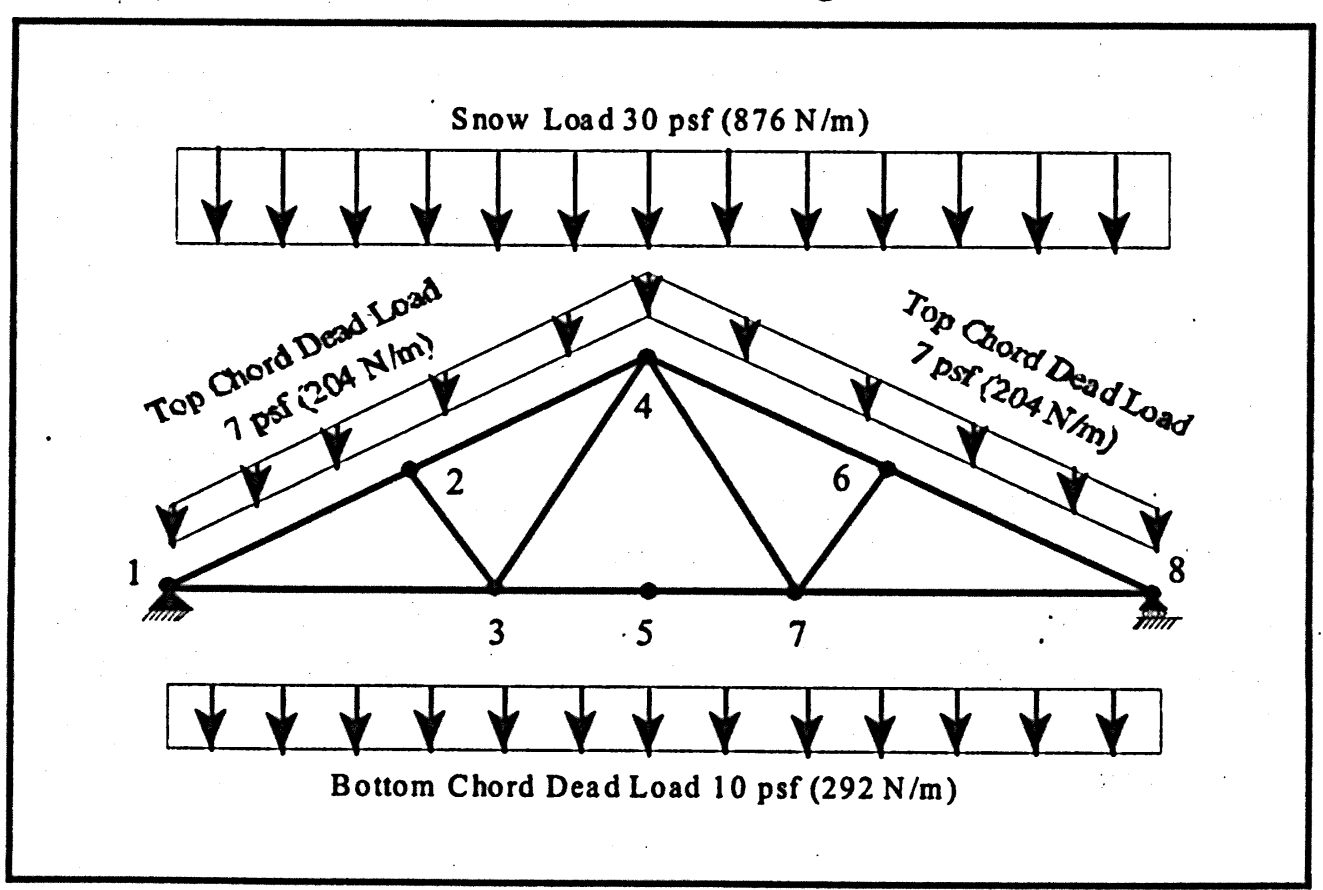

Figure 3. Modeled Fink truss with applied loads. 
To accomplish this study, six types of joint models were implemented. These models are:

1. Truss type analysis (Pinned), where the web members of a truss are pinned at both ends to continuous top and bottom chords and the ridge, heel, and tension splice joints are all assumed as pinned.

2. Frame type analysis (Rigid), where the web members are pinned to continuous top chords and the ridge joint is pinned, while the heel, tension splice, and web at the bottom chord joints are assumed as rigid.

3. Semi-rigid analysis (Mod_1, Mod_2, Mod_3, and Mod_4), where the web members are pinned to continuous top chords and the ridge joint is pinned, while the heel, tension splice, and web at the bottom chord joints are assumed as semi-rigid, i.e., these joints have some axial and rotational stiffnesses. This variation in axial and rotational stiffnesses was achieved by the variation of the axial rigidity (EA) and bending rigidity (EI).

The reduction in axial rigidity and rotational rigidity was achieved by reducing the cross-sectional areas of the heel, tension splice and web for the bottom chord member joints. The semi-rigid models (Mod_1, Mod_2, Mod_3, and Mod_4) have $1 / 2$-in. long members with reduced dimensions for the heel (members 1-2 and 68), web (members 2-3, 3-4, 4-7, and 6-7) and tension splice (members 3-5 and 57) at the bottom chords of $1 \frac{1 / 4}{4} 2 \frac{1 / 2}{\text { in., }} 1 \times 2$ in., $3 / 4 \times 1 \frac{1}{2}$ in. and $1 / 2 \times 1$ in., respectively. Table 24 lists the section properties for the $1 / 2$ in. long edge elements used in the four semi-rigid models.

\section{Basic Assumptions and Model Description of Large Timber Truss}

The second truss considered in this study was a large timber truss. The truss has a $100 \mathrm{ft}$ span, 1:25 slope, $12 \mathrm{ft}$ height, with panels spaced at $100 \mathrm{ft}$, and a 25 -ft spacing between trusses. Table 25 shows truss member sizes.

Figures 4 and 5 show the overall layout of the model including the element joint and (node) numbering scheme. Southern Pine wood was used as the material model with a modulus of elasticity of $1600 \mathrm{ksi}$. A 60 psf load was assumed, which yielded a distributed load of $0.125 \mathrm{kips} / \mathrm{in}$. acting along the entire length of the truss. 
Table 24. Section properties for $1 / 2$-in. edge elements of semi-rigid models.

\begin{tabular}{|c|c|c|c|c|}
\hline \multirow[t]{2}{*}{ Property } & \multicolumn{4}{|c|}{ Semi-rigid models } \\
\hline & Mod_1 & Mod_2 & Mod_3 & Mod_4 \\
\hline Width, b, in. (mm) & $11 / 4(31.75)$ & $1(25.40)$ & $3 /(19.05)$ & $1 / 2(12.70)$ \\
\hline Depth, $h$, in. (mm) & $21 / 2(63.50)$ & $2(50.80)$ & $11 / 2(38.10)$ & $1(25.40)$ \\
\hline Area, $A$, in. $^{2}\left(\mathrm{~mm}^{2}\right)$ & $3.125(2016)$ & $2.000(1290)$ & $1.125(725.8)$ & $0.500(322.6)$ \\
\hline Shear area (strong axis), $\mathrm{Sa}$, in. ${ }^{2}\left(\mathrm{~mm}^{2}\right)$ & $2.655(1713)$ & $1.699(1096)$ & $0.956(616.8)$ & $0.425(274.2)$ \\
\hline Shear area (weak axis), $\mathrm{Sa}_{3}$, in. $^{2}\left(\mathrm{~mm}^{2}\right)$ & $2.655(1713)$ & $1.699(1096)$ & $0.956(616.8)$ & $0.425(274.2)$ \\
\hline Torsional moment of inertia, ${ }$, in. ${ }^{4}\left(\mathrm{~mm}^{4}\right)$ & $1.118(465347)$ & $0.458(190634)$ & $0.145(60354)$ & $0.029(12071)$ \\
\hline Moment of inertia (strong axis), $1_{2}$, in. $^{4}\left(\mathrm{~mm}^{4}\right)$ & $1.628(677625)$ & $0.667(277626)$ & $0.211(87825)$ & $0.042(17482)$ \\
\hline Moment of inertia (weak axis), $l_{y}$, in. $^{4}\left(\mathrm{~mm}^{4}\right)$ & $0.407(169406)$ & $0.167(69511)$ & $0.053(22060)$ & $0.010(4162)$ \\
\hline Section modulus (strong axis), $S_{2}$, in.' $^{\prime}\left(\mathrm{mm}^{3}\right)$ & $1.302(21336)$ & $0.667(10930)$ & $0.281(4605)$ & $0.083(1360)$ \\
\hline Section modulus (weak axis), $\mathrm{S}_{,}$, in. ${ }^{3}\left(\mathrm{~mm}^{3}\right)$ & $0.651(10668)$ & $0.333(5457)$ & $0.141(2311)$ & $0.042(688.3)$ \\
\hline $\begin{array}{l}\text { where: } \\
A=b \times h \\
S a_{2}=S a_{3}=A / 1.177 \\
J_{1}=\left(\frac{1}{3}-0.21\left(\frac{b}{h}\right)\left(1-\frac{b^{4}}{12\left(h^{4}\right)}\right)\right. \\
I_{2}=b h^{3} / 12 \text { and } I_{3}=h b^{3} / 12 \\
S_{2}=2 I_{2} / h \text { and } S_{3}=2 I_{3} / b\end{array}$ & $h \mathrm{~b}^{3}$ & & & \\
\hline
\end{tabular}

Table 25. Nominal dimensions for-elements in large timber truss.

\begin{tabular}{|c|c|}
\hline Element Numbers & Nominal Dimension \\
\hline $1-24$ & $2-4$ in. $\times 12$ in. \\
\hline $42-45$ & $3 \times 8$ in. \\
\hline $38-41,46-49$ & $3 \times 12$ in. \\
\hline $30-32$ & $6 \times 6$ in. \\
\hline 29,33 & $6 \times 10$ in. \\
\hline $27,28,34,35$ & $6 \times 12$ in. \\
\hline $25,26,36,37$ & $6 \times 14$ in. \\
\hline
\end{tabular}

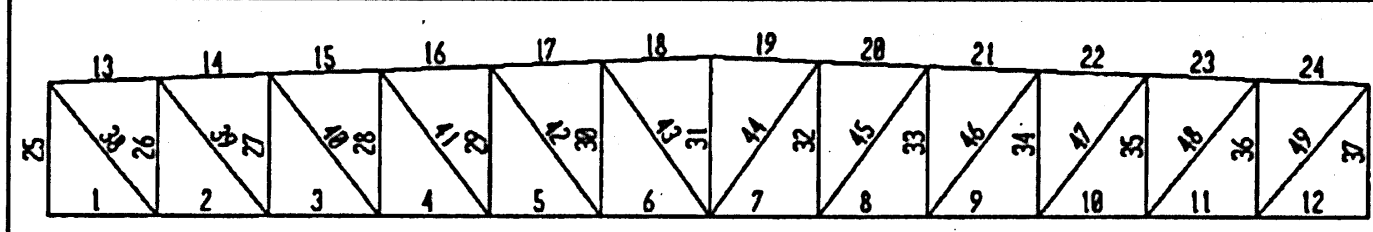

Figure 4. Large timber truss model with element numbers.

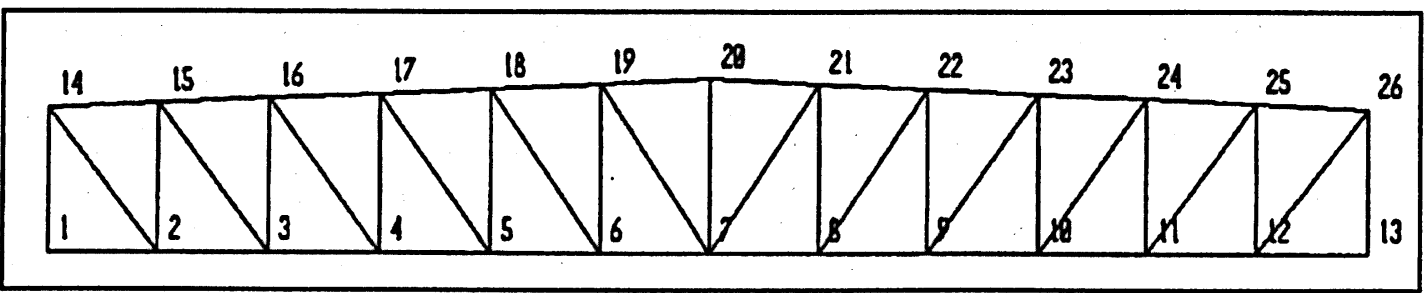

Figure 5. Large timber truss model with node numbers. 
Three separate analyses were performed to evaluate the influence of joint rigidity on the overall behavior of the truss and the redistribution of forces. These analyses were:

1. Truss type analysis (Pinned), where the web members of a truss are pinned at both ends to continuous top and bottom chords

2. Frame type analysis (Rigid), where the web members are rigidly connected at both ends to continuous top and bottom chords

3. Semi-rigid analysis, where the web members are semi-rigidly connected to continuous top chords, i.e., these joints have some axial and rotational stiffnesses. This variation in axial and rotational stiffnesses was achieved by the variation of the axial rigidity (EA) and bending rigidity (EI).

The reduction in axial and rotational rigidity was achieved in exactly the same way as the Fink Truss model. In this analysis though, only one semi-rigid model was used, with the $1 / 2$-in. long edge members having a 50 percent reduction in area and moment of inertia.

\section{Results of Analyzed Fink Truss Models}

Tables 26, 27, and 28 list the results of the internal forces (axial and shear forces and moments) for the three different models (Pinned, Rigid and Semi-rigid). Figure 6 shows the moment diagram for the semi-rigid truss model is shown in, while Figure 7 shows the shear diagram. Figures 8, 9, and 10 show the moment diagrams for the top chords, bottom chords and web members for the semi-rigid truss model, respectively. The results of the internal forces in the top chords of the truss for the three different models indicated that the axial forces and moments are slightly different. The results of the internal forces in the bottom chords of the truss for the three different models (Table 27), indicated that the axial forces and moments are different. The difference between axial forces was small. However, the difference between moments was particularly significant. For example, the moments at the i-end of member 5-7 are $0 \mathrm{lb}$-in. (Pinned), $887.4 \mathrm{lb}$-in. (Rigid) and $340 \mathrm{lb}$-in. (Semi-rigid), and the moments at node $\mathrm{j}$ are $2613 \mathrm{lb}$-in. (Pinned), $1726 \mathrm{lb}$-in. (Rigid) and $2226 \mathrm{lb}$-in. (Semi-rigid). Figures 11 and 12 show the moments for member 5-7 at nodes $i$ and $j$, respectively, for the six different models. The change in the axial forces for the web members of the three models was not significant (Table 27). However, there is a difference in the resulting moments at node $j$ in both members $2-3$ and 6-7. That is attributed to the varying rotational stiffness in the joints for each case. 
Table 26. Forces at 1 - and $J$-ends in top chord members.

\begin{tabular}{|c|c|c|c|c|c|c|c|c|c|c|c|c|c|}
\hline \multirow[b]{2}{*}{ Force } & \multirow[b]{2}{*}{ End } & \multicolumn{3}{|c|}{ Momber 1-2 } & \multicolumn{3}{|c|}{ Member 2-4 } & \multicolumn{3}{|c|}{ Member 4-6 } & \multicolumn{3}{|c|}{ Member 6-8 } \\
\hline & & Semi-rigid & Rigid & Pinned & Semi-rigld & Figid & Pinned & Seml-rigld & Rigid & Pinned & Soml-rigld & Rigld & Pinned \\
\hline \multirow[t]{2}{*}{$\begin{array}{l}\text { Axial,lb } \\
\text { (N) }\end{array}$} & i-end & \begin{tabular}{|l}
2817 \\
$(12530)$ \\
\end{tabular} & \begin{tabular}{|l}
2818 \\
$(12534)$
\end{tabular} & $\begin{array}{l}2832 \\
(12597) \\
\end{array}$ & \begin{tabular}{|l}
2445 \\
$(10875)$.
\end{tabular} & \begin{tabular}{|l}
2435 \\
$(10831)$ \\
\end{tabular} & \begin{tabular}{|l}
2458 \\
$(10933)$ \\
\end{tabular} & $\begin{array}{l}-2243 \\
(-9977) \\
\end{array}$ & \begin{tabular}{|l}
-2232 \\
$(-9928)$ \\
\end{tabular} & \begin{tabular}{|l}
-2256 \\
$(-10035)$ \\
\end{tabular} & $\begin{array}{l}-2616 \\
(-11636) \\
\end{array}$ & \begin{tabular}{|l}
-2616 \\
$(-11636)$ \\
\end{tabular} & \begin{tabular}{|l|}
-2630 \\
$(-11698)$ \\
\end{tabular} \\
\hline & jend & \begin{tabular}{|l}
-2616 \\
$(-11636)$ \\
\end{tabular} & \begin{tabular}{|l}
-2616 \\
$(-11636)$ \\
\end{tabular} & \begin{tabular}{|l}
-2630 \\
$(-11698)$ \\
\end{tabular} & $\begin{array}{l}-2243 \\
(-9977) \\
\end{array}$ & \begin{tabular}{|l}
-2232 \\
$(-9928)$ \\
\end{tabular} & \begin{tabular}{|l}
-2256 \\
$(-10035)$ \\
\end{tabular} & \begin{tabular}{|l}
2445 \\
$(16875)$ \\
\end{tabular} & \begin{tabular}{|l}
2435 \\
$(10831)$
\end{tabular} & \begin{tabular}{|l|}
2458 \\
$(10933)$ \\
\end{tabular} & \begin{tabular}{|l|}
2817 \\
$(12530)$ \\
\end{tabular} & \begin{tabular}{|l|}
2818 \\
$(12534)$
\end{tabular} & \begin{tabular}{|l}
2832 \\
$(12597)$ \\
\end{tabular} \\
\hline \multirow[t]{2}{*}{$\begin{array}{l}\text { Shear,lb } \\
\text { (N) }\end{array}$} & iend & $188.5(838.4)$ & \begin{tabular}{|l|}
196.0 \\
$(872.0)$ \\
\end{tabular} & \begin{tabular}{|l}
187.4 \\
$(834.0)$ \\
\end{tabular} & $297.5(1323)$ & \begin{tabular}{|l|}
296.6 \\
$(1319)$ \\
\end{tabular} & $\begin{array}{l}298.3 \\
(132 \pi \\
\end{array}$ & $\begin{array}{l}-188.2 \\
(-837.1) \\
\end{array}$ & $\begin{array}{l}-189.1 \\
(-841.0) \\
\end{array}$ & \begin{tabular}{|l}
-187.4 \\
$(-834.0)$ \\
\end{tabular} & $\begin{array}{l}-294.6 \\
(-1310) \\
\end{array}$ & \begin{tabular}{|l}
-289.7 \\
$(-1289)$ \\
\end{tabular} & \begin{tabular}{|l|}
-298.3 \\
$(-1327)$ \\
\end{tabular} \\
\hline & jend & 294.6 (1310) & $\begin{array}{l}289.7 \\
\text { (1289) } \\
\end{array}$ & \begin{tabular}{|l|}
298.3 \\
$(1327)$ \\
\end{tabular} & $188.2(837.1)$ & \begin{tabular}{|l}
189.1 \\
$(841.0)$ \\
\end{tabular} & \begin{tabular}{|l|}
187.4 \\
$(834.0)$ \\
\end{tabular} & \begin{tabular}{|l}
-297.5 \\
$(-1323)$ \\
\end{tabular} & \begin{tabular}{|l|}
-296.6 \\
$(-1319)$ \\
\end{tabular} & \begin{tabular}{|l}
-298.3 \\
$(-1327)$ \\
\end{tabular} & \begin{tabular}{|ll}
-188.5 & $!$ \\
$(-838.4)$ & \\
\end{tabular} & \begin{tabular}{|l|}
-196.0 \\
$(-872.0)$ \\
\end{tabular} & \begin{tabular}{|l|}
-187.4 \\
$(-834.0)$ \\
\end{tabular} \\
\hline \multirow[t]{2}{*}{$\begin{array}{l}\text { Moment, } \\
\text { b-in. (N.m) }\end{array}$} & i-end & \begin{tabular}{|l|}
-173.4 \\
$(-19.59)$ \\
\end{tabular} & $\begin{array}{l}-628.0 \\
(-71.00) \\
\end{array}$ & 0 & $\begin{array}{l}-4974 \\
(-562.0) \\
\end{array}$ & \begin{tabular}{|l}
-4893 \\
$(-553.0)$ \\
\end{tabular} & \begin{tabular}{|l}
-5046 \\
$(-570.0)$ \\
\end{tabular} & 0 & 0 & 0 & \begin{tabular}{|l|}
-4974 \\
$(-562.0)$ \\
\end{tabular} & \begin{tabular}{|l}
-4893 \\
$(-553.0)$ \\
\end{tabular} & \begin{tabular}{|l|}
-5046 \\
$(-570.0)$ \\
\end{tabular} \\
\hline & jend & 4974 (562.0) & \begin{tabular}{|l|}
4893 \\
$(553.0)$
\end{tabular} & \begin{tabular}{|l|}
5046 \\
$(570.0)$
\end{tabular} & 0 & 0 & 0 & \begin{tabular}{|l|}
4974 \\
$(562.0)$
\end{tabular} & \begin{tabular}{|l|}
4893 \\
$(553.0)$
\end{tabular} & \begin{tabular}{|l|}
5046 \\
$(570.0)$
\end{tabular} & \begin{tabular}{|l|}
173.0 \\
$(19.55)$
\end{tabular} & \begin{tabular}{|l|}
628.0 \\
$(71.00)$
\end{tabular} & 0 \\
\hline
\end{tabular}


Table 27. Forces at $i$ - and $j$-ends in bottom chord members.

\begin{tabular}{|c|c|c|c|c|c|c|c|c|c|c|c|c|c|}
\hline \multirow[b]{2}{*}{ Force } & \multirow[b]{2}{*}{ End } & \multicolumn{3}{|c|}{ Member 1-3 } & \multicolumn{3}{|c|}{ Member 3.5 } & \multicolumn{3}{|c|}{ Member 5-7 } & \multicolumn{3}{|c|}{ Member 7-8 } \\
\hline & & $\begin{array}{l}\text { Semi- } \\
\text { rigid }\end{array}$ & Rigid & Pinned & $\begin{array}{l}\text { Semi- } \\
\text { rigld }\end{array}$ & Rigid & Pinned & $\begin{array}{l}\text { Semi- } \\
\text { rigidd }\end{array}$ & Rigid & Pinned & $\begin{array}{l}\text { Seml- } \\
\text { rigid }\end{array}$ & Rigld & Pinned \\
\hline \multirow[t]{2}{*}{$\begin{array}{l}\text { Axial,lb } \\
\text { (N) }\end{array}$} & i-end & $\begin{array}{c}-2528 \\
(-11245) \\
\end{array}$ & $\begin{array}{c}-2526 \\
(-11236) \\
\end{array}$ & $\begin{array}{c}-2542 \\
(-11307) \\
\end{array}$ & $\begin{array}{c}-1592 \\
(-7081) \\
\end{array}$ & $\begin{array}{c}-1586 \\
(-7055) \\
\end{array}$ & $\begin{array}{r}-1599 \\
(-7112) \\
\end{array}$ & $\begin{array}{c}-1592 \\
(-7081) \\
\end{array}$ & $\begin{array}{c}-1586 \\
(-7055) \\
\end{array}$ & $\begin{array}{c}-1599 \\
(-7112) \\
\end{array}$ & $\begin{array}{c}-2528 \\
(-11245) \\
\end{array}$ & $\begin{array}{c}-2526 \\
(-11236) \\
\end{array}$ & $\begin{array}{c}-2542 \\
(-11307) \\
\end{array}$ \\
\hline & j-end & $\begin{array}{c}2528 \\
(11245) \\
\end{array}$ & $\begin{array}{c}2526 \\
(11236) \\
\end{array}$ & $\begin{array}{c}2542 \\
(11307) \\
\end{array}$ & $\begin{array}{r}1592 \\
(7081) \\
\end{array}$ & $\begin{array}{c}1586 \\
(7055) \\
\end{array}$ & $\begin{array}{r}1599 \\
(7112) \\
\end{array}$ & $\begin{array}{c}1592 \\
(7081) \\
\end{array}$ & $\begin{array}{c}1586 \\
(7055) \\
\end{array}$ & $\begin{array}{c}1599 \\
(7112) \\
\end{array}$ & $\begin{array}{c}2528 \\
(11245) \\
\end{array}$ & $\begin{array}{c}2526 \\
(11236) \\
\end{array}$ & $\begin{array}{c}2542 \\
(11307) \\
\end{array}$ \\
\hline \multirow[t]{2}{*}{$\begin{array}{l}\text { Shear,lb } \\
(\mathrm{N})\end{array}$} & i-end & $\begin{array}{c}71.15 \\
(316.5) \\
\end{array}$ & $\begin{array}{c}67.42 \\
(300.0)\end{array}$ & $\begin{array}{c}70.00 \\
(311.0) \\
\end{array}$ & $\begin{array}{r}92.50 \\
(411.4) \\
\end{array}$ & $\begin{array}{c}93.34 \\
(415.0) \\
\end{array}$ & $\begin{array}{r}93.34 \\
(415.0) \\
\end{array}$ & 0 & 0 & 0 & $\begin{array}{r}115.5 \\
(513.7) \\
\end{array}$ & $\begin{array}{r}119.2 \\
(530.0) \\
\end{array}$ & $\begin{array}{r}116.7 \\
(519.0) \\
\end{array}$ \\
\hline & j-end & $\begin{array}{r}115.5 \\
(513.7) \\
\end{array}$ & $\begin{array}{c}119.2 \\
(530.0) \\
\end{array}$ & $\begin{array}{c}116.7 \\
(519.0) \\
\end{array}$ & 0 & 0 & 0 & $\begin{array}{r}92.50 \\
(411.4) \\
\end{array}$ & $\begin{array}{c}93.34 \\
(415.0) \\
\end{array}$ & $\begin{array}{c}93.34 \\
(415.0) \\
\end{array}$ & $\begin{array}{c}71.15 \\
(316.5) \\
\end{array}$ & $\begin{array}{c}67.42 \\
(300.0) \\
\end{array}$ & $\begin{array}{r}70.00 \\
(311.0) \\
\end{array}$ \\
\hline \multirow[t]{2}{*}{$\begin{array}{l}\text { Moment, lb } \\
\text {-in. }(\mathrm{N} \cdot \mathrm{m})\end{array}$} & i-end & $\begin{array}{c}267.6 \\
(30.23) \\
\end{array}$ & $\begin{array}{r}628.0 \\
(71.00) \\
\end{array}$ & 0 & $\begin{array}{c}-2226 \\
(-251.5) \\
\end{array}$ & $\begin{array}{c}-1726 \\
(-195.0) \\
\end{array}$ & $\begin{array}{c}-2613 \\
(-295.0) \\
\end{array}$ & $\begin{array}{c}340.9 \\
(38.51) \\
\end{array}$ & $\begin{array}{c}887.4 \\
(100.0) \\
\end{array}$ & 0 & $\begin{array}{c}-2217 \\
(-250.5) \\
\end{array}$ & $\begin{array}{c}-2274 \\
(-257.0) \\
\end{array}$ & $\begin{array}{c}-2613 \\
(-295.0) \\
\end{array}$ \\
\hline & j-end & $\begin{array}{c}2217 \\
(250.5) \\
\end{array}$ & $\begin{array}{r}2274 \\
(257.0) \\
\end{array}$ & $\begin{array}{c}2613 \\
(295.0) \\
\end{array}$ & $\begin{array}{c}-340.9 \\
(-38.51) \\
\end{array}$ & $\begin{array}{c}-887.4 \\
(-100.0)\end{array}$ & 0 & $\begin{array}{c}2226 \\
(251.5) \\
\end{array}$ & $\begin{array}{c}1726 \\
(195.0)\end{array}$ & $\begin{array}{c}2613 \\
(295.0)\end{array}$ & $\begin{array}{c}-267.8 \\
(-30.26)\end{array}$ & $\begin{array}{c}-628.0 \\
(-71.00)\end{array}$ & 0 \\
\hline
\end{tabular}


Table 28. Forces at $i$ - and $j$-ends in web chord members.

\begin{tabular}{|c|c|c|c|c|c|c|c|c|c|c|c|c|c|}
\hline \multirow[b]{2}{*}{ Force } & \multirow[b]{2}{*}{ End } & \multicolumn{3}{|c|}{ Member 2-3 } & \multicolumn{3}{|c|}{ Member 3-4 } & \multicolumn{3}{|c|}{ Member 4-7 } & \multicolumn{3}{|c|}{ Member 6-7 } \\
\hline & & $\begin{array}{l}\text { Seml- } \\
\text { rigld }\end{array}$ & Rigld & Pinned & $\begin{array}{l}\text { Semi- } \\
\text { rigid }\end{array}$ & Rigid & Pinned & $\begin{array}{l}\text { Seml- } \\
\text { rigid }\end{array}$ & Rigid & Pinned & $\begin{array}{l}\text { Seml- } \\
\text { rigld }\end{array}$ & Rigid & Pinned \\
\hline $\begin{array}{l}\text { Axial,lb } \\
\text { (N) }\end{array}$ & i-end & $\begin{array}{r}-616.2 \\
(-2741) \\
\end{array}$ & $\begin{array}{r}-613.6 \\
(-2729) \\
\end{array}$ & $\begin{array}{l}-620.7 \\
(-2761) \\
\end{array}$ & $\begin{array}{r}-881.7 \\
(-3922)\end{array}$ & $\begin{array}{l}-875.9 \\
(-3896) \\
\end{array}$ & $\begin{array}{r}889.7 \\
(3957) \\
\end{array}$ & $\begin{array}{r}881.7 \\
(3922) \\
\end{array}$ & $\begin{array}{l}875.9 \\
(3896) \\
\end{array}$ & $\begin{array}{l}889.7 \\
(3957)\end{array}$ & $\begin{array}{c}-616.2 \\
(-2741) \\
\end{array}$ & $\begin{array}{l}-613.6 \\
(-2729) \\
\end{array}$ & $\begin{array}{l}-620.7 \\
(-2761)\end{array}$ \\
\hline & j-end & $\begin{array}{l}616.2 \\
(2741) \\
\end{array}$ & $\begin{array}{r}613.6 \\
(2729) \\
\end{array}$ & $\begin{array}{l}620.7 \\
(2761) \\
\end{array}$ & $\begin{array}{l}881.7 \\
(3922) \\
\end{array}$ & $\begin{array}{l}875.9 \\
(3896) \\
\end{array}$ & $\begin{array}{r}-889.7 \\
(-3957) \\
\end{array}$ & $\begin{array}{r}-881.7 \\
(-3922) \\
\end{array}$ & $\begin{array}{r}-875.9 \\
(-3896) \\
\end{array}$ & $\begin{array}{r}-889.7 \\
(-3957) \\
\end{array}$ & $\begin{array}{r}616.2 \\
(2741) \\
\end{array}$ & $\begin{array}{r}613.6 \\
(2729) \\
\end{array}$ & $\begin{array}{r}620.7 \\
(2761) \\
\end{array}$ \\
\hline $\begin{array}{l}\text { Shear,lb } \\
\text { (N) }\end{array}$ & i-end & 0 & $\begin{array}{c}-12.34 \\
(-54.90) \\
\end{array}$ & 0 & 0 & 0 & 0 & 0 & 0 & 0 & 0 & $\begin{array}{c}12.34 \\
(54.90) \\
\end{array}$ & 0 \\
\hline & j-end & 0 & $\begin{array}{r}12.34 \\
(54.90) \\
\end{array}$ & 0 & 0 & 0 & 0 & 0 & 0 & 0 & 0 & $\begin{array}{c}-12.34 \\
(-54.90) \\
\end{array}$ & 0 \\
\hline $\begin{array}{l}\text { Moment,lb- } \\
\text { in. }(\mathrm{N} \cdot \mathrm{m})\end{array}$ & i-end. & 0 & 0 & 0 & $\begin{array}{c}39.26 \\
(4.436) \\
\end{array}$ & 0 & 0 & 0 & 0 & 0 & 0 & 0 & 0 \\
\hline & j-end & $\begin{array}{c}-29.67 \\
(-3.352) \\
\end{array}$ & $\begin{array}{c}-553.2 \\
(-62.50)\end{array}$ & 0 & 0 & $\begin{array}{r}-5.153 \\
(-0.58) \\
\end{array}$ & 0 & $\begin{array}{c}39.26 \\
(-4.436) \\
\end{array}$ & $\begin{array}{r}-5.153 \\
(-0.58) \\
\end{array}$ & 0 & $\begin{array}{l}29.68 \\
(3.353)\end{array}$ & $\begin{array}{c}553.2 \\
(62.50) \\
\end{array}$ & 0 \\
\hline
\end{tabular}




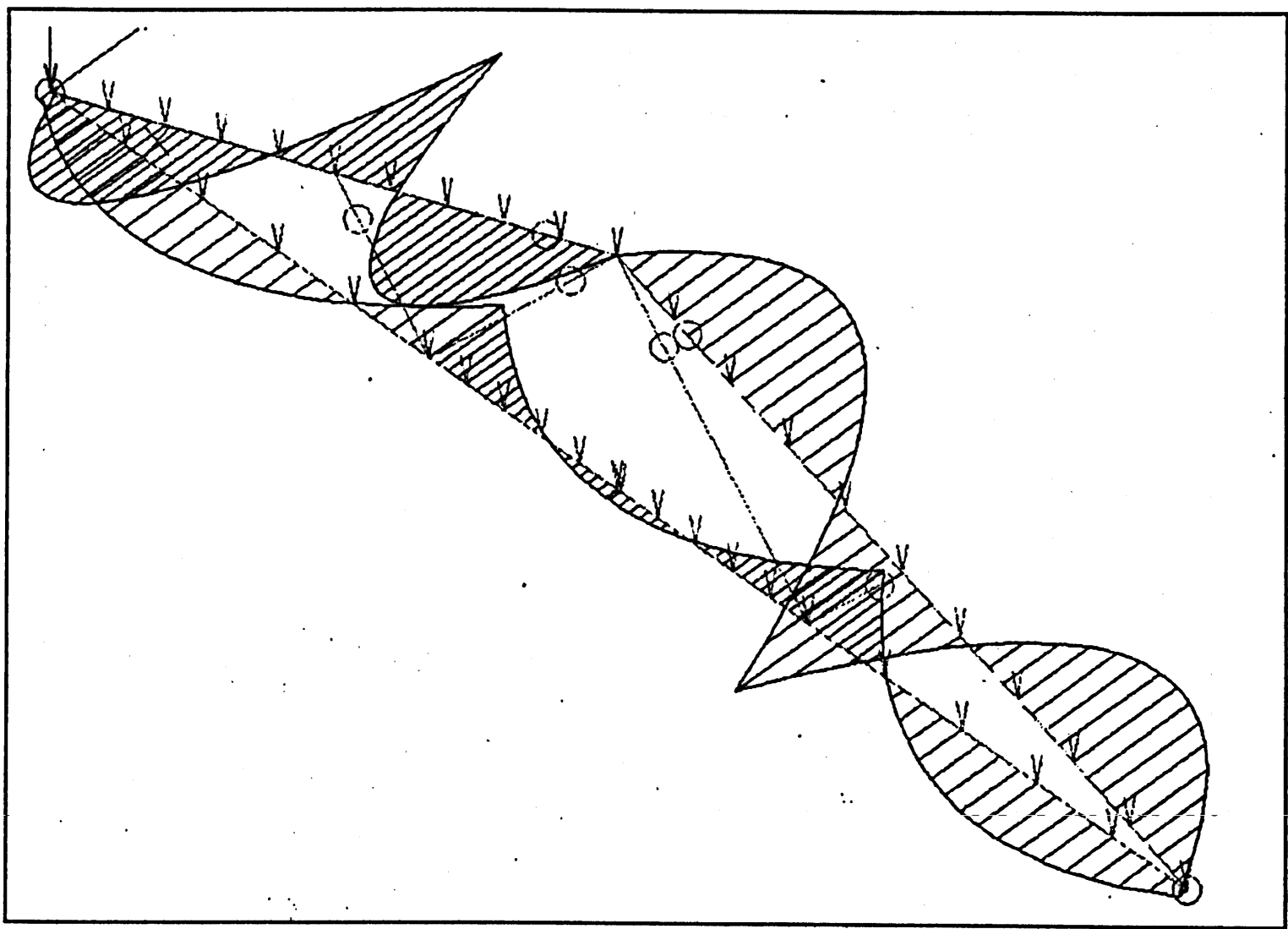

Figure 6. Moment diagram for semi-rigid truss model.

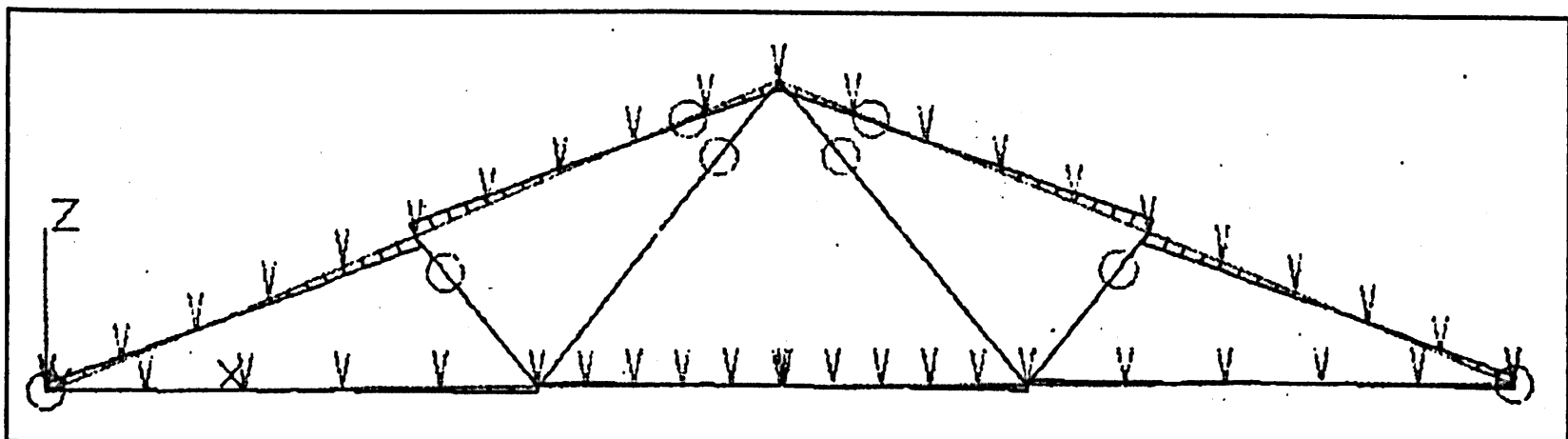

Figure 7. Shear diagram for seml-rigid truss model.. 
68

USACERL TR 98/89

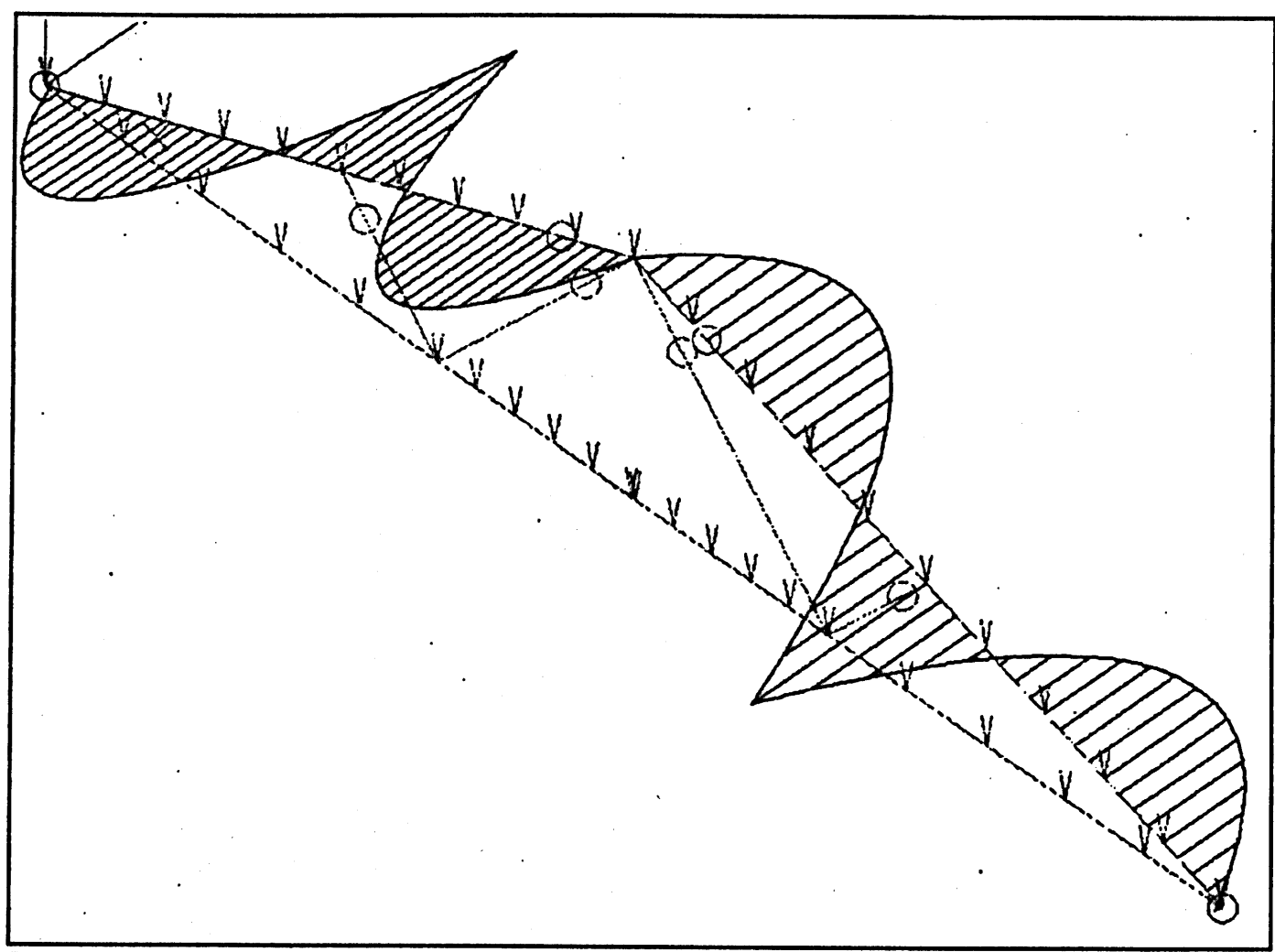

Figure 8. Moment diagram for top chord of semirigid truss model.

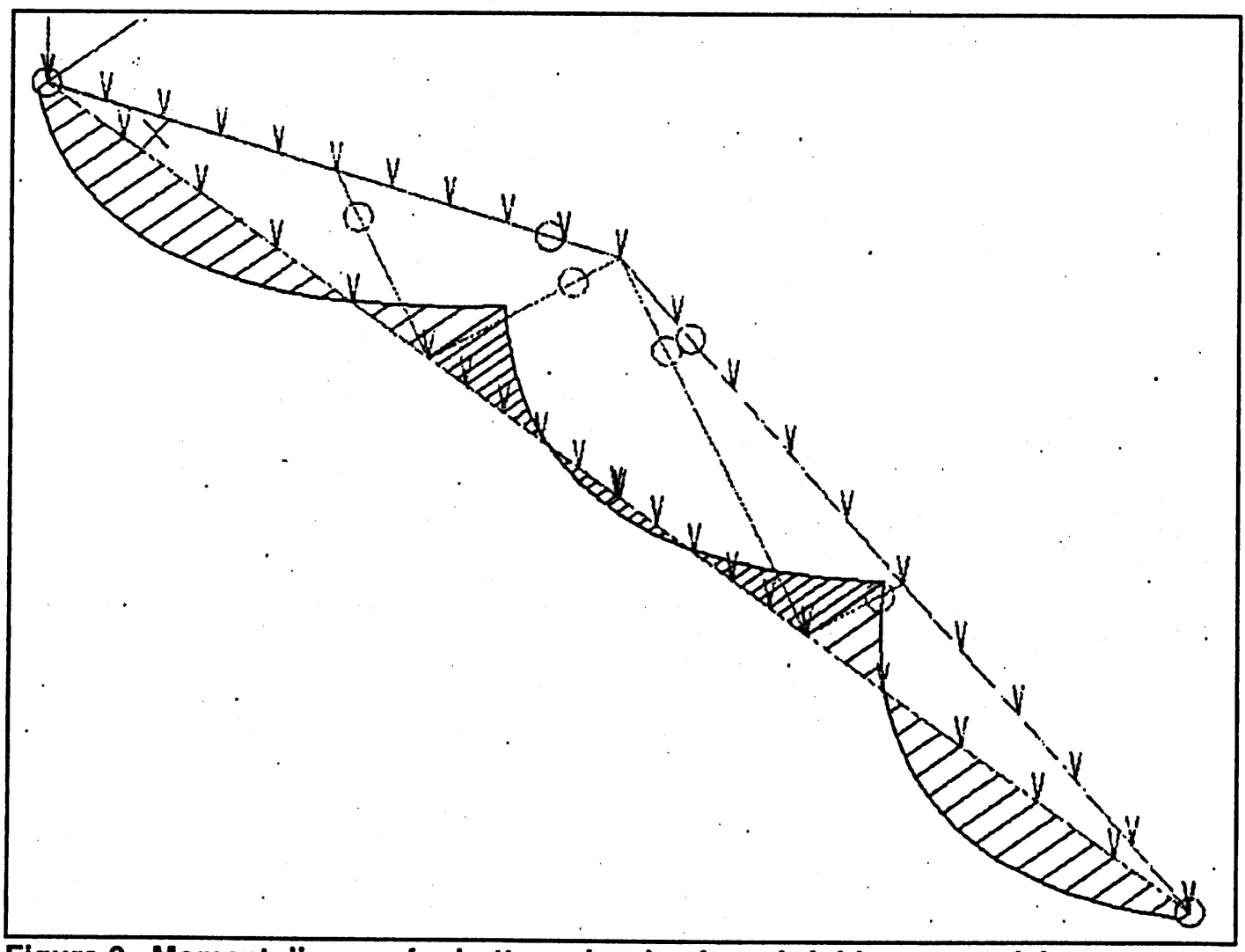

Figure 9. Moment diagram for bottom chords of semirigid truss model. 


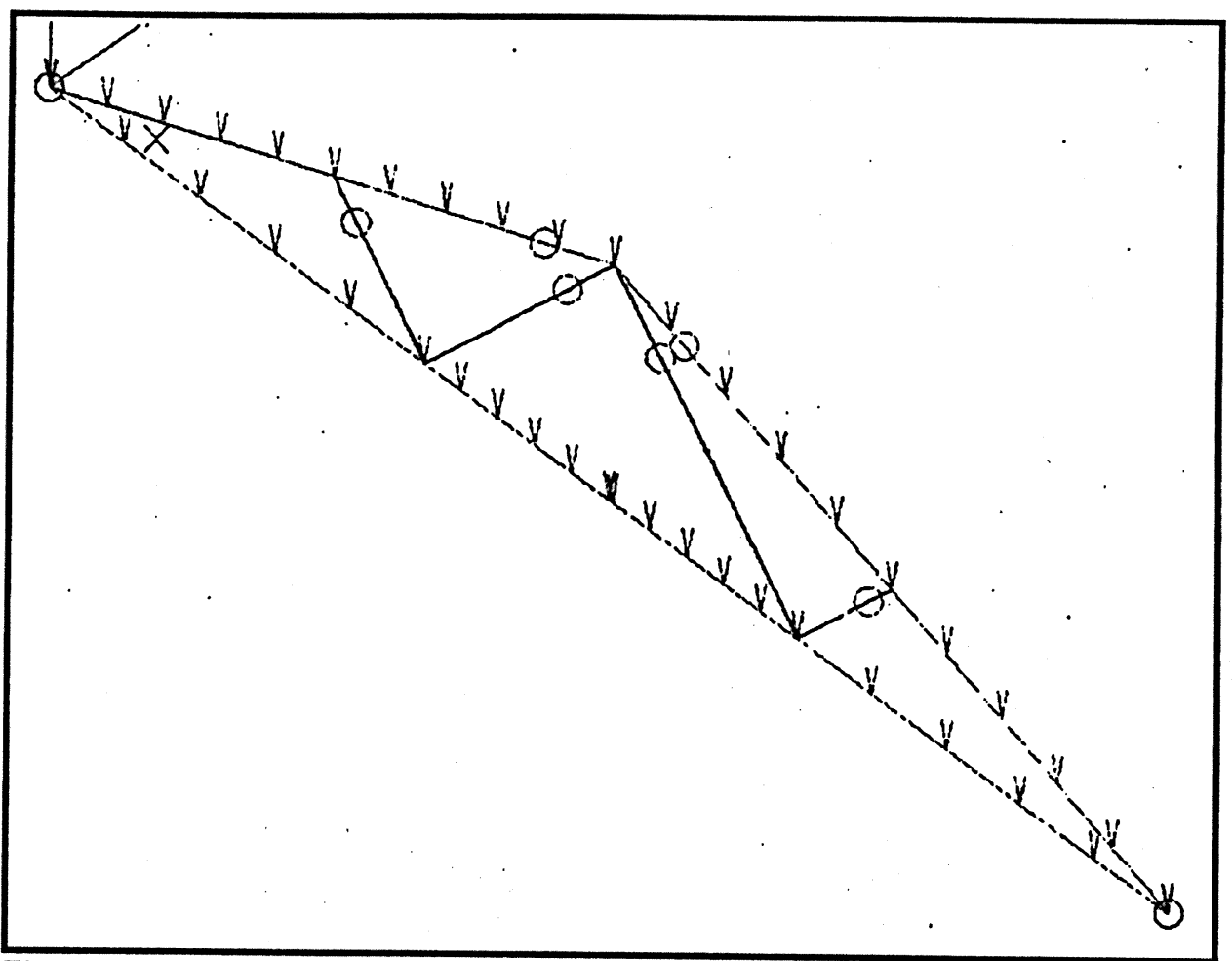

Figure 10. Moment diagram for web chords of semi-rigid truss model.

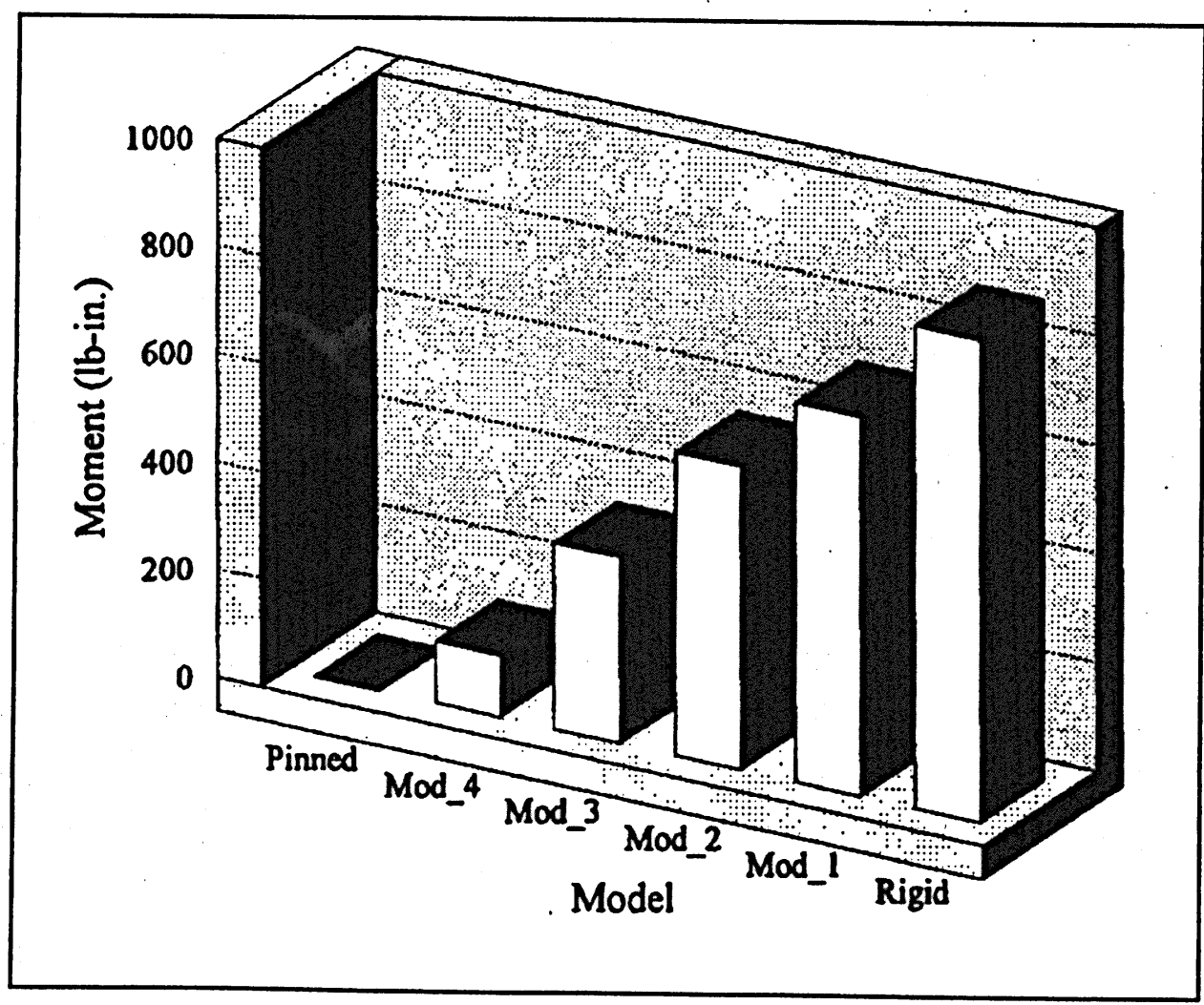

Figure 11. Moments for member 5-7 at node i for the six different models. 


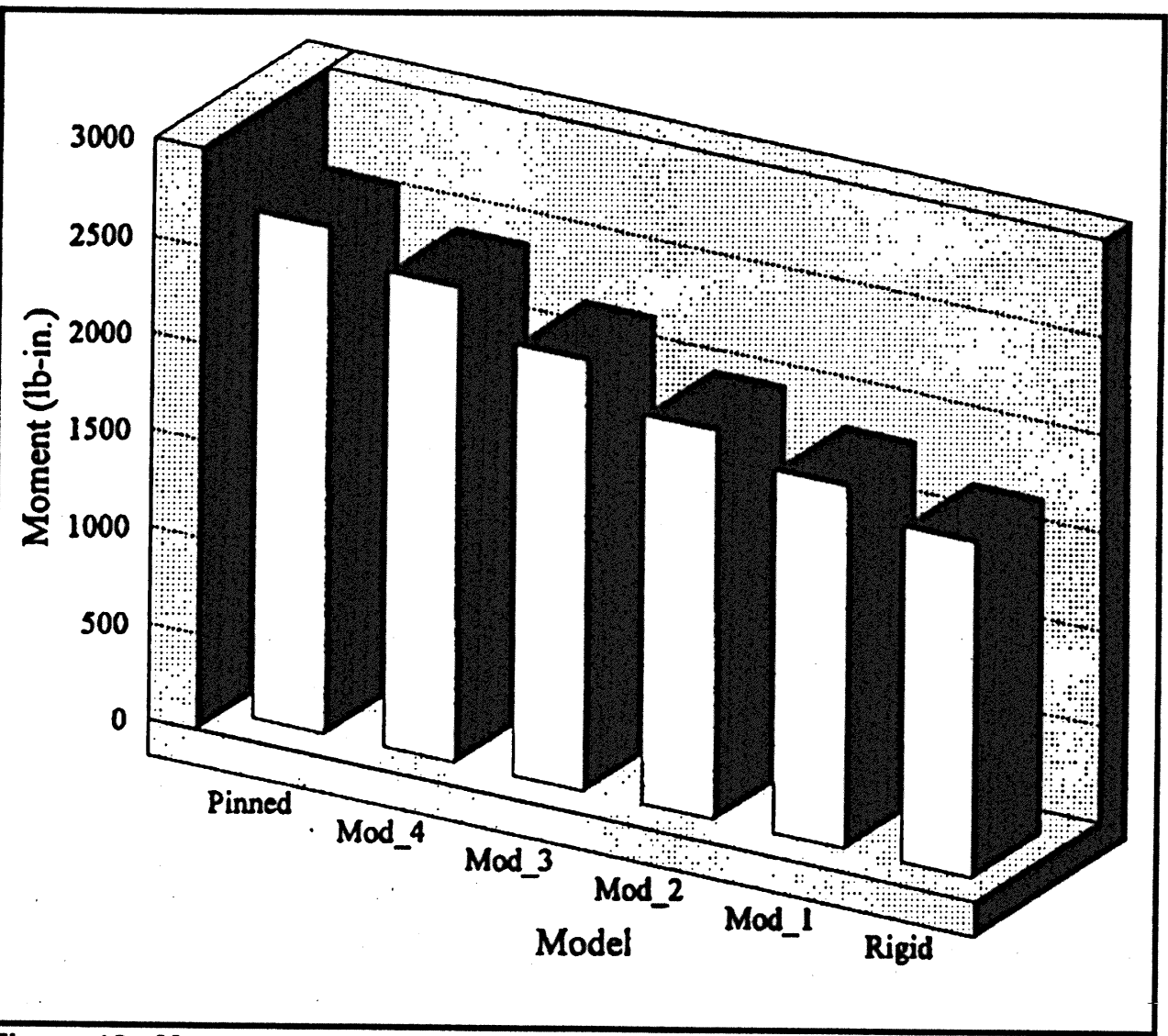

Figure 12. Moments for member 5-7 at node j for the six different models.

Table 29 summarizes the predicted downward joint displacements for the three different models. The table shows that the maximum displacement was at the tension splice joint (joint 5). At this joint, the maximum deflection was 0.3709 in. for the pinned model, $0.2075 \mathrm{in}$. for the rigid model, and $0.2733 \mathrm{in}$. for the semi-rigid model. In a comparison of the maximum deflection, the pinned model predicted a 79 percent higher deflection than the rigid model, while the semirigid model predicted a 32 percent higher deflection than the rigid model. Figure 13 shows the displacement results for the tension splice joint (joint 5) for the six analyzed models.

The results of the internal forces (axial and shear forces and moments) for the four semi-rigid models (Mod_1, Mod_2, Mod_3, and Mod_4) are presented in Tables $30,31,32,33,34$, and 35 . Tables 29 and 30 present the results for the top chords, Tables 31 and 32 present the results for the bottom chords, and Tables 33 and 34 present the results for the web members. A summary of the predicted joint displacements for the four analyzed semi-rigid models is shown in Table 36. 
Table 29. Comparison of predlcted joint displacements from each of the three models.

\begin{tabular}{|c|c|c|c|}
\hline Displacement & \multicolumn{3}{|c|}{ Method of Analysis } \\
\cline { 2 - 4 } In. (mm) & Semi-rigid & Rigid & Pinned \\
\hline Joint 2 & $0.1547(3.929)$ & $0.1519(3.858)$ & $0.1530(3.887)$ \\
\hline Joint 3 & $0.1683(4.275)$ & $0.1654(4.200)$ & $0.1666(4.232)$ \\
\hline Joint 4 & $0.1660(4.216)$ & $0.1631(4.142)$ & $0.1642(4.171)$ \\
\hline Joint 5 & $0.2733(6.942)$ & $0.2075(5.271)$ & $0.3709(9.421)$ \\
\hline Joint 6 & $0.1547(3.929)$ & $0.1519(3.858)$ & $0.1530(3.887)$ \\
\hline Joint 7 & $0.1683(4.275)$ & $0.1654(4.200)$ & $0.1666(4.232)$ \\
\hline
\end{tabular}

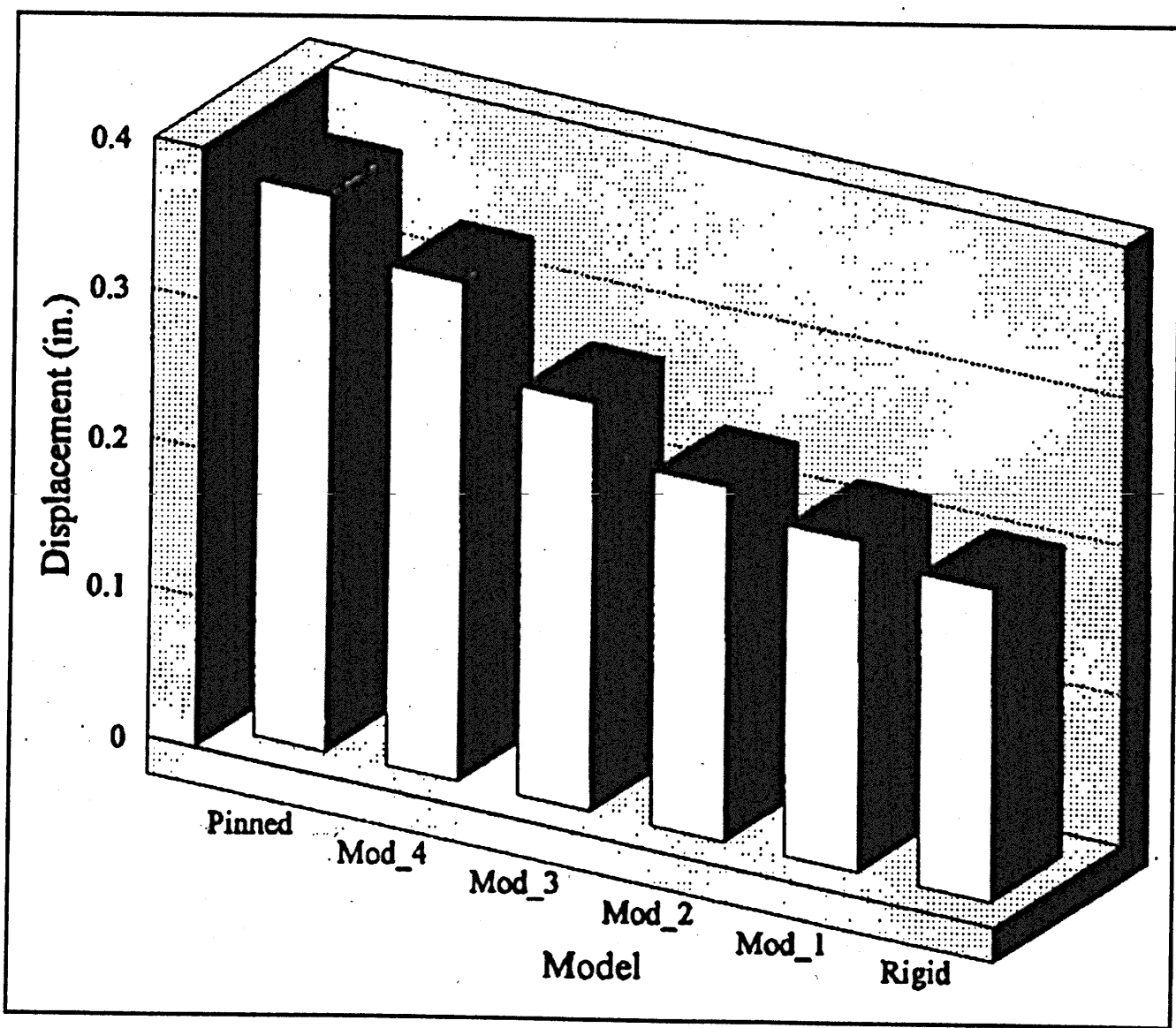

Figure 13. Displacements for tension splice joint for the six different models. 
Table 30. Forces at 1 - and j-ends in top chord members for semi-rigid models.

\begin{tabular}{|l|c|c|c|c|c|c|c|c|c|}
\hline \multirow{2}{*}{ Force } & \multirow{3}{*}{ End } & \multicolumn{6}{|c|}{ Member 1-2 } & \multicolumn{5}{|c|}{ Member 2-4 } \\
\cline { 3 - 10 } & Mod_1 & Mod_2 & Mod_3 & Mod_4 & Mod_1 & Mod_2 & Mod_3 & Mod_4 \\
\hline Axial, Ib & i-end & 2814 & 2815 & 2817 & 2823 & 2437 & 2440 & 2445 & 2451 \\
(N) & & $(12517)$ & $(12521)$ & $(12530)$ & $(12557)$ & $(10840)$ & $(10853)$ & $(10875)$ & $(10902)$ \\
\hline & j-end & -2613 & -2613 & -2616 & -2621 & -2234 & -2238 & -2243 & -2249 \\
& & $(-11623)$ & $(-11623)$ & $(-11636)$ & $(-11658)$ & $(-9937)$ & $(-9955)$ & $(-9977)$ & $(-10004)$ \\
\hline Shear, Ib & i-end & 191.8 & 190.5 & 188.5 & 186.5 & 296.9 & 297.1 & 297.5 & 297.8 \\
(N) & & $(853.1)$ & $(847.3)$ & $(838.4)$ & $(829.6)$ & $(1321)$ & $(1322)$ & $(1323)$ & $(1325)$ \\
\hline & F-end & 291.2 & 292.5 & 294.6 & 296.5 & 188.8 & 188.5 & 188.2 & 187.9 \\
& & $(1295)$ & $(1301)$ & $(1310)$ & $(1319)$ & $(839.8)$ & $(838.4)$ & $(837.1)$ & $(835.8)$ \\
\hline Moment, & i-end & -419.3 & -322.8 & -173.4 & -23.17 & -4919 & -4941 & -4974 & -5000 \\
Ib-in. (N.m) & & $(-47.37)$ & $(-36.47)$ & $(-19.59)$ & $(-2.618)$ & $(-555.7)$ & $(-558.2)$ & $(-562.0)$ & $(-564.9)$ \\
\hline & j-end & 4919 & 4941 & 4974 & 5000 & 0 & 0 & 0 & 0 \\
& & $(555.7)$ & $(558.2)$ & $(562.0)$ & $(564.9)$ & & & & \\
\hline
\end{tabular}

Table 31. Forces at 1 - and j-ends in top chord members for semi-rigid models.

\begin{tabular}{|c|c|c|c|c|c|c|c|c|c|}
\hline \multirow[b]{2}{*}{ Force } & \multirow[b]{2}{*}{ End } & \multicolumn{4}{|c|}{ Member $4-6$} & \multicolumn{4}{|c|}{ Member 6-8 } \\
\hline & & Mod_1 & Mod_2 & Mod_3 & Mod_4 & Mod_1 & Mod_2 & Mod_3 & Mod_4 \\
\hline $\begin{array}{l}\text { Axial, } \\
\text { lb (N) }\end{array}$ & i-end & $\begin{array}{l}-2234 \\
(-9937)\end{array}$ & $\begin{array}{l}-2238 \\
(-9955)\end{array}$ & $\begin{array}{l}-2243 \\
(-9977)\end{array}$ & $\begin{array}{c}-2249 \\
(-10004)\end{array}$ & $\begin{array}{c}-2613 \\
(-11623)\end{array}$ & $\begin{array}{c}-2613 \\
(-11623)\end{array}$ & $\begin{array}{c}-2616 \\
(-11636)\end{array}$ & $\begin{array}{c}-2621 \\
(-11658)\end{array}$ \\
\hline & jend & $\begin{array}{c}2437 \\
(10840) \\
\end{array}$ & $\begin{array}{r}2440 \\
(10853) \\
\end{array}$ & $\begin{array}{c}2445 \\
(10875) \\
\end{array}$ & $\begin{array}{c}2451 \\
(10902) \\
\end{array}$ & $\begin{array}{c}2814 \\
(12517) \\
\end{array}$ & $\begin{array}{c}2815 \\
(12521) \\
\end{array}$ & $\begin{array}{c}2817 \\
(12530) \\
\end{array}$ & $\begin{array}{c}2823 \\
(12557) \\
\end{array}$ \\
\hline $\begin{array}{l}\text { Shear, } \\
\text { Ib (N) }\end{array}$ & i-end & $\begin{array}{l}-188.8 \\
(-839.8) \\
\end{array}$ & $\begin{array}{l}-188.5 \\
(-838.4) \\
\end{array}$ & $\begin{array}{l}-188.2 \\
(-837.1) \\
\end{array}$ & $\begin{array}{l}-187.9 \\
(-835.8)\end{array}$ & $\begin{array}{l}-291.2 \\
(-1295)\end{array}$ & $\begin{array}{l}-292.5 \\
(-1301)\end{array}$ & $\begin{array}{l}-294.6 \\
(-1310)\end{array}$ & $\begin{array}{l}-296.5 \\
(-1319)\end{array}$ \\
\hline & j-end & $\begin{array}{l}-296.9 \\
(-1321) \\
\end{array}$ & $\begin{array}{l}-297.1 \\
(-1322) \\
\end{array}$ & $\begin{array}{r}-297.5 \\
(-1323) \\
\end{array}$ & $\begin{array}{r}-297.8 \\
(-1325) \\
\end{array}$ & $\begin{array}{c}-191.8 \\
(-853.1) \\
\end{array}$ & $\begin{array}{c}-190.5 \\
(-847.3) \\
\end{array}$ & $\begin{array}{r}-188.5 \\
(-838.4) \\
\end{array}$ & $\begin{array}{r}-186.5 \\
(-829.6) \\
\end{array}$ \\
\hline $\begin{array}{l}\text { Moment, lb- } \\
\text { in. }(\mathrm{N} \cdot \mathrm{m})\end{array}$ & i-end & 0 & 0 & 0 & 0 & $\begin{array}{c}-4919 \\
(-555.7) \\
\end{array}$ & $\begin{array}{c}-4941 \\
(-558.2) \\
\end{array}$ & $\begin{array}{c}-4974 \\
(-562.0) \\
\end{array}$ & $\begin{array}{r}-5000 \\
(-564.9) \\
\end{array}$ \\
\hline & jend & $\begin{array}{c}4919 \\
(555.7)\end{array}$ & $\begin{array}{c}4941 \\
(558.2)\end{array}$ & $\begin{array}{c}4974 \\
(562.0)\end{array}$ & $\begin{array}{r}5000 \\
(564.9) \\
\end{array}$ & $\begin{array}{r}418.9 \\
(47.33) \\
\end{array}$ & $\begin{array}{r}322.4 \\
(36.42) \\
\end{array}$ & $\begin{array}{r}173.0 \\
(19.55) \\
\end{array}$ & $\begin{array}{r}22.83 \\
(2.579) \\
\end{array}$ \\
\hline
\end{tabular}

Table 32. Forces at I- and j-ends in bottom chord members for semi-rigid models.

\begin{tabular}{|c|c|c|c|c|c|c|c|c|c|}
\hline \multirow[b]{2}{*}{ Force } & \multirow[b]{2}{*}{ End } & \multicolumn{4}{|c|}{ Member 1-3 } & \multicolumn{4}{|c|}{ Member 3-5 } \\
\hline & & Mod_1 & Mod_2 & Mod_3 & Mod_4 & Mod_1 & Mod_2 & Mod_3 & Mod_4 \\
\hline \multirow[t]{2}{*}{$\begin{array}{l}\text { Axial, } \\
\text { Ib (N) }\end{array}$} & i-end & $\begin{array}{c}-2524 \\
(-11227)\end{array}$ & $\begin{array}{c}-2525 \\
(-11231)\end{array}$ & $\begin{array}{c}-2528 \\
(-11245)\end{array}$ & $\begin{array}{c}-2534 \\
(-11271)\end{array}$ & $\begin{array}{c}-1587 \\
(-7059)\end{array}$ & $\begin{array}{l}-1589 \\
(-7068)\end{array}$ & $\begin{array}{l}-1592 \\
(-7081)\end{array}$ & $\begin{array}{l}-1595 \\
(-7095)\end{array}$ \\
\hline & jend & $\begin{array}{c}2524 \\
(11227) \\
\end{array}$ & $\begin{array}{r}2525 \\
(11231) \\
\end{array}$ & $\begin{array}{c}2528 \\
(11245) \\
\end{array}$ & $\begin{array}{r}2534 \\
(11271) \\
\end{array}$ & $\begin{array}{r}1587 \\
(7059) \\
\end{array}$ & $\begin{array}{r}1589 \\
(7068) \\
\end{array}$ & $\begin{array}{c}1592 \\
(7081) \\
\end{array}$ & $\begin{array}{c}1595 \\
(7095) \\
\end{array}$ \\
\hline \multirow[t]{2}{*}{$\begin{array}{l}\text { Shear, } \\
\text { ib (N) }\end{array}$} & i-end & $\begin{array}{c}69.08 \\
(307.3) \\
\end{array}$ & $\begin{array}{c}70.19 \\
(312.2) \\
\end{array}$ & $\begin{array}{r}71.15 \\
(316.5) \\
\end{array}$ & $\begin{array}{c}70.77 \\
(314.8) \\
\end{array}$ & $\begin{array}{r}92.50 \\
(411.4) \\
\end{array}$ & $\begin{array}{r}92.50 \\
(411.4) \\
\end{array}$ & $\begin{array}{r}92.50 \\
(411.4) \\
\end{array}$ & $\begin{array}{r}92.50 \\
(411.4) \\
\end{array}$ \\
\hline & j-end & $\begin{array}{c}117.6 \\
(523.1)\end{array}$ & $\begin{array}{c}116.5 \\
(518.2)\end{array}$ & $\begin{array}{c}115.5 \\
(513.7)\end{array}$ & $\begin{array}{c}115.9 \\
(515.5)\end{array}$ & 0 & 0 & 0 & 0 \\
\hline \multirow[t]{2}{*}{$\begin{array}{l}\text { Moment,lb } \\
\text {-in. }(\mathrm{N} \cdot \mathrm{m})\end{array}$} & i-end & $\begin{array}{c}515.2 \\
(58.21) \\
\end{array}$ & $\begin{array}{c}418.0 \\
(47.23)\end{array}$ & $\begin{array}{c}267.6 \\
(30.23) \\
\end{array}$ & $\begin{array}{r}116.4 \\
(13.15) \\
\end{array}$ & $\begin{array}{c}-1869 \\
(-211.2) \\
\end{array}$ & $\begin{array}{r}-2009 \\
(-227.0) \\
\end{array}$ & $\begin{array}{r}-2226 \\
(-251.5) \\
\end{array}$ & $\begin{array}{r}-2454 \\
(-277.3) \\
\end{array}$ \\
\hline & jend & $\begin{array}{c}2201 \\
(248.7) \\
\end{array}$ & $\begin{array}{c}2174 \\
(245.6) \\
\end{array}$ & $\begin{array}{c}2217 \\
(250.5) \\
\end{array}$ & $\begin{array}{r}2411 \\
(272.4) \\
\end{array}$ & $\begin{array}{c}-697.8 \\
(-78.84)\end{array}$ & $\begin{array}{r}-557.6 \\
(-63.00) \\
\end{array}$ & $\begin{array}{c}-340.9 \\
(-38.51) \\
\end{array}$ & $\begin{array}{c}-112.9 \\
(-12.76)\end{array}$ \\
\hline
\end{tabular}


Table 33. Forces at 1 - and $j$-ends in bottom chord members for semi-rigid models.

\begin{tabular}{|c|c|c|c|c|c|c|c|c|c|}
\hline \multirow[b]{2}{*}{ Force } & \multirow[b]{2}{*}{ End } & \multicolumn{4}{|c|}{ Members 5-7 } & \multicolumn{4}{|c|}{ Members $7-8$} \\
\hline & & Mod_1 & Mod_2 & Mod_3 & Mod_4 & Mod_1 & Mod_2 & Mod_3 & Mod_4 \\
\hline \multirow[t]{2}{*}{$\begin{array}{l}\text { Axial, Ib } \\
\text { (N) }\end{array}$} & i-end & $\begin{array}{l}-1587 \\
(-7059)\end{array}$ & $\begin{array}{c}-1589 \\
(-7068)\end{array}$ & $\begin{array}{l}-1592 \\
(-7081)\end{array}$ & $\begin{array}{l}-1595 \\
(-7095)\end{array}$ & $\begin{array}{c}-2524 \\
(-11227)\end{array}$ & $\begin{array}{c}-2525 \\
(-22231)\end{array}$ & $\begin{array}{c}-2528 \\
(-11245)\end{array}$ & $\begin{array}{c}-2534 \\
(-11271)\end{array}$ \\
\hline & end & $\begin{array}{r}1587 \\
(7059) \\
\end{array}$ & $\begin{array}{c}1589 \\
(7068) \\
\end{array}$ & $\begin{array}{c}1592 \\
(7081) \\
\end{array}$ & $\begin{array}{r}1595 \\
(7095) \\
\end{array}$ & $\begin{array}{c}2524 \\
(11227) \\
\end{array}$ & $\begin{array}{c}2525 \\
(11231)\end{array}$ & $\begin{array}{c}2528 \\
(11245)\end{array}$ & $\begin{array}{c}2534 \\
(11271)\end{array}$ \\
\hline \multirow[t]{2}{*}{$\begin{array}{l}\text { Shear, Ib } \\
\text { (N) }\end{array}$} & i-end & 0 & 0 & 0 & 0 & $\begin{array}{c}117.6 \\
(523.1)\end{array}$ & $\begin{array}{c}116.5 \\
(518.2)\end{array}$ & $\begin{array}{c}115.5 \\
(513.7)\end{array}$ & $\begin{array}{c}115.9 \\
(515.5)\end{array}$ \\
\hline & jend & $\begin{array}{r}92.50 \\
(411.4) \\
\end{array}$ & $\begin{array}{r}92.50 \\
(411.4) \\
\end{array}$ & $\begin{array}{r}92.50 \\
(411.4) \\
\end{array}$ & $\begin{array}{c}92.50 \\
(411.4) \\
\end{array}$ & $\begin{array}{c}69.08 \\
(307.3)\end{array}$ & $\begin{array}{c}70.19 \\
(312.2)\end{array}$ & $\begin{array}{c}71.15 \\
(316.5)\end{array}$ & $\begin{array}{c}70.76 \\
(314.7)\end{array}$ \\
\hline \multirow[t]{2}{*}{$\begin{array}{l}\text { Moment, lb-in. } \\
\text { (N.m) }\end{array}$} & i-end & $\begin{array}{r}697.8^{\circ} \\
(78.84) \\
\end{array}$ & $\begin{array}{r}557.6 \\
(63.00) \\
\end{array}$ & $\begin{array}{c}340.9 \\
(38.51) \\
\end{array}$ & $\begin{array}{c}112.9 \\
(12.76) \\
\end{array}$ & $\begin{array}{c}-2201 \\
(-248.7) \\
\end{array}$ & $\begin{array}{c}-2174 \\
(-245.6) \\
\end{array}$ & $\begin{array}{r}-2217 \\
(-250.5) \\
\end{array}$ & $\begin{array}{c}-2411 \\
(-272.4) \\
\end{array}$ \\
\hline & j-end & $\begin{array}{c}1869 \\
(211.2)\end{array}$ & $\begin{array}{c}2009 \\
(227.0)\end{array}$ & $\begin{array}{c}2226 \\
(251.5)\end{array}$ & $\begin{array}{c}2454 \\
(277.3)\end{array}$ & $\begin{array}{c}-515.4 \\
(-58.23)\end{array}$ & $\begin{array}{l}-418.2 \\
(-47.25)\end{array}$ & $\begin{array}{c}-267.8 \\
(-30.26)\end{array}$ & $\begin{array}{c}-116.7 \\
(-13.18)\end{array}$ \\
\hline
\end{tabular}

Table 34. Forces at 1 - and $j$-ends in web chord members for semi-rigid models.

\begin{tabular}{|c|c|c|c|c|c|c|c|c|c|}
\hline \multirow[b]{2}{*}{ Force } & \multirow[b]{2}{*}{ End } & \multicolumn{4}{|c|}{ Members 2-3 } & \multicolumn{4}{|c|}{ Members 3-4 } \\
\hline & & Mod_1 & Mod_2 & Mod_3 & Mod_4 & Mod_1 & Mod_2 & Mod_3 & Mod_4 \\
\hline \multirow[t]{2}{*}{$\begin{array}{l}\text { Axial, Ib } \\
(\mathrm{N})\end{array}$} & i-end & $\begin{array}{c}-614.0 \\
(-2731) \\
\end{array}$ & $\begin{array}{r}-614.7 \\
(-2734) \\
\end{array}$ & $\begin{array}{l}-616.2 \\
(-2741) \\
\end{array}$ & $\begin{array}{r}-618.3 \\
(-2750) \\
\end{array}$ & $\begin{array}{r}-877.4 \\
(-3903) \\
\end{array}$ & $\begin{array}{c}-879.1 \\
(-3910) \\
\end{array}$ & $\begin{array}{c}-881.7 \\
(-3922) \\
\end{array}$ & $\begin{array}{r}-885.2 \\
(-3937) \\
\end{array}$ \\
\hline & jend & $\begin{array}{r}614.0 \\
(2731) \\
\end{array}$ & $\begin{array}{r}614.7 \\
(2734) \\
\end{array}$ & $\begin{array}{r}616.2 \\
(2741) \\
\end{array}$ & $\begin{array}{r}618.3 \\
(2750) \\
\end{array}$ & $\begin{array}{r}877.4 \\
(3903) \\
\end{array}$ & $\begin{array}{r}879.1 \\
(3910) \\
\end{array}$ & $\begin{array}{r}881.7 \\
(3922) \\
\end{array}$ & $\begin{array}{r}885.2 \\
(3937) \\
\end{array}$ \\
\hline \multirow[t]{2}{*}{$\begin{array}{l}\text { Shear, Ib } \\
\text { (N) }\end{array}$} & i-end & $\begin{array}{c}-7.201 \\
(-32.03) \\
\end{array}$ & $\begin{array}{c}-3.864 \\
(-17.19) \\
\end{array}$ & 0 & 0 & 0 & 0 & 0 & 0 \\
\hline & j-end & $\begin{array}{r}7.201 \\
(32.03) \\
\end{array}$ & $\begin{array}{c}3.864 \\
(17.19) \\
\end{array}$ & 0 & 0 & 0 & 0 & 0 & 0 \\
\hline \multirow[t]{2}{*}{$\begin{array}{l}\text { Moment, } \\
\text { lb-in. }(\mathrm{N} \cdot \mathrm{m})\end{array}$} & i-end & 0 & 0 & 0 & 0 & $\begin{array}{c}-8.938 \\
(-1.010) \\
\end{array}$ & $\begin{array}{l}8.495 \\
(0.96) \\
\end{array}$ & $\begin{array}{c}39.26 \\
(4.436) \\
\end{array}$ & $\begin{array}{r}29.19 \\
(3.298) \\
\end{array}$ \\
\hline & j-end & $\begin{array}{c}-319.2 \\
(-36.06)\end{array}$ & $\begin{array}{c}-171.3 \\
(-19.35)\end{array}$ & $\begin{array}{c}-29.67 \\
(-3.352)\end{array}$ & $\begin{array}{c}13.52 \\
(1.527)\end{array}$ & 0 & 0 & 0 & 0 \\
\hline
\end{tabular}

Table 35. Forces at $\mathrm{i}$ - and j-ends in web chord members for semi-rigid models.

\begin{tabular}{|c|c|c|c|c|c|c|c|c|c|}
\hline \multirow[b]{2}{*}{ Force } & \multirow[b]{2}{*}{ End } & \multicolumn{4}{|c|}{ Members 4-7 } & \multicolumn{4}{|c|}{ Members 6.7 } \\
\hline & & Mod_1 & Mod_2 & Mod_3 & Mod_4 & Mod_1 & Mod_2 & Mod_3 & Mod_4 \\
\hline \multirow[t]{2}{*}{$\begin{array}{l}\text { Axial, Ib } \\
\text { (N) }\end{array}$} & i-end & $\begin{array}{r}877.4 \\
(3903) \\
\end{array}$ & $\begin{array}{r}879.1 \\
(3910) \\
\end{array}$ & $\begin{array}{r}881.7 \\
(3922) \\
\end{array}$ & $\begin{array}{r}885.2 \\
(3937) \\
\end{array}$ & $\begin{array}{l}-614.0 \\
(-2731) \\
\end{array}$ & $\begin{array}{l}-614.7 \\
(-2734) \\
\end{array}$ & $\begin{array}{l}-616.2 \\
(-2741) \\
\end{array}$ & $\begin{array}{r}-618.3 \\
(-2750) \\
\end{array}$ \\
\hline & jend & $\begin{array}{r}-877.4 \\
(-3903) \\
\end{array}$ & $\begin{array}{r}-879.1 \\
(-3910) \\
\end{array}$ & $\begin{array}{r}-881.7 \\
(-3922) \\
\end{array}$ & $\begin{array}{r}-885.2 \\
(-3937) \\
\end{array}$ & $\begin{array}{c}6140 \\
(2731) \\
\end{array}$ & $\begin{array}{r}614.7 \\
(2734) \\
\end{array}$ & $\begin{array}{c}616.2 \\
(2741) \\
\end{array}$ & $\begin{array}{r}618.3 \\
(2750) \\
\end{array}$ \\
\hline \multirow[t]{2}{*}{$\begin{array}{l}\text { Shear, Ib } \\
\text { (N) }\end{array}$} & i-end & 0 & 0 & 0 & 0 & $\begin{array}{c}7.201 \\
(32.03) \\
\end{array}$ & $\begin{array}{r}3.865 \\
(17.19) \\
\end{array}$ & 0 & 0 \\
\hline & jend & 0 & 0 & 0 & 0 & $\begin{array}{c}-7.201 \\
(-32.03) \\
\end{array}$ & $\begin{array}{c}-3.865 \\
(-17.19) \\
\end{array}$ & 0 & 0 \\
\hline \multirow[t]{2}{*}{$\begin{array}{l}\text { Moment, } \\
\text { lb-in. (N.m) }\end{array}$} & i-end & 0 & 0 & 0 & 0 & 0 & 0 & 0 & 0 \\
\hline & jend & $\begin{array}{c}8.950 \\
(1.011)\end{array}$ & $\begin{array}{r}-8.487 \\
(-0.96)\end{array}$ & $\begin{array}{c}-39.26 \\
(-4.436)\end{array}$ & $\begin{array}{c}-29.18 \\
(-3.297)\end{array}$ & $\begin{array}{c}319.2 \\
(36.06)\end{array}$ & $\begin{array}{c}171.3 \\
(19.35)\end{array}$ & $\begin{array}{c}29.68 \\
(3.353)\end{array}$ & $\begin{array}{c}-13.52 \\
(-1.527)\end{array}$ \\
\hline
\end{tabular}


Table 36. Comparison of predicted joint displacements for semi-rigid models.

\begin{tabular}{|c|c|c|c|c|}
\hline \multirow{2}{*}{$\begin{array}{l}\text { Displacement, } \\
\text { in. (mm) }\end{array}$} & \multicolumn{4}{|c|}{ Semi-Rigid Models } \\
\cline { 2 - 5 } & Mod_1 & Mod_2 & Mod_3 & Mod_4 \\
\hline Joint 2 & $0.1525(3.874)$ & $0.1532(3.891)$ & $0.1547(3.929)$ & $0.1588(4.034)$ \\
\hline Joint 3 & $0.1660(4.216)$ & $0.1667(4.234)$ & $0.1683(4.275)$ & $0.1725(4.382)$ \\
\hline Joint 4 & $0.1637(4.158)$ & $0.1644(4.176)$ & $0.1660(4.216)$ & $0.1703(4.326)$ \\
\hline Joint 5 & $0.2207(5.606)$ & $0.2371(6.022)$ & $0.2733(6.942)$ & $0.3330(8.458)$ \\
\hline Joint 6 & $0.1525(3.874)$ & $0.1532(3.891)$ & $0.1547(3.929)$ & $0.1588(4.034)$ \\
\hline Joint 7 & $0.1660(4.216)$ & $0.1667(4.234)$ & $0.1683(4.275)$ & $0.1725(4.382)$ \\
\hline
\end{tabular}

The results from these four semi-rigid models were investigated to observe the change in axial and shear forces, moments, and displacements. By varying the stiffness in the various joints, the axial and shear forces were found to be insignificant (Tables 29-34). However, the values for the moments changed as mentioned before, especially for the bottom chord members (Tables 32-33). Furthermore, the displacements were the parameter most affected by the change in joint stiffness. The tension splice joint (joint 5 ) was the most affected location as mentioned before, where the displacements were $0.2207,0.2371,0.2733$, and 0.3330 in., respectively (Table 36 ). As a result, that parameter was primarily. selected for choosing the appropriate model as the aforementioned semi-rigid model for this type of truss. After evaluating the resulting internal forces and displacements for the four different semi-rigid models,.Model Mod_3 was considered as the most appropriate model to simulate the truss with semi-rigid joints.

The results of this model were introduced in Tables 26, 27, 28, and 29 for the semi-rigid model. " The weak elements at the heel, web at the bottom chord, and tension splice joints are $3 / 4 \times 1 \frac{1}{2}$-in. cross-sectional area. This reduction in crosssectional area reduces the axial and rotational stiffnesses of these joints. The axial rigidity (EA) of the weakened members at the heel, web at the bottom chord and tension splice joints is reduced from $12,800,000$ to $1,800,000 \mathrm{lb}$, and the bending rigidity was reduced from $17,066,720 \mathrm{lb}$-sq in. to $337,500 \mathrm{lb}$-sq in.

\section{Results of Analyzed Large Timber Truss Models}

Results of the internal stresses within selected members from the three different analyses are shown in Tables 37 through 44 . As seen in the results of the internal stresses for representative top chord, bottom chord, vertical, and diagonal members, the effect of joint rigidity normally had only a very small affect on the distribution and magnitude of stresses in the members. 
Table 37. Stresses* in Element \#6.

\begin{tabular}{|l|c|c|c|c|}
\hline & & Pinned & Semi-Rigid & Rigid \\
\hline Axial & i-end & 1.986 & 1.986 & 1.986 \\
\hline fa (ksi) & j-end & 1.986 & 1.986 & 1.986 \\
\hline Shear & i-end & 0.001 & 0.001 & 0.001 \\
\hline fv (ksi) & j-end & 0.001 & 0.001 & 0.001 \\
\hline Bending & i-end & 0.210 & 0.207 & 0.206 \\
\hline fb (ksi) & j-end & 0.239 & 0.240 & 0.240 \\
\hline Bending \& & i-end & 2.196 & 2.193 & 2.193 \\
\hline Axial (ksi)** & j-end & 2.225 & 2.227 & 2.226 \\
\hline
\end{tabular}

Table 38. Ratio of stresses to rigid model for element \#6.

\begin{tabular}{|l|c|c|c|c|}
\hline & & Pinned & Semi-Rigid & Rigid \\
\hline \multirow{2}{*}{ Axial } & i-end & 1.000 & 1.000 & 1.000 \\
\cline { 2 - 5 } & j-end & 1.000 & 1.000 & 1.000 \\
\hline \multirow{2}{*}{ Shear } & i-end & 0.878 & 1.020 & 1.000 \\
\cline { 2 - 5 } & j-end & 0.878 & 1.020 & 1.000 \\
\hline \multirow{2}{*}{ Bending } & i-end & 1.015 & 1.001 & 1.000 \\
\cline { 2 - 5 } & j-end & 0.997 & 1.003 & 1.000 \\
\hline \multirow{2}{*}{$\begin{array}{l}\text { Bending \& } \\
\text { Axial** }\end{array}$} & i-end & 1.001 & 1.000 & 1.000 \\
\cline { 2 - 5 } & j-end & 1.000 & 1.000 & 1.000 \\
\hline
\end{tabular}

Table 39. Stresses* for element \#18.

\begin{tabular}{|c|c|c|c|c|}
\hline & & Pinned & Semi-Rigid & Rigid \\
\hline \multirow{2}{*}{$\begin{array}{l}\text { Axial } \\
\text { f. (ksi) }\end{array}$} & i-end & -1.993 & -1.993 & -1.993 \\
\hline & jend & -1.987 & -1.993 & -1.987 \\
\hline \multirow{2}{*}{$\begin{array}{l}\text { Shear } \\
\text { f. (ksi) }\end{array}$} & i-end & 0.113 & 0.113 & 0.113 \\
\hline & jend & -0.125 & -0.125 & -0.125 \\
\hline \multirow{3}{*}{$\begin{array}{l}\text { Bending } \\
f_{0}(k s i)\end{array}$} & i-end & -0.404 & -0.406 & -0.407 \\
\hline & center & 0.547 & 0.546 & 0.546 \\
\hline & Jend & -0.625 & -0.623 & -0.623 \\
\hline \multirow{3}{*}{$\begin{array}{l}\text { Bending } \\
\& \\
\text { Axial (ksi)** }\end{array}$} & i-end & 2.398 & 2.399 & 2.400 \\
\hline & center & 2.537 & 2.540 & 2.536 \\
\hline & jend & 2.612 & 2.617 & 2.610 \\
\hline
\end{tabular}


Table 40. Ratio of stresses to rigid model for element \#18.

\begin{tabular}{|l|c|c|c|c|}
\hline \multirow{2}{*}{ Axial } & & Pinned & Semi-Rigid & Rigid \\
\hline \multirow{3}{*}{ Shear } & i-end & 1.000 & 1.000 & 1.000 \\
\cline { 2 - 5 } & j-end & 1.000 & 1.003 & 1.000 \\
\hline \multirow{3}{*}{ Bending } & i-end & 0.999 & 1.000 & 1.000 \\
\cline { 2 - 5 } & j-end & 1.001 & 1.000 & 1.000 \\
\hline & i-end & 0.994 & 0.998 & 1.000 \\
\cline { 2 - 5 } & center & 1.001 & 1.001 & 1.000 \\
\cline { 2 - 5 } & j-end & 1.003 & 1.000 & 1.000 \\
\hline \multirow{3}{*}{$\begin{array}{l}\text { Bending } \\
\text { Axial** }\end{array}$} & i-end & 0.999 & 1.000 & 1.000 \\
\cline { 2 - 5 } & center & 1.000 & 1.001 & 1.000 \\
\cline { 2 - 5 } & j-end & 1.001 & 1.003 & 1.000 \\
\hline \multirow{2}{*}{}
\end{tabular}

"Stresses based on linear elasticity only

*"Maximum absolute value

Table 41. Stresses* for element \#30.

\begin{tabular}{|c|c|c|c|c|}
\hline & & Pinned & Semi-Rigid & Rigid \\
\hline \multirow{2}{*}{$\begin{array}{l}\text { Axial } \\
f . \text { (ksi) }\end{array}$} & i-end & -0.404 & -0.399 & -0.399 \\
\hline & j-end & -0.404 & -0.399 & -0.399 \\
\hline \multirow{2}{*}{$\begin{array}{l}\text { Shear } \\
f_{y} \text { (ksi) }\end{array}$} & i-end & 0.000 & -0.002 & -0.002 \\
\hline & j-end & 0.000 & -0.002 & -0.002 \\
\hline \multirow{2}{*}{$\begin{array}{l}\text { Bending } \\
f_{0}(\mathrm{ksi})\end{array}$} & i-end & 0.000 & 0.113 & 0.114 \\
\hline & jend & 0.000 & -0.090 & -0.091 \\
\hline \multirow{2}{*}{$\begin{array}{l}\text { Bending \& } \\
\text { Axial (ksi)** }\end{array}$} & i-end & 0.404 & 0.511 & 0.513 \\
\hline & j-end & 0.404 & 0.489 & 0.490 \\
\hline
\end{tabular}

Table 42. Ratio of stresses to rigid model for element \#30.

\begin{tabular}{|l|c|c|c|c|}
\hline & & Pinned & Semi-Rigid & Rigid \\
\hline \multirow{2}{*}{ Axial } & i-end & 1.012 & 1.000 & 1.000 \\
\cline { 2 - 5 } & j-end & 1.012 & 1.000 & 1.000 \\
\hline \multirow{2}{*}{ Shear } & i-end & 0.000 & 0.976 & 1.000 \\
\cline { 2 - 5 } & jend & 0.000 & 0.976 & 1.000 \\
\hline \multirow{2}{*}{$\begin{array}{l}\text { Bending } \\
\text { Axial** }\end{array}$} & i-end & 0.000 & 0.988 & 1.000 \\
\cline { 2 - 5 } & j-end & 0.000 & 0.985 & 1.000 \\
\cline { 2 - 4 } & i-end & 0.787 & 0.997 & 1.000 \\
\hline \multirow{2}{*}{ "Stresses based on linear elasticity only } & 0.823 & 0.997 & 1.000 \\
\hline \multirow{2}{*}{$*$ Maximum absolute value } \\
\hline
\end{tabular}


Table 43. Stresses ${ }^{\star}$ for element \#43.

\begin{tabular}{|c|c|c|c|c|}
\hline & & Pinned & Semi-Rigid & Rigid \\
\hline \multirow{2}{*}{$\begin{array}{l}\text { Axial } \\
f_{2}(\mathrm{ksi})\end{array}$} & i-end & 0.018 & 0.018 & 0.018 \\
\hline & j-end & 0.018 & 0.018 & 0.018 \\
\hline \multirow{2}{*}{$\begin{array}{l}\text { Shear } \\
\text { f (ksi) }\end{array}$} & i-end & 0.000 & -0.001 & .0 .005 \\
\hline & j-end & 0.000 & -0.001 & -0.005 \\
\hline \multirow{2}{*}{$\begin{array}{l}\text { Bending } \\
f_{b} \text { (ksi) }\end{array}$} & i-end & 0.000 & -0.034 & -0.034 \\
\hline & j-end & 0.000 & -0.108 & -0.109 \\
\hline \multirow{2}{*}{$\begin{array}{l}\text { Bending \& } \\
\text { Axial (ksi)** }\end{array}$} & i-end & 0.018 & 0.052 & 0.051 \\
\hline & j-end & 0.018 & 0.126 & 0.127 \\
\hline
\end{tabular}

Table 44. Ratio of stresses to rigid model for element \#43.

\begin{tabular}{|l|c|c|c|c|}
\hline \multirow{2}{*}{ Axial } & & Pinned & Semi-Rigid & Rigid \\
\hline \multirow{2}{*}{ Shear } & i-end & 1.025 & 1.006 & 1.000 \\
\cline { 2 - 5 } & j-end & 1.025 & 1.006 & 1.000 \\
\hline \multirow{2}{*}{ Bending } & i-end & 0.000 & 0.152 & 1.000 \\
\cline { 2 - 5 } & j-end & 0.000 & 0.152 & 1.000 \\
\hline & i-end & 0.000 & 1.001 & 1.000 \\
\cline { 2 - 5 } & j-end & 0.000 & 0.994 & 1.000 \\
\hline $\begin{array}{l}\text { Bending \& } \\
\text { Axial*** }\end{array}$ & i-end & 0.351 & 1.003 & 1.000 \\
\cline { 2 - 5 } & j-end & 0.142 & 0.995 & 1.000 \\
\hline
\end{tabular}

These small differences usually amounted to a change of at most 3 percent. For a small number of cases, the variation in joint rigidity had a significant effect on the magnitude and distribution of stresses. For example, in the bottom chord element \#6, shear stresses were nearly 23 percent lower when the joint was modeled as pinned as compared with either the semi-rigid, or rigid configuration. The remainder of the differences was confined to the web members. These differences are primarily due to the fact that pinned connections obviously cannot develop bending or shear stresses in the attached members. Although the ratios of the stresses obtained from the pinned model to those obtained from the rigid model are very small, the actual shear and bending stresses developed in the pinned model are themselves small. This indicates that truss action is the dominant load carrying mechanism for a truss of this size and geometry. Even though the joints are fixed, the majority of the load is transmitted as axial stress. This is further supported by the fact that the difference in deflection at the center of the truss between the pinned case and the rigid case is only about 1 percent. 


\section{Recommended Structural Evaluation Procedure for Wood Trusses}

As a result of the finite element analysis, the joint model selected, i.e., whether the connection is considered to be rigid, pinned, or somewhere in between, controls the predicted overall structural truss behavior based on the maximum deflection. An engineer could evaluate the influence of different joint models on the predicted structural behavior of trusses by incorporating semi-rigidity into the analysis and design of trusses. Unequal elastic connections at two ends of a member may exist in some cases. For a truss member with a semi-rigid end, the other end may be specified as pinned, rigid or semi-rigid.

The following is a recommended general procedure that may be used by engineers for the structural analysis of wood trusses through finite element modeling:

1. Determine all the dimensions of the different members of the truss from existing drawings if available. If drawings are not available, take field measurements and prepare a layout drawing for the truss.

2. Check each member carefully for existing defects, e.g., splits, checks, rot, knots, etc., to determine if a reduction in the cross-sectional area is needed. If a member is split along its entire length, it shall be modeled as two independent members. If the split is only along part of the length, the engineer shall use his/her judgment to determine the proper model to use. Based on this, specified dimensions are assigned for each member to be incorporated in the analysis.

3. Determine wood type and material properties, i.e., modulus of elasticity, density, and Poisson's ratio from existing drawings or specifications if available. If drawings are not available, determine this information by field inspection and NDT methods described in Chapter 2. Specified material properties based on the existing condition of the wood material should be assigned to each member in the truss.

4. Determine the type of connections and joint configurations from existing drawings and specifications. If drawings are not available, a thorough field inspection of the joints is needed. Based on this, the end connections, i.e., rigid, pinned or semi-rigid, are specified.

5. Determine the actual loads, i.e., dead, live, snow, etc., and their distribution on the structure. 
6. By using finite element analysis, analyze the truss by considering all connections pinned. The geometric layout, specified cross-sectional dimensions, material properties, and actual loads determined in steps $1,2,3$, and 5, are incorporated in the analysis. In this case, rotation is allowed at all the joints. The results from this analysis will produce the maximum deflection due to the fact that a truss with pinned connections has more flexibility than a truss with rigid, semi-rigid, or any combination of end fixities.

7. Rerun the analysis for the same truss by considering all connections rigid. The geometric layout, specified cross-sectional dimensions, material properties, and actual loads are not changed. In this case, rotation is not allowed at all the joints. As a result, minimum deflection is estimated due to the fact that rigid connections produce a stiff overall structure.

8. Compare the induced member stresses obtained from steps 6 and 7 and compare them to the member capacities. If the member capacities exceed the induced member stresses for both cases, then the members satisfy all strength requirements. If the induced member stresses exceed the member capacities for either case, then the connections shall be modeled as semi-rigid and the analysis rerun as discussed in step 9.

9. As mentioned earlier in this chapter, the actual connection for wood trusses is semi-rigid. Therefore, end connections for each member determined in step 4 are incorporated in a third model that may simulate the actual behavior of the truss. Semi-rigidity is incorporated by assuming a fictitious element at the end of the member with a reduced cross-sectional area. From the results of the analysis performed on the Fink truss, an equal reduction of 50 to 65 percent of the width, as well as the depth of the member will provide reasonable results.

10. Compare the results of the semi-rigid model in step 9 with that of the pinned model in step 6, as well as those of the rigid model in step 7. The deflection should fall in between the maximum and minimum deflections determined in steps 6 and 7.

11. The results of deflection and stresses are compared to the allowable values in existing codes to verify the adequacy of the truss and if any repair is needed.

12. Analyze the joints according to either the ASD or the LRFD specifications. Compare the induced joint stresses with the joint capacities. If the joint capacities exceed the induced stresses, the joint satisfies all strength require- 
ments. If the induced stresses exceed the joint capacities, a finite element analysis (such as those discussed in the following section) shall be performed. If the resulting stresses do not exceed the capacities of the material, the joint satisfies all strength requirements. Otherwise, the joint will need to be reinforced.

\section{Recommended Evaluation Procedure for Bolted Wood Connections}

Several different strategies can be followed for the analytical evaluation of bolted connections. These strategies range from the simple code prescribed methods, to very complex three-dimensional finite element analyses incorporating the nonlinear, orthotropic material properties of wood. Typically, the code methods are sufficiently conservative to account for errors associated with the inherently necessary simplifications and assumptions and are therefore well suited for design. However, when a more accurate analysis is required, one must look to the finite element method for the solution. This method includes relatively simple linear-elastic 2-D models as well as much more complex nonlinear 3-D models.

The first step in the evaluation of a bolted connection is to obtain all the dimensions and layout of the connection and the members associated with that connection, including the bolt clearance dimensions, as well as all loads acting on the joint. The engineer must next choose the type of analysis to use: either design code methods based on ASD or LRFD, or finite element methods using either 2-D, or 3-D models with material models of various complexities. The following paragraphs outline the recommended procedures for each of the methods.

The obvious advantage to using design code methods is their simplicity. Because of this simplicity, the methods are conservative and may predict premature failure. Both ASD and LRFD versions of the design code follow similar procedures. Minimum edge, end, and spacing distances are given to achieve full design load. The influence of the geometry of the connection on the capacity is accounted for with an adjustment factor. The minimum end distance for loading parallel to grain is 7D for softwoods and 5D for hardwoods (where $\mathrm{D}$ is the diameter of the bolt). If a crack or a split exists at the end of the joint, it is recommended that, if the end distance is equal to $7 \mathrm{D}$, the capacity of the connection be reduced to 75 percent. If the end distance is equal to or greater than 10D, the full capacity can be achieved. These code provisions are based on the "Yield Model," which incorporates the following assumptions: 
1. No shear strain

2. The connector fits tightly in the hole (no clearance)

3. No friction between members or along the bolt

4. Small displacement theory is valid

5. Failure is only due to wood crushing beneath the bolt (no splitting)

6. Constant material properties through the thickness

7. No rotation of connection during loading

8. Bolt ends are free to rotate the bolt.

Tests have shown that the type of material model used, bolt hole clearances, and friction at the bolt contact area all impact the behavior and strength of the connection. For this reason, finite element methods must be used to incorporate these effects. Although a linear, isotropic stress-strain model is much simpler, it does not accurately predict the behavior of the joint since tests have shown markedly nonlinear behavior at even very low loads. Hence, the finite element model used should include both nonlinear effects above 75 to 80 percent of crushing stress in compression, and the loss of strength in the direction perpendicular to the grain of the wood. Differences in bolt hole clearances affect the behavior in that the contact area increases as the bolt/hole clearance decreases. This causes the radial stress in the wood to increase on the loaded side as a consequence of the smaller contact area. This is true in the linear range of material behavior, but the onset of nonlinearity causes nonuniform deformations in the wood and consequently the contact area once again increases.

It is recommended that, if bolt/hole clearances are included in the analysis of the joint, the nonlinear behavior of wood must also be included so as not to overestimate the radial stresses. Friction between the bolt and the member also affects the magnitude and distribution of not only the radial stresses, but also the tangential stresses on the boundary. Unfortunately, researchers greatly disagree over how those stresses are affected. However, it is agreed that the effects of friction remain localized. Until more research is completed, it is recommended that the effects of friction be ignored. Finite element analyses require the prediction of failure modes. For the case of uncracked material, failure occurs when the stress in any one of the principal material directions (parallel to grain, perpendicular to grain, and shear) exceeds the material strength in that direction. This is referred to as the maximum normal stress criterion. Although this seems logical enough, wood has inherent flaws that negate such a simplification due to severe stress concentrations that arise with the presence of sharp cracks or other defects. 
Unfortunately, little research has been conducted on this subject to comprehensively enumerate all of the failure modes. Some research has successfully used linear-elastic fracture mechanics (LEFM) to predict failure of several wood members and joint geometries with various defects. The above discussion relates only to 2-D finite element models and does not include behavior such as bending of the bolt. Only 3-D models can accurately include such behaviors. To effectively develop such models, it is necessary to create realistic 3-D constitutive models. The following simplifications were made in a previous successful attempt at creating a constitutive model:

1. Wood is idealized as a 3-D, homogeneous, orthotropic material

2. Wood is modeled as a homogeneous continuum

3. Wood is linear elastic for only short-term behavior (typically only valid for parallel to grain compression for a range of loading below 75 to 80 percent of the crushing strength)

4. Wood is modeled to have no growth defects, and its orientation of grain is assumed to be parallel to the applied load.

The constitutive model used for the steel bolt was idealized as being perfectly elastic plastic and isotropic while that of the wood was assumed to be tri-linear compression behavior and tri-linear shear stiffness degradation. The results of this test provided for good correlation between the model and experimental data. Although this investigation proved successful, more research must be completed to verify the 3-D model. 


\section{Summary and Conclusions}

This study documented comprehensive procedures for the structural evaluation of heavy wood truss structures. The original allowable stresses of typical species of wood materials can be reduced significantly due to the change in code requirements and material conditions. As a result, a comprehensive investigation was made in terms of the allowable stresses presented in the codes spanning 1944 to 1991. All the parameters that describe the existing conditions of the structure's materials that may increase or decrease the actual and allowable stresses were identified and included in the final evaluation procedure.

The study also documented the identification of commercially available nondestructive tests that can be used to determine the mechanical properties of existing members. This nondestructive method identification process was based on several factors that contribute to the behavior and performance of wood species. These factors include size, moisture content, stress wave techniques, and mechanical grading. Furthermore, an evaluation was presented with respect to these nondestructive methods based on the various mechanical and physical properties of wood.

Issues related to modeling of wood structures necessary to create models that can reproduce the behavior of the prototypes were also investigated. Although truss joints are designed as pin connections, joints possess some level of rotational capacity that can influence the response of structures to loads and change the response from that of a true truss to that of a frame. As a result, the rotational capacities of common joint details were investigated to ascertain their rotational stiffness. The analytical computer modeling process considered moment stiffness such as roof trusses modeled as frame and truss elements, i.e., only axial loads. Hence, finite element analysis was carried out on two specific geometries (a Fink truss and a large timber truss) considering the joints pinned, fixed, and somewhere in between for the boundary conditions. As predicted, the structural behavior for a truss was primarily affected by the joint model adopted in the analysis. Semi-rigid joints should be incorporated into the analysis and design of trusses to model the actual behavior of wood trusses. 


\section{References}

Abbott, A.R., and G. Elcock, "Pole Testing in the European Context," Proceedings, 6th Nondestructive Testing of Wood Symposium, Pullman, WA (Washington State University, September 1987), pp 277-302.

Aggour, M.S., A. Hachichi, and M.A. Meyer, "Nondestructive Evaluation of Timber Bridge Piles," Proceedings of the American Society of Civil Engineers Structures Congress, Special Publication on Evaluation and Upgrading of Wood Structures (New Orleans, LA, New York, NY, September 1986), pp 82-95.

American Forest \& Paper Association, National Design Specification, "Wood Construction, Structural Lumber, Glued Laminated Timber, Timber Pilings, Connections," ANSI/NFoPA NDS. 1991, American National Standard (Washington, DC, rev.1991 ed.).

American Society of Civil Engineers Committee on Wood, Evaluation, Maintenance and Upgrading of Wood Structures, A Guide and Commentary (1982), $428 \mathrm{pp}$.

Anthony, R.W., and J.-Bodig, "Nondestructive -Evaluation of Timber Structures for Reliable Performance," Proceedings, 2nd Pacific Timber Engineering Conference, Auckland, New Zealand (August 1989).

Army Regulation (AR) 420-70, Buildings and Structures (Headquarters, Department of the Army [HQDA], Washington, DC, 29 May 1992).

Beall, F.C., and W.W. Wilcox, Relationship of Acoustic Emission to Mass Loss From Decay During Radial Compressive Testing, Unpublished Research Note (Tacoma, WA: Weyerhaeuser Company, DATE).

Bolvin, W.K., Modeling of Joints for the Dynamic Analysis of Truss Structures, NASA-TP-2661 (May 1987), 43 pp.

Browne, C.M. and W.E. Kuchar, "Determination of Material Properties for Structural Evaluation of TRESTLE," Proceedings, 5th International Nondestructive Testing of Wood Symposium, Pullman, WA (Washington State University, September 1985), pp 361-384.

Chudnoff, M., W.E. Eslyn, and D.B. McKeever, "Decay in Mine Timbers: Part III, SpeciesIndependent Stress Grading," Forest Products Journal, vol 34, No. 3 (1984), pp 43-50.

Derbyshire, H., E.R. Miller, and H. Turkulin, "Investigations into the Photodegradation of Wood Using Microtensile Testing, Part 1: The Application of Microtensile Testing to Measurement of Photodegradation Rates," Holz als Roh- und Werkstoff, vol 53, No. 5 (September 1995), pp 339-345. 
Derbyshire, H., E.R. Miller, and H. Turkulin, "Investigations into the Photodegradation of Wood Using Microtensile Testing, Part 2: An Investigation of the Changes in Tensile Strength of Different Softwood Species During Natural Weathering," Holz als Roh-und Werkstoff, vol 54, No. 1 (January 1996), pp 1-6.

Dunlop, J.I., "Testing of Poles by Acoustic Resonance," Wood Science Technology, vol 17 (1983), pp 31-38.

Fantozzi, J., and P.E. Humphrey, "Effects of Bending Moments on the Tensile Performance of Multiple-Bolted Timber Connectors: Part I. A Technique to Model Such Joints," Wood and Fiber Science, vol 27, No. 1 (January 1995), pp 55-67.

Faust, T.D., M. Fuller, and J.T. Rice, "A Method of Testing the Full Cross Section of Wood in Tension Perpendicular to the Grain, Technical Note," Forest Products Journal, vol 44, No. 3 (March 1994), pp 23-26.

Foliente, G.C., "Hysteresis Modeling of Wood Joints and Structural Systems," Journal of Structural Engineering, vol 121, No. 6 (ASCE, June 1995), pp 1013-1022.

Foliente, G.C., M.P. Singh, and J.D. Dolan, "Response Analysis of Wood Structures Under Natural Hazard Dynamic Loads," Wood and Fiber Science, vol 28, No. 1 (January 1996), pp 110-127.

Gerhards, C.C., Effect of Knots on Stress Waves in Lumber, Research Paper FPL 384 (U.S. Department of Agriculture [USDA], Forest Service, Forest Products Laboratory, September 1982), $28 \mathrm{pp}$.

Gorman, T.M., "Designing, Engineering, and Testing Wood Structures," Journal of Materials Education, vol 13, No. 5/6 (1991), pp 473-485.

Graubner, W., Encyclopedia of Wood Joints (The Taunton Press, Inc., 1992), 151 pp.

Hoyle, R.J,. and Pellerin, R.F., "Stress Wave Inspection of a Wood Structure," Proceedings, 4th Nondestructive Testing of Wood Symposium, Pullman, WA: Washington State University, August"1978, ;pp 33-45.

Hoyle, R.J. and P.S. Rutherford, Stress Wave Inspection of Bridge Timbers and Decking, Final Report for Research Project Y-3400 (Department of Civil and Environmental Engineering, Washington State University, Pullman, WA, 1987).

Institution of Civil Engineers, Symposium on Non-Destructive Testing of Concrete and Timber, London (1970), $122 \mathrm{pp}$.

Jauslin, C., P.J. Pellicane, and R.M. Gutkowski, "Finite-Element Analysis of Wood Joints," Jounal of Materials in Civil Engineering, vol 7, No. 1 (American Society of Civil Engineers [ASCE], February 1995), pp 50-58.

Kallio, E. and W.L. Galligan, "Factors Affecting the Use of Lumber by Truss Fabricators in the United States," Forest Products Research Society (Madison, WI, 1978), 80 pp.

Lanius, R.M., R. Tichy, and W.M. Bulleit, "Strength of Old Wood Joists," Journal of the Structural Division: Proceedings, American Society of Civil Engineers, vol 107, No. ST12 (New York, NY, December 1981), pp 2349-2363. 
Le Govic, C. and M. Khebibeche, "Methodological Developments in the Testing of Wood Based Panels, Part I: Tensile and Compression Tests," Materials and Structures, vol 27, No. 168 (May 1994), pp 229-236.

Lee, I.D.G., "Ultrasonic Pulse Velocity Testing Considered as a Safety Measure for Timber Structures," Proceedings, 2nd Nondestructive Testing of Wood Symposium, Spokane, WA (Washington State University, Pullman, WA, April 1965), pp 475-485.

Mtenga, P.V., S.M. Cramer, A.H. Peyrot, and R.W. Wolfe, "System Factors for Light-Frame Wood Truss Assemblies," Journal of Structural Engineering, vol 121, No. 2 (ASCE, February 1995), pp 290-300.

Murphy, M.W., D.E. Franklin, and R.A. Palylyk, A Nondestructive Testing Technique for Wood Poles (British Columbia Hydro Research and Development, Surrey, BC, 1987).

National Forest Products Association, National Design Specification for Stress-Grade Lumber and Its Fastenings (Washington, DC, 1971 ed.)

National Forest Products Association, National Design Specification for Stress-Grade Lumber and Its Fastenings (Washington, DC, 1973 ed.).

National Forest Products Association, Design Values for Wood Construction, A Supplement to the 1977 Edition of National Design Specification for Wood Construction (Washington, DC, June 1978), $20 \mathrm{pp}$.

National Forest Products Association, National Design Specification, Wood Construction, Structural Lumber, Glued Laminated Timber, Timber Pilings, Fastenings (Washington, DC, 1982 ed.).

National Forest Products Association, National Design Specification, Wood Construction, Structural Lumber, Glued Laminated Timber, Timber Pilings, Fastenings (Washington, DC, 1986 ed.).

National Lumber Manüfacturers Association, National Design Specification for Stress-Grade Lumber and Its Fastenings (Washington, DC, 1944), 64 pp.

Neal, D.W., "Establishment of Elastic Properties for In-Place Timber Structures," Proceedings, 5th Nondestructive Testing of Wood Symposium (Washington State University, Pullman, WA, September 1985), pp 353-359.

Oliver-Villanueva, J.-V., M. Quer, and G. Becker, "Influence of Structural Parameters on the Nondestructive Evaluation of Ash Timber (Fraxinus excelsior L.)," Holz als Roh- und Werkstoff, vol 54, No. 2 (March 1996), pp 109-112.

Olivito, R.S., "Ultrasonic Measurements in Wood," Materials Evaluation (April 1996), pp 514-517.

Patton-Mallory, M., S.M. Cramer, F.W. Smith, P.J. Pellicane, "Nonlinear Material Models for Analysis of Bolted Wood Connections," Journal of Structural Engineering, vol 123, No.8 (ASCE, August 1997), pp 1063-1070.

Patton-Mallory, M., P.J. Pellicane, and F.W. Smith, "Modeling Boleted Connections in Wood: Review," Journal of Structural Engineering, vol 123, No. 8 (ASCE, August 1997), pp 1054-1062. 
Patton-Mallory, M., and R.C. De Groot, "Acousto-Ultrasonics for Evaluating Decayed Wood Products," Proceedings, 2nd Pacific Timber Engineering Conference, Auckland, New Zealand (August 1989).

Pellerin, R.F., R.C. De Groot, G.R. and Esenther, "Nondestructive Stress Wave Measurements of Decay and Termite Attack in Experimental Wood Units," Proceedings, 5th Nondestructive Testing of Wood Symposium (Washington State University, Pullman, WA, September 1985), pp 319-352.

Pellerin, R.F., "Inspection of Wood Structures for Decay Using Stress Waves," Proceedings, 2nd Pacific Timber Engineering Conference, Auckland, New Zealand (August 1989).

Pellicane, P.J., J. Bodig, and A.L. Mrema, "Modeling Wood in Transverse Compression," Journal of Testing and Evaluation, vol 22, No. 4 (July 1994), pp 376-382.

Pellicane, P.J., J. Bodig, and A.L. Mrema, "Behavior of Wood in Transverse Compression," Journal of Testing and Evaluation, vol 22, No. 4 (July 1994), pp 383-387.

- Ross, R.J., and R.F.Pellerin, Nondestructive Testing for.Assessing. Wood Members in Structures: A Review, General Technical Report, FPL-GTR-70 (USDA, Forest Service, Forest Products Laboratory, August 1991), 27 pp.

Ross, R.J., R.C. DeGroot, and W.J. Nelson, "Technique for Nondestructive Evaluation of Biologically Degraded Wood," Experimental Techniques (September/October 1994), pp 29-32.

Rutherford, P.S., R.J. Hoyle, R.C. De Groot, and R.F. Pellerin, "Dynamic vs. Static MOE in the Transverse Direction in Wood," Proceedings, 6th Nondestructive Testing of Wood Symposium (Washington State University, Pullman, WA, September 1987), pp 67-80.

USDA Forest Service, Nondestructive Testing Methods To Predict Effect of Degradation on Wood: A Critical Assessment, General Technical Report, FPL 19 (Forest Products Laboratory, Forest Service, USDA, 1978).

Vatovec, M., R. Gupta; and T. Miller, "Testing and Evaluation of Metal-Plate-Connected Wood Truss Joints," Journal of Testing and Evaluation, vol 24, No. 2 (March 1996), pp 63-72.

Vatovec, M., T.H. Miller, and R. Gupta, "Modeling of Metal-Plate-Connected Wood Truss Joints," Transactions of the ASAE, vol 39, No. 3 (May-June 1996), pp 1101-1111.

Wang, S.C., O. Suchsland, and J.H. Hart, "Dynamic Test for Evaluating Decay in Wood," Forest Products Journal, vol 30, No. 7 (1980), pp 35-37. 


\section{Appendix: Nondestructive Measuring Equipment and Methods}

Table A1 lists suppliers of nondestructive test equipment.

Table A1. Nondestructive equipment and organization locations.

\begin{tabular}{|c|c|}
\hline Nondestructive Method & Organization and Address \\
\hline $\begin{array}{l}\text { Calipers } \\
\text { 721B Full Function Series, 721A Basic } \\
\text { Series }\end{array}$ & $\begin{array}{l}\text { Starrett } 721 \text { Series Electronic Digital Calipers } \\
\text { Starrett } \\
\text { The L.S. Starrett Company } \\
121 \text { Crescent Street } \\
\text { Athol, MA 01331 } \\
\text { Phone: (508) 249-3551 } \\
\text { Fax: (508) 249-8495 }\end{array}$ \\
\hline Vernier Caliper & Manchester University, United Kingdom \\
\hline $\begin{array}{l}\text { Moisture Meters } \\
\text { Models MT90, MT270, MT700, } \\
\text { MT808, CT33, CT100 }\end{array}$ & $\begin{array}{l}\text { Pin Type and "No Pins" } \\
\text { Electrophysics } \\
\text { Box } 1143 \text {, Station B } \\
\text { London, Ontario N6A 5K2, Canada } \\
\text { Phone: }(800) \text { 244-9908 } \\
\text { Fax: }(800) 244-9908\end{array}$ \\
\hline Moisture Meters & $\begin{array}{l}54 \text { The Tramex Moisture Encounter \& } 195 \text { The Tramex Compact Moisture } \\
\text { Measure } \\
\text { Patchell Publishing Pty Ltd } \\
69-71 \text { Rosstown Road, Carnegie VIC } 3163 \\
\text { Melbourne, Australia } \\
\text { Phone: } 61395635655 \\
\text { Fax: } 61395716006 \\
\text { E-mail: bic@build.com.au }\end{array}$ \\
\hline Moisture Meters & $\begin{array}{l}\text { Model DC-2000, DC-2000-C, Wood Portable Moisture Meter } \\
\text { AQUA Measure Instrument Company } \\
\text { Moisture Register Products Division } \\
1712 \text { Earhart Court } \\
\text { P.O. Box } 369 \\
\text { La Verne, California } 91750-0369 \\
\text { Phone: (909) 392-5833/36 } \\
\text { Fax: (909) 392-5838 } \\
\text { E-mail: aquamoist@aol.com }\end{array}$ \\
\hline Hygrometers & $\begin{array}{l}\text { Taylor Hygro-Thermometer 5502, Taylor Precision Hygro-Thermometer } \\
\text { 5565, Digital Hygro-Thermometer } 10215 \\
\text { Allergy Supply Company } \\
11994 \text { Star Court } \\
\text { Herndon, VA 22071-1514 } \\
\text { Phone: (800) 323-6744, Local: (703) 391-2011 } \\
\text { Fax: (703) 391-2014 } \\
\text { E-mail:Allergy@AllergySupply.com }\end{array}$ \\
\hline
\end{tabular}




\begin{tabular}{|c|c|}
\hline Nondestructive Method & Organization and Address \\
\hline $\begin{array}{l}\text { Ultrasonic Stress Measuring Devices } \\
\text { Also developing an acoustic emission } \\
\text { monitoring device that measures the } \\
\text { stress in a structural member and } \\
\text { estimates the remaining safe life of } \\
\text { that member }\end{array}$ & $\begin{array}{l}\text { Hand-held Ultrasonic Device } \\
\text { Constructed Facilities Center (CFC) } \\
\text { West Virginia University } \\
\text { P.O. Box } 6103 \\
\text { Morgantown, WV 26506-6103 } \\
\text { Direct questions concerning Non-Destructive Evaluation to: } \\
\text { Samer Petro } \\
\text { Phone: (304) 293-7608 ext. } 636 \\
\text { Fax: (304) 293-7109 } \\
\text { E-mail: petro@cemr.wvu.edu }\end{array}$ \\
\hline $\begin{array}{l}\text { Machine Stress Rating (MSR) } \\
\text { Stress Grading Tables }\end{array}$ & $\begin{array}{l}\text { DART } \\
\text { Eldeco Industries Ltd } \\
24034390 \text { Grange Street } \\
\text { Burnaby BC V5H 1P6, Canada } \\
\text { Contact: } \\
\text { David Orames } \\
\text { Phone: (604) 454-9209 } \\
\text { Fax: (604) 454-9209 } \\
\end{array}$ \\
\hline $\begin{array}{l}\text { Proof Testing Machine } \\
\text { Modulus of Rupture (MOR) }\end{array}$ & $\begin{array}{l}\text { Eldeco MOR Machine } \\
\text { Eldeco Industries Ltd } \\
24034390 \text { Grange Street } \\
\text { Burnaby BC V5H 1P6, Canada } \\
\text { Contact: } \\
\text { David Orames } \\
\text { Phone: (604) 454-9209- } \\
\text { Fax: (604) 454-9209 }\end{array}$ \\
\hline $\begin{array}{l}\text { Static Tester } \\
\text { Modulus of Elasticity (MOE) }\end{array}$ & $\begin{array}{l}\text { Eldeco Static Tesster } \\
\text { Eldeco Industries Ltd } \\
24034390 \text { Grange Street } \\
\text { Burnaby BC V5H 1P6, Canada } \\
\text { Contact: } \\
\text { David Orames } \\
\text { Phone: (604) 454-9209 } \\
\text { Fax: (604) 454-9209 } \\
\end{array}$ \\
\hline $\begin{array}{l}\text { Microwave Analysis System } \\
\text { (electromagnetic radiation) } \\
\text { Density. Locates slope-of-grain, } \\
\text { knots, and other defects. }\end{array}$ & $\begin{array}{l}\text { Eldeco Microwave Analysis System } \\
\text { Eldeco Industries Ltd } \\
24034390 \text { Grange Street } \\
\text { Burnaby BC V5H 1P6, Canada } \\
\text { Contact: } \\
\text { David Orames } \\
\text { Phone: (604) 454-9209 } \\
\text { Fax: (604) 454-9209 }\end{array}$ \\
\hline In-line Tension Testing Machine & $\begin{array}{l}\text { In-line Tension Testing Machine } \\
\text { Eldeco Industries Ltd } \\
24034390 \text { Grange Street } \\
\text { Burnaby BC V5H 1P6, Canada } \\
\text { Contact: } \\
\text { David Orames } \\
\text { Phone: (604) 454-9209 } \\
\text { Fax: (604) 454-9209 }\end{array}$ \\
\hline
\end{tabular}




\section{A.1 Description of Commercially Available Nondestructive Methods}

\section{A.1.1 Size}

A.1.1.1 Callpers. With Starrett 721 Calipers, the precise level of electronic measuring features can be chosen; the 721A Basic Series, or the powerful 721B Full Function Series with data transmission capabilities. All calipers feature an exclusive, Starrett-designed microprocessor chip for fast, dependable, and simple operation. All models have hardened stainless steel bodies for long life, and thumb-operated fine adjustment and locking mechanisms for one-hand use. Four sizes (6-in./150 mm, 9in./225 mm, 12 -in. $/ 300 \mathrm{~mm}, 24$-in. $/ 600 \mathrm{~mm}$ ) are available; all with resolutions of 0.0005 in. $(0.01 \mathrm{~mm})$.

\section{B Full Function Series}

\section{Electronic Features}

The 721B Series gives more than the 721A electronic functions and provides data transmission for analytical and documentation purposes. A unique SHIFT button on the 721B makes operation fast and simple. With this feature, only three other buttons (plus ON/OFF) are needed to access all of the 721B's electronic functions.

- Instant inch/millimeter conversion (except for straight metric models).

- Zero at any position.

- Hold readout at any position.

- Easily establish minimum and maximum limits by using SHIFT and then pressing LIMITS. A flashing display indicates out-of-limits readings.

- Data output transmission to:

- Starrett 702 Computer Workstation

- Starrett 772 Series Advanced Data Collection Systems

- Starrett 741 Series Data Multiplexers

- Other devices that support RS232-C 


\section{Design Features}

- Large, high-contrast LCD readout eases reading and reduces errors.

- Knurled thumb-screw securely locks slide at any setting.

- Thumb-operated adjusting roll for precision measurements.

- Long-wearing carbide faces on outside contacts (6-in./150 mm models).

- Optional attachments to provide depth gauging capabilities.

- 1-year minimum battery life with two 3-volt batteries (No. CR2032).

ON/OFF button, plus automatic OFF after 15 minutes of nonuse.

\section{A Basic Series}

The 721A Basic Series Calipers have the basic design, operating features and accuracy of the 721B Full Function Series, but do not have data output capabilities, Shift button, or Limits functions. The 721A Series provides these electronic features:

- Instant inch/millimeter conversion (except for straight millimeter models).

- Zero at any position.

- Hold readout at any position.

- ON/OFF button, plus automatic OFF after 15 minutes of nonuse. 
Specifications (Series 721A and 721B)

Description Inch Millimeter

Resolution $\quad 0.0005$-in. $0.01 \mathrm{~mm}$

Linear Accuracy

6-in. $(150 \mathrm{~mm}) \quad+/-0.001-$ in. $\quad+/-0.03 \mathrm{~mm}$

Jaw Depths (Approximate)

Outside

6-in. $(150 \mathrm{~mm}) \quad 1 \frac{1}{2}-$-in. $\quad 38 \mathrm{~mm}$

9-in. (225 mm) 11/2-in. $\quad 38 \mathrm{~mm}$

12-in. $(300 \mathrm{~mm}) \quad 2 \frac{1}{2}$-in. $\quad 63 \mathrm{~mm}$

24-in. $(600 \mathrm{~mm}) \quad 2 \frac{1}{2}$-in. $\quad 63 \mathrm{~mm}$

Inside

$\begin{array}{lll}\text { 6-in. }(150 \mathrm{~mm}) & 5 / 8 \text {-in. } & 16 \mathrm{~mm} \\ \text { 9-in. }(225 \mathrm{~mm}) & 5 / 8 \text {-in. } & 16 \mathrm{~mm} \\ \text { 12-in. }(300 \mathrm{~mm}) & 3 / 4-\text {-in. } & 19 \mathrm{~mm} \\ \text { 24-in. }(600 \mathrm{~mm}) & 3 / 4-\text {-in. } & 19 \mathrm{~mm}\end{array}$

\section{A.1.1.2 Micrometers}

Every aspect of the 733 Full Function Series and the 734 Basic Series reflects the precision assured by features such as micro-lapped carbide measuring faces, a rigid frame, and an extremely hard, stable one-piece spindle. Comfort and convenience are assured by a balanced frame that tapers for use in tight confines. Finally, a unique microprocessor designed by Starrett makes operation fast and easy, while providing new levels of measurement control, power and 
versatility, including data output to Starrett peripherals and other devices for SPC analysis and documentation.

\section{Full Function Series}

\section{Electronic Features}

Simplicity of operation is assured by a new SHIFT button. This feature activates different functions, so that all features are easily accessed by four keyboard buttons.

- Instant inch/millimeter conversion (except for straight metric models).

- Measurement “HOLD” button.

- Ability to zero tool at any position.

- Ability to retain and return to the true zero reading.

- PRESET button to install any reading at any position.

- Ability to install minimum and maximum limits (except on straight metric units).

- Data output transmission to:

- Starrett 702 Computer Workstation

- Starrett 772 Series Advanced Data Collection Systems

- $\quad$ Starrett 741 Series Data Multiplexers

- Other devices that support RS232-C.

\section{Design Features}

- Conventional graduations on the thimble and sleeve are standard.

- $\quad$ Ring-type knurled lock nut for quick, sure locking.

- Attractive no-glare black wrinkle finish on frame. 
- Smooth-action friction thimble for uniform pressure.

- Single battery for dependable power for over 1 year's normal usage.

- Automatic OFF after 30 minutes of nonuse conserves battery life.

- Large, high-contrast LCD readout eases reading and reduces errors.

- Starrett "no-glare" satin chrome finish on thimble and sleeve.

\section{Basic Series}

734 Basic Series Micrometers have all the basic design, operating features and accuracy of the 733 Full Function Series, but do not have output capability. The 734 Series provides these electronic features:

- Instant in./millimeter conversion (except on straight millimeter models).

- Measurement HOLD button.

- Ability to zero at any position.

- $\quad$ ON/OFF-button, plus automatic OFF after 30 minutes of nonuse.

Specifications (Series 733 and 734)

Description

Resolution up to 4-in. (100 mm)

Resolution over 4-in. (100 mm)

Accuracy*

Range
Inch

Millimeter

0.00005-in. $\quad 0.001 \mathrm{~mm}$

0.0001-in. $\quad 0.001 \mathrm{~mm}$

$+/-0.0001$-in. $+/-0.003 \mathrm{~mm}$

1-in.

$25 \mathrm{~mm}$

\footnotetext{
Accuracies above 1-in. (25 mm) are as good as setting to a gage because the mechanical and electronic components are the same on all ranges.
} 


\section{A.1.2 Moisture Content}

\section{A.1.2.1 Moisture Meters}

The moisture content of wood is measured as the ratio of the weight of water in a given piece of wood, to the weight of wood when it is completely dry (or "oven dry") and is usually expressed as a percentage. The "green" wood of a freshly felled tree may have a moisture content anywhere in the range 30 to over 200 percent, depending on the species. Almost all of this water must be removed from the wood before it is fit to be used. The desired moisture content depends upon the intended use, and also upon the annual average relative humidity at the place where the wood is to be used.

Wood is a cellulose material that behaves somewhat like a sponge, so that even wood that has been "kiln dried" down to 7 percent may in fact later reabsorb water from the atmosphere. Furthermore, wood is constantly gaining or losing water to or from the environment; the moisture content of wood changes as the relative humidity changes. Coats of varnish or paint may greatly slow down this process, but cannot generally stop it completely.

As the moisture content of improperly dried or stored wood changes, so does the wood expand or contract, potentially producing all manner of disastrous defects (and hence wood warping occurs). With a wood moisture meter, the means to measure and hence control the moisture content of valuable wood is possible.

Equilibrium Moisture Content (EMC) of wood is the moisture content that will eventually be attained by any piece of wood when stored indefinitely at a particular relative humidity. For most woodworkers across most of North America, 6 to 8 percent is a good wood moisture content to aim for. Wood warping nightmares are evident in structural members. However, it is addressed by avoiding irreversible damage, preventing checking and deformation, eliminating shrinkage and failed joints, and testing commercially dried wood before buying.

\section{A.1.2.1.1 Pin Type Moisture Meters}

This traditional style of meter has two sharp pins that must be physically pushed into the wood sample. The pins may be part of the meter casing (and therefore pushed by hand) or may be mounted separately in a probe (that can be pushed or hammered with great force) connected to the meter itself via a cable. By using a pair of nails or wood screws inserted into your wood sample, and hooked up to built-in meter pins with wire, a "hammer probe" can be made. The 
pin-type meters are accurate to half of one percent. These meters include a 2year unconditional guarantee. All models work on a single standard 9-volt transistor type battery.

\section{Model MT90:Range 6\% - 16\%, Dual-Color LED}

Moisture contents from 6 to 16 percent are marked on a rotary scale surrounding the central control knob and on/off switch. Half-inch steel pins are built into the meter case. To operate, just turn the knob until the LED lamp changes in color from red to green, and read off the moisture content from the scale. Covers the range of moisture contents most critical to proper wood drying. Pocket-sized portability is especially convenient for trips to the lumber store. Includes extension leads and clips. Case size $4.0 \times 2.5 \times 1.5$ in..

\section{Model MT270: Range 4\%-30\% Analog Meter}

A classic design, incorporating a precision analog meter with a single scale marked from 4 to 30 percent. Built-in spring steel pins. Simplicity itself to use: just push the button on the front panel and the needle points to the measured moisture content. Also provided is a combined battery tester and calibration check resistor, together with extension leads and clips. A pocket-sized tester with truly professional performance. Case size $4.4 \times 3.2 \times 1.5 \mathrm{in}$.

\section{Model MT700: Range 4\% - 80\%, Digital Display}

Instant push-button display of moisture content (to nearest whole percent point) on:a large easy-to-read liquid crystal display. Even more rugged than models above; fewer moving mechanical parts. Useful for drying very green wood; popular for green woodturning and steam bending. Especially suited for field work such as building inspection. "Lo Bat" symbol appears in display as battery power warning. Includes calibration checker and extension leads with clips. Case size $5.6 \times 3.3 \times 1.5$ in.

\section{Model MT808: Range 4\% - 100\%, Microprocessor}

For discerning woodworkers who demand performance, precision, and power.

- Power: Wide range 4 to 100 percent with push-button corrections for wood temperature and 200 wood species. Fast and easy to use; final reading in less than one second. Large LCD display of moisture, species, and temperature. 
- Precision: Digital readout in 0.1 steps below 10 percent, in 1 percent steps above 10 percent. Auto ranging: five separate moisture scales covering 4 to 100 percent. Auto zeroing: superb accuracy guaranteed even for the driest wood. Self calibrating: automatic adjustments made every few seconds.

- Performance: Software correction for $\mathbf{2 7}$ wood groups covering 200 individual species, and compensation for wood temperatures from freezing to boiling. Built-in pins plus socket for external hammer or drying chamber probes. Flashing low battery warning. Case size $5.6 \times 3.3 \times 1.5$ in.

\section{Model DC-2000. Wood/lumber Moisture Meter}

Outstanding Features:

- Easy to use: simply insert the needle into the test area.

- Completely portable: tough pocket size instrument weighs less than 8 ounces.

- Eliminates guesswork: easy to read L.C.D. display shows actual moisture content - no calibration chart or tables.

- Advanced, micro-controller circuit: no adjustments are necessary.

- Operates on a single 9-Volt battery.

- Test wood moistare content from 5 to 65 percent.

- Ideal for contractors, lumber yards, exterminators, and hobbyists.

The Model DC-2000 is a battery operated portable meter designed and calibrated to test the moisture content of lumber, wood products, and surfaces to be painted. This easy-to-operate instrument can be used in factories, mills, and yards by anyone regardless of their technical skill. The pocket-sized and compact DC2000 weighs less than $1 \mathrm{lb}$, making the instrument completely portable.

The DC-2000 has two built-in 7/16-in. needles and determines the moisture content by measuring the electrical resistance between the needles that are driven into the wood. The instrument reads the wettest portion of the wood rather than averaging the moisture content that, might otherwise be misleading. The 
DC-2000 can be operated by anyone regardless of technical skill to obtain accurate, immediate results.

Several tests can be taken along a board in less than a minute to obtain not only moisture content, but also to disclose any gradients or wet streaks. In addition to its accuracy and versatility, the DC-2000 can be used to estimate the shrinkage of wood and to check for gradient distribution of moisture.

You will know when wood is subject to rot, or when walls or wood surfaces are dry enough for painting. A feature of the sensitivity of the DC-2000 is its application to the tracing of water leaks in walls and roofs.

\section{Model DC-2000-C, Wood/lumber Moisture Meter}

The availability of three different heavy duty needle electrodes makes the DC-2000-C a versatile instrument that can be used on all wood applications from kiln dried to air dried woods. The electrode heads are made of durable $\mathrm{Cy}$ colac plastic to withstand hard usage. The heavy duty needles are designed for use on the most dense wood, yet can be withdrawn after tests without breakage or bending.

Equipped with auto-ranging, the instrument provides accurate, reliable readings over a wide range from 5 to 65 percent moisture content. In addition, wood technology indicates that wood rot is most common when wood moisture content exceeds 20 percent. Users in the pest industry will find the DC-2000 invaluable in helping to locate conditions where wood decay and "dry-rot" are creating a breeding ground for pest.

Needle Electrodes

- Electrode \#1 - This heavy duty electrode utilizes four tempered needles with 7/16 in. exposed length. The needles provide a penetration depth of about $7 / 16$ in., but the instrument will supply reasonably accurate results on lumber up to 2 in. thick.

- Electrode \#2 - This electrode is a combination of the electrode block and needles from Electrode \#1 with the Driver - Extractor handle from Electrode \#3. This heavy duty electrode utilizes four tempered needles with $7 / 16$ in. exposed length. This is an excellent electrode to use when a large number of tests must be made on a very hard wood. 
- Electrode \#3 - This deep penetration electrode uses twin needles with insulated shanks and exposed tips. This heavy duty electrode utilizes two tempered needles with 7/8-in, exposed length. The length of the needles permits testing to the center of a 2 -in. board.

Carrying Pouch

A convenient Durable Cordura Nylon Carrying Pouch is available as a option for the Model DC-2000 allowing the instrument to be carried on a belt. This Padded Pouch protects the instrument from damage and provides cover over the sharp needles. The DC-2000-C will also fit in the pouch, but room is not available for the optional Needle Electrodes or Connecting Cable.

\section{Moisture Readings}

The DC-2000 is equipped with auto-ranging, there is no need for moisture range selection. A Species Selector Switch is a feature of this premium instrument that provides better accuracy when testing a wide range of wood types. Except for certain variations in the temperature or species of wood, the dial readings are accurate without further correction. Temperature correction tables and calibration charts for 36 specific wood species are provided for easy reference and use.

\section{A.1.2.1.2 No Pins Moisture Meters}

These meters.use sophisticated electronics to sense water inside wood. A sensing pad is pressed against the wood sample, which is consequently not punctured or damaged. Pinless meters are extremely fast in operation, and enormous quantities of wood can be measured very quickly, just by sliding the meter sensing pad along the length of each board. These meters are essential for some applications, such as testing finished or antique furniture, fiberglass boats, building inspection; or any situation where the holes from pin-type meters would not be acceptable. On the other hand, remote measuring (of boards drying in a stack, for example) with pinless meters is both technically difficult and quite expensive. The no-pins meters are accurate to one percent. These meters include a 2-year unconditional guarantee. All models work on a single standard 9-volt transistor type battery.

\section{Model CT33: Range 0\%-30\%, Analog Meter}

Versatile, accurate, and easy to read with large analog meter scale. Senses to 1in. depth. Calibrated for standard wood density of 0.5 , with detailed calibration 
charts provided for wood densities 0.2 to 1.0. A list of wood densities is provided for 200 species. Qualitative readings on fiberglass, drywall, paper, cardboard, etc. Low battery warning light. Case size $4.5 \times 3.3 \times 1.5$ in.

\section{Model CT100: Range 0\%-30\%, Digital \& Species}

The immensely popular CT100 was the first digital "no pins" moisture meter introduced to the woodworking market, in September 1993. One-in. depth sensing, with electronic species compensation; just turn the density control to the setting for a specific material and the large LCD display instantly shows the corrected moisture content. Rugged and reliable for industry, yet affordable for the hobbyist. Low battery warning symbol in display. Incredible slimline pocket size only $4.7 \times 2.7 \times 1.0$ in.

\section{A.1.2.1.3 Species Corrections}

All moisture meters are calibrated for one particular material or group of materials. In the case of wood moisture meters, the industry standard is Douglas Fir. However, different wood species have slightly different properties, which influence the meter reading. This means that for species other than the calibration standard, the meter readings must be corrected in some way. For low-cost meters, there is usually a chart or table provided in the instructions, and the user makes the correction manually after obtaining a reading. At higher cost, there may be a switch or knob to select different species. Push-button correction for many different species is available in advanced microprocessor-based meters. Species corrections are required equally for both "pin type" and "no pins" meters.

\section{A.1.2.1.4 Choosing the Right Meter}

A decision must first be made on whether to use the "pin type" or "no pins" meter for a specific application. This is a key decision for the reasons outlined above, and also because it influences how much the meter is likely to cost. Next consider factors such as the range of coverage, accuracy, method of moisture content display, method of use, method of species correction, ease of use with external and/or built-in pins (if applicable), availability of accessories, warranty and customer support, and the cost.

\section{A.1.2.1.5 Building Inspection}

Construction lumber for various types of buildings is generally best suited at moisture contents around 12 to 15 percent. If you are purchasing or accepting deliveries of lumber, a moisture meter is extremely useful in verifying this. 
Some building codes set limits on the allowed moisture content. For example, most codes in Canada require a maximum moisture content of 19 percent. For this kind of application, a pin-type meter is usually the best. The pinholes made by the meter will not be visible when construction is complete. Model MT700 is very popular with construction companies because of the large clear digital readout and wide range (4 to 80 percent).

A common need is to inspect drywall, plaster, roofing, insulation, or flooring in a finished and lived-in building, to search for possible water leaks. Here, Model CT100 "no pins" meter is the perfect choice. With no physical damage and 1-in. depth sensing, this meter can reveal potential problem areas long before there is any visible sign of water. This meter is frequently used by air quality control companies to inspect drywall (a toxic fungus can grow behind the drywall if the moisture level is too high). A pinless meter is also available that can sense to a depth of 1.5 in.

\section{A.1.2.2 Hygrometers}

\section{Taylor Combination Hygrometer/Thermometers}

These Taylor Combination Hygrometer/Thermometers take the guesswork out of determining temperature and humidity. Since they accurately measure both, - a humidifier or dehumidifier can be checked if working. Available models include the Taylor Hygro-Thermometer 5502 (31/4-in. gauge), Taylor Precision Hygro-Thermometer 5565 (5-in. gauge), and the Digital Hygro-Thermometer 10215. The Digital Hygro-Thermometer provides digital display for temperature and relative humidity from a single compact console. Temperature range of 14 to $140^{\circ} \mathrm{F}$ with R.H. range of 10 to-99 percent. Features current temperature and humidity displays, max/min temperature and humidity memory, ${ }^{\circ} \mathrm{C}$ to ${ }^{\circ} \mathrm{F}$. switches and low battery indication.

\section{A.1.3 Stress Wave Techniques}

\section{A.1.3.1 Ultrasonic Testing of Covered Timber Bridges}

This project represents the development of a hand-held ultrasonic timber bridge monitoring device that can be conveniently used by field personnel for data collection and interpretation of results. This device was used to conduct ultrasonic field testing on wooden members in the Salt Creek Timber bridge located in Muskingum County, OH. The key investigators in this project are Samer H. 
Petro, West Virginia University, Constructed Facilities Center, Department of Civil and Environmental Engineering, Udaya Halabe and Powrisi Klinkhachorn.

The historic Salt Creek Timber Bridge is located in Muskingum County, $\mathrm{OH}$ and is the only covered timber bridge in $\mathrm{OH}$ with a Warren truss construction. The Salt Creek Timber Bridge was built in 1876 using White Oak. A wooden shake roof added in 1879 was still on the bridge in the 1960's and was leaking badly that resulted in rain soaking portions of the top chord. A metal corrugated roof was later added. Unfortunately, the damage done by the leaky original roof has only now become apparent. One $20 \mathrm{ft}$ segment of the top chord is seriously affected with dry rot. This is an obvious candidate for replacement. However, there are other portions of the top chord that look and sound defect free but may be seriously affected with dry rot.

The frequencies associated with ultrasonics in wood and other composite materials range from $100 \mathrm{kHz}$ to $250 \mathrm{kHz}$. For this field test, $125 \mathrm{kHz}$ sensors were used with 1 in. diameter that could penetrate up to 12 in. in the transverse direction, i.e., through the thickness of the member). A quick grip spring-loaded clamp was also used for clamping the transducers to normalize the force applied during testing. A hand-held ultrasonic device developed by the Constructed Facilities Center (CFC) at West Virginia University (WVU) was used in the field testing. The device reads the travel time of ultrasonic waves through wood, then calculates the ultrasonic wave velocity, and converts it to modulus of elasticity (MOE) and modulus of rupture (MOR) for a given wood. The device also measures signal amplitude in the frequency domain. The signal amplitude can be related to the presence of defects and level of degradation in a given timber member. The frequency domain analysis introduced an added sensitivity to the ultrasonic velocity measurements that helped detect knots and defects. Velocity measurements and frequency domain signal amplitude measurements made in the transverse direction were used for defect detection. This device can be conveniently operated by a field technician without any special knowledge of ultrasonic theory. The instrument can be used for in-situ evaluation of timber structural members as well as for predicting material properties.

This bridge was tested using the hand-held ultrasonic device that included frequency domain analysis. Special field accessories such as transducer clamping and quick release attachments for standardizing the force applied on the ultrasonic transducers (and establish normalized signals) were also used. The testing consisted of transverse measurements (in the tangential and radial directions) using the through transmission method. Ultrasonic velocity measure- 
ments as well as frequency domain measurements were conducted on the upper and lower chords of the trusses.

The results of the ultrasonic testing confirmed known locations of decay and revealed structurally weak areas and dry rot not visible to the naked eye. The frequency domain analysis introduced an added sensitivity to the ultrasonic velocity measurements that helped detect knots and defects.

This device has many potential applications. For example, the device can be used to evaluate timber members and joints in bridges and buildings, timber guard rails, posts, and piles. Several state and federal agencies have expressed interest in using such a portable device for in-situ evaluation of timber structures.

\section{A.1.4 Mechanical Grading}

Machine Stress Rating (MSR) is a process of sorting lumber according to its structural value. Grading of MSR is similar to visual grading except that each piece of lumber produced is measured for its bending stiffness before it is visually inspected. Truly quality controlled, tested lumber is not available in visual grades. The design values available in the higher MSR grades are not available in visual grades. In the larger picture of allocating our natural resources, MSR can help direct the best of the dimension lumber to its highest and best use.

Lumber specialties use MSR lumber for basically two reasons: less waste and better performance. With visual grades, as much as 10 to 20 percent was not usable due to knots, wane, and an appearance that was too poor to allow it to be used in quality built trusses. It has also been found, using MSR SPF lumber for chord material reduces the chance of having Ceiling-Floor Partition Separation.

MSR lumber and lumber specialties offer consistent high quality products, inspected to ensure performance to your expectations. In an MSR machine, approximately 26 rollers guide the lumber through the machine at high speed, while measurements are taken of the bending stiffness by two load cells. The two measurements are combined to compensate for deviations from straightness.

Machine Stress Rating (MSR) or Stress Grading are terms used in different countries to describe a process of testing lumber/timber samples as they pass 
through a mill, to determine the sample strength. This is important in several industries:

- General structural work in wood. Structural engineers can design wooden buildings, confident that the wood sections they choose for aesthetic reasons are strong enough to perform the structural functions needed.

- Roof truss fabrication. Roof trusses in most countries must use wood of known strength, to withstand the loads of roof material, wind, snow and other natural force.

- $\quad$ Finger jointing plants. Stress testing of wood either before or after (or both) is a requirement for operators of this type of plant.

- Laminating plants. Where several pieces of lumber/timber are glued together into a composite laminated beam, there is very good reason to be confident in the strength of the component pieces.

Remanufacturers are usually small businesses, which buy standard lumber/timber from a sawmill, pass it through a machine, and sell it with the official marks added that show it to be of known and certifiable strength. This can be a very profitable business activity with a comparatively small outlay.

There are developing areas where the use of wood of known strength can be important: wood used in some of the traditional Asian homes could well be strength tested where it is structural in nature. These timbers are sometimes large in section, and sometimes laminated as well. At the other extreme, the makers of arrows for archery need to know that the arrows they make will not snap under bow pressure. The DART technology is fully capable of expansion to meet these diverse needs. MSR's lumber or stress graded timber is recognized by color spots and printed marks.

\section{A.1.4.1 Eldeco DART MSR (Machine Stress Rating) machines, or Stress Grad- ers}

The DART is receiving growing recognition as a machine that will measure lumber (or timber), either of solid or finger jointed construction and mark it so it can be physically sorted, and sold at a price related to its strength. It is "cutting edge" technology, aimed at maximum quality in the tested lumber. 
The DART uses the tried and proven method of bending a stick slightly as it passes through the machine, and making continual measurements of Modulus of Elasticity (M.O.E.). There is a very strong correlation between M.O.E. and strength, and the computer within the DART marks the wood with ink spots in colors indicating its strength. This correlation between M.O.E. in bending, and strength, has been proven over many years, and many thousands of safely built structures, and it has the unqualified confidence of structural engineers.

The DART can be installed in a production line, and with no mechanical adjustment can grade lumber/timber of any size from $2 \times 3$ to $2 \times 12$ in.

- It is actually calibrated in metric sizes from $75 \times 35$ to $300 \times 35$.

- It is used with wood that has been passed through a planer/molder, and has been kiln dried. It has been used with softwoods of the pine, fir and spruce varieties.

- Speed is adjustable from $100 \mathrm{ft} /$ minute to $1000 \mathrm{ft} /$ minute. The top speed is not precisely known: tests will be undertaken in a mill environment to determine top speed.

The DART is small in size, light in weight, and has a small number of moving parts and loaded rollers and bearings. Because of this, it is quiet in operation, low in maintenance needs and economical in spare parts and repairs. The DART must be regularly calibrated, by the rules pertaining to this type of machine. However the DART is so stable that a calibration task is a mere formality. The DART makes measurements very accurately, and from its built in data logging software, can provide a wealth of useful data for quality control purposes. The DART can be configured for either of the 2 main operating philosophies, machine control or output control, which different countries use.

- Machine control relies on the machine measurements holding their settings. The operator has no access to grading set points. One depends on the machine's accuracy.

- Output control gives the operator access to the grade set points so that fine tuning can be done in production to active optimum production quality. 


\section{A.1.4.2 The Eldeco M.O.R. of Proof Testing Machine}

Wood tested on a DART or any other MSR or stress grading machine is required by the rules to be periodically tested to a much higher force level. The Eldeco MOR machine is a fully automatic proof tester that is used to test timber/lumber samples in an off-line, static mode. The operator only has to slide a sample into the machine and press a button. The machine then automatically bends the sample on edge (the DART bends it on the flat) to a preset force. The M.O.E. at this force is displayed to the operator. The operator may then apply a heavier force, and determine the Modulus of Rupture. If the sample breaks under this heavier force, the quality control process is actioned, according to the standards in force locally. The operator requires no physical effort to use this machine, nor does he/she have to read gauges or make adjustments. The fully automatic control system and electric powered hydraulic drive makes all adjustments and measurement, and produces accurate results immediately.

This machine uses the same computer and operator interface as the DART, and is designed to be usable by any person. In some countries, this machine is required to be located at the mill, and used very frequently to check the DART. In other places, it is not compulsory, but is a preferred machine for a quality conscious mill.

\section{A.1.4.3 Eideco Static Tester}

In some countries, rules require that a static tester be located by the DART. This machine performs a static test on a sample, testing it on the flat, the same mode as the DART test it. It uses calibrated weights and gravity to obtain a check on the DART results very quickly and simply. A microprocessor unit built into it displays the M.O.E. of a sample instantly with no effort or adjustments by the operator.

\section{A.1.4.4 Eldeco Microwave Analysis System}

The use of electromagnetic radiation has been known for years to be a means of measuring certain characteristics of wood. The simplest measurement is that of density, and there is some evidence of correlation between the density and strength of a piece of wood. However, Eldeco and research groups associated with them have developed a device that uses the electromagnetic waves to measure the things they are most suited for. 
The Eldeco microwave unit can very accurately measure the slope of grain in a sample of lumber/timber, as it passes through the machine at any speed. This is a characteristic that has traditionally been a manual activity, and it can be a difficult thing to decide at times. This machine can assist the operator, by marking the wood with color spots indicative of slope of grain, or produce data in any format desired. It can also very accurately measure and chart knots and major defects as small as - in., and generate signals to allow an optimizer device to automatically cut them out of a length of wood. By interconnecting a DART, a microwave and other instruments, a complete system is possible that will measure the full length of every sample, and provide a lot of essential data for the mills that are looking to the next century.

\section{A.1.4.5 In-line Tension Testing Machine}

One of the many wood products that MSR lumber or stress graded timber is used for is in making fingerjointed sections. The rules for testing finger joints generally call for a machine to apply a tension force to the long finger jointed sample; this is the mode in which a finger joint will generally fail. There is need for an economical machine to automatically, reliably and accurately apply the specified tension to every fingerjointed section produced by a mill. This machine is intended to fill that need. Its operation will be based on the tried and proven computer and operator interface that has gained wide acceptance in the DART.

\section{A.1.4.6 Eldeco DART - Stress Grading Tables}

Countries who are involved in the production or use of Machine Stress Rated lumber in most ases have their own sets of rules, based on local engineering standards and policies, so it is difficult to provide tables that are meaningful to all situations. The end result to a user is that he/she has lumber/timber marked with a strength mark of some type that can be related to engineering units. The structural engineer who designs a building will express the design in the same units so there is no confusion regarding the size of lumber/timber to be used for the structure (Table A2). These rules list the sample's M.O.E., which is the actual thing that the DART measures, and provide a table of conversions from this to strength grades.

Examples of just two numbering systems for these strength grades are provided. Interested individuals can obtain information regarding more systems from the lumber/timber regulating bodies in their own country. 
Table A2. Stress table information.

\begin{tabular}{|l|l|l|}
\hline Strength Type & USA and Canada & Australia \\
\hline Low strength & $900 \mathrm{Fb}-1.0 \mathrm{E}$ & $\mathrm{F} 2$ \\
\hline Medium strength & $2100 \mathrm{Fb}-1.8 \mathrm{E}$ & $\mathrm{F} 11$ \\
\hline High strength & $3000 \mathrm{Fb}-2.4 \mathrm{E}$ & $\mathrm{F} 34$ \\
\hline
\end{tabular}

The DART by its design can be converted to grade lumber/timber in accordance with the rules of virtually any country. The standard model can be operated to either Canadian/U.S., or Australian standards.

Different countries use different means of indelibly marking the product. The example below is a facsimile typical Canadian grade stamp, showing the responsible body, the lumber mill number, the species of wood, the actual strength grade, and most important, the words MACHINE RATED:

\author{
A.F.P.A. $\bullet 94$ \\ S - P - F MACHINE RATED
}

$1800 \mathrm{Fb} 1.6 \mathrm{E}$

This marking may be stamped on the wood, printed by computer technology or as a label affixed with adhesive. 
USACERL DISTRIBUTION

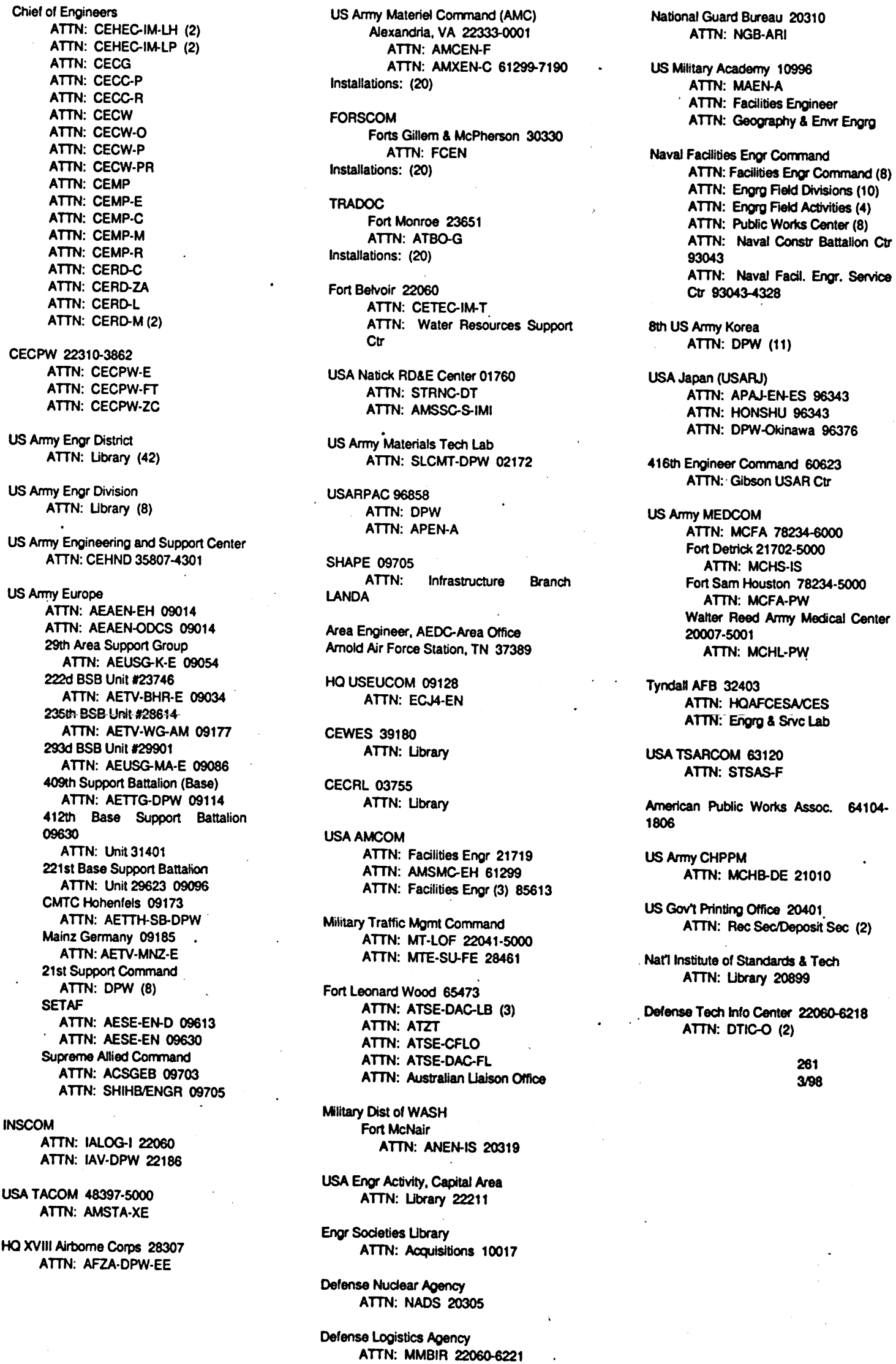


